United States Department of Commerce National Institute of Standards and Technology

NIST

PUBLICATIONS

NIST Special Publication 807

\title{
U.S. Assessment of the New Diamond Technology in Japan
}

Albert Feldman and Lyle H. Schwartz, Editors
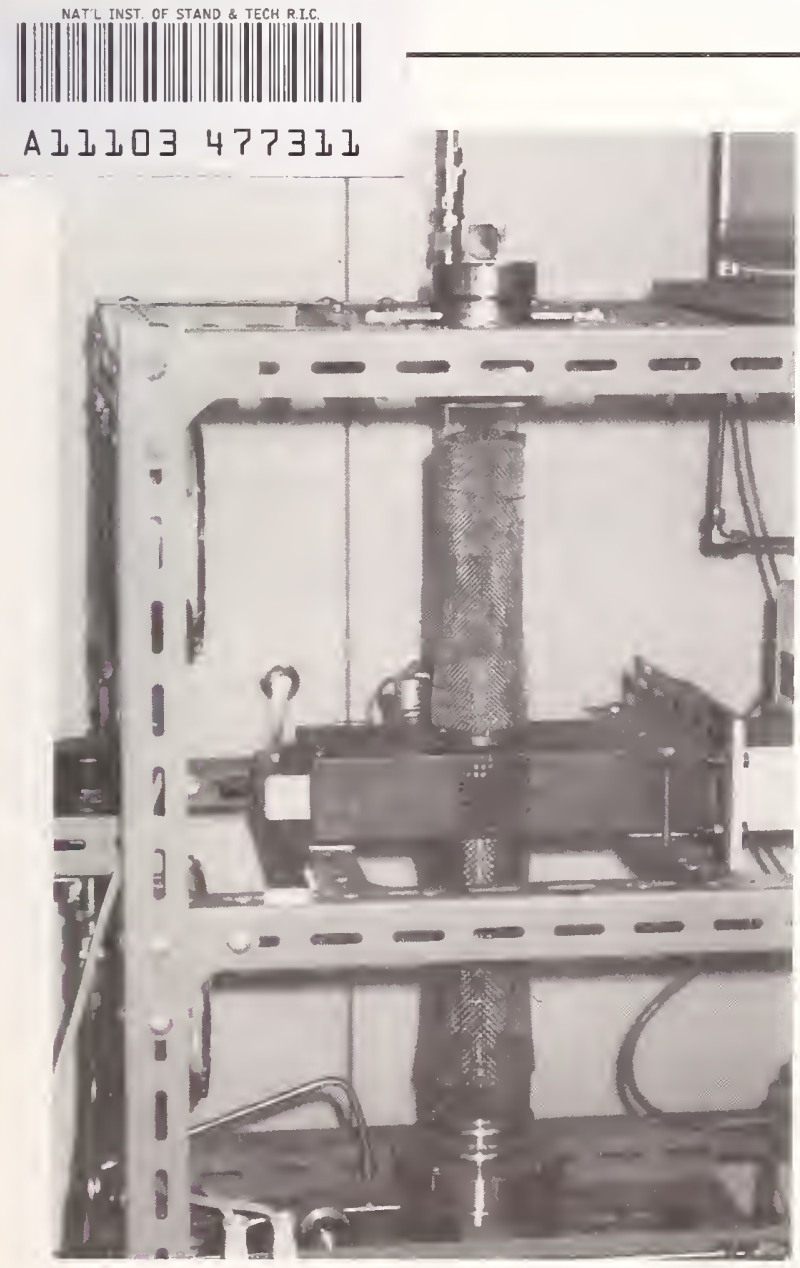

$-Q C$

100

.457

\#807

1991

C. 2 


\section{NIST Special Publication 807}

\section{U.S. Assessment of the New \\ Diamond Technology in Japan}

Edited by

Albert Feldman

Lyle H. Schwartz

Materials Science and Engineering Laboratory

National Institute of Standards and Technology

Gaithersburg, MD 20899

January 1991

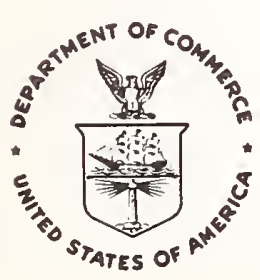

U.S. Department of Commerce Robert A. Mosbacher, Secretary

National Institute of Standards and Tcchnology John W. Lyons, Director 
National Institute of Standards and Technology

Special Publication 807 Natl. Inst. Stand. Technol.

Spec. Publ. 807

96 pages (Jan. 1991)

CODEN: NSPUE2
U.S. Government Printing Office Washington: 1991

For sale by the Superintendent of Documents U.S. Government Printing Office Washington, DC 20402 
CONTENTS

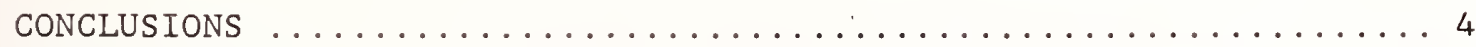

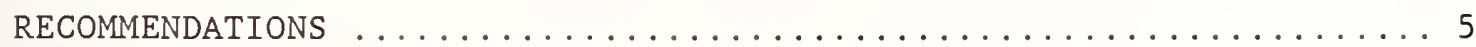

INTRODUCTION $\ldots \ldots \ldots \ldots \ldots \ldots \ldots \ldots \ldots \ldots \ldots \ldots \ldots \ldots \ldots \ldots$

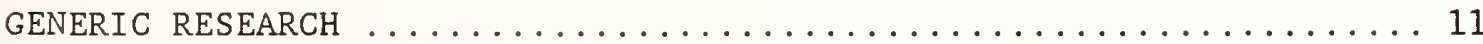

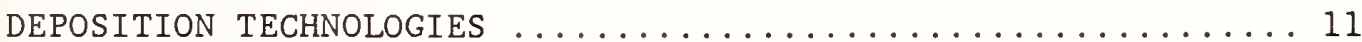

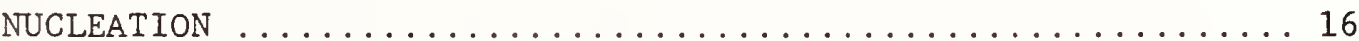

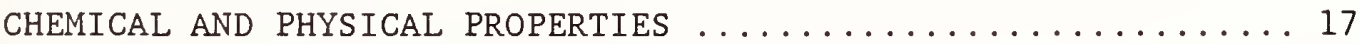

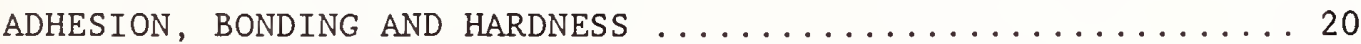

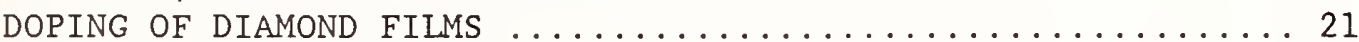

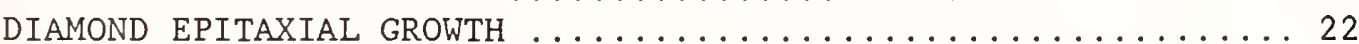

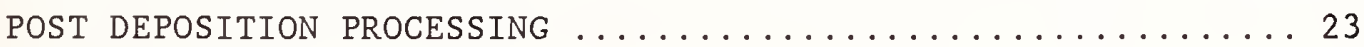

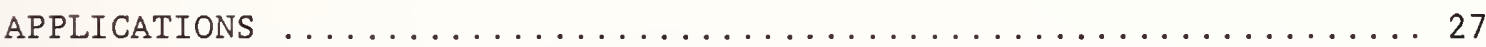

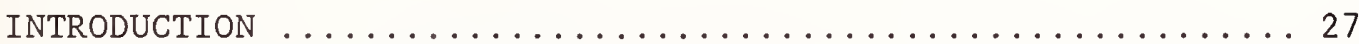

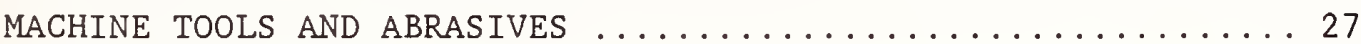

THERMAL MANAGEMENT ........................ 30

ELECTRONIC AND OPTOELECTRONIC DEVICES .............. 31

OPTICAL APPLICATIONS: COATINGS, LENSES, WINDOWS AND

$\mathrm{X}-\mathrm{RAY}$ WINDOWS ....................... 32

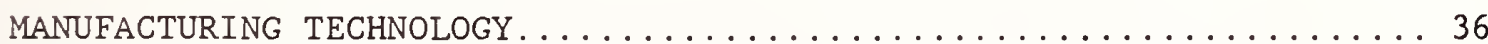

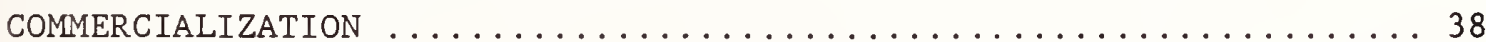

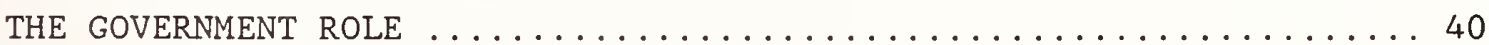

APPENDIX A - Planning and Implementation of the Assessment......44

APPENDIX B - Brief Assessment of the New Diamond Technology in

Europe and in other Countries .............45

APPENDIX C - Site Visit Reports ...................... 48

APPENDIX D - Adminstration of Science and Technology in Japan ....75

APPENDIX E - Delegation Members .................... 80

APPENDIX F - Biographies of Delegation Members .............82

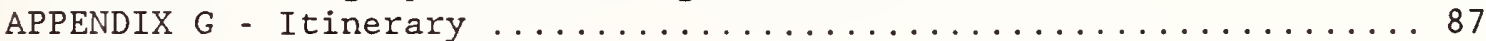

APPENDIX H - List of Companies, Universities, and

Government Agencies Visited ............ 89

APPENDIX I - Alphabetical Listing of Abbreviations ............992 
U.S. ASSESSMENT OF THE NEW DIAMOND TECHNOLOGY IN JAPAN

Contributing Authors

Lyle H. Schwartz, Chairman

National Institute of .Standards and Technology

John C. Angus

Case Western Reserve University

Jerome J . Cuomo

IBM Research Laboratory

Albert Feldman

National Institute of Standards and Technology

Jeffrey T. Glass

North Carolina State University

Sandor Holly

Rockwell International

James W. MitchelI

AT\&T Bell Laboratories

Ronald A. Rudder

Research Triangle Institute

Keith A. Snail

Naval Research Laboratory

C. Martin Stickley

BDM International, Inc.

(Currently University of Central Florida)

Michael A. Tamor

Ford Motor Company

Walter A. Yarbrough

Pennsylvania State University 


\begin{abstract}
This assessment of Japanese diamond technology was undertaken at the request of the joint committees for implementation of the 1988 United States-Japan Agreement on Cooperation in Research and Development in Science and Technology under the auspices of the Committee on Materials, Office of Science and Technology Policy. The purposes of the study were to assess the level of scientific activity, areas of intended commercialization, progress in commercialization, the role of the Japanese government in assisting industry to exploit the new diamond technology, and the relative positions of Japan and the U.S. in all aspects of synthesized diamond technology. Japanese efforts were chosen for assessment because Japan is the apparent world leader in the drive for commercialization of this technology. The principal focus of the study was diamond produced by chemical vapor deposition, with a peripheral investigation of cubic boron nitride and diamond-like carbon. Based on this assessment, a set of Conclusions and Recommendations is presented. This assessment is based on site visits in Japan between May 28 and June 5, 1990.
\end{abstract}

Key words: abrasives, adhesion, BN, bonding, boron nitride, chemical vapor deposition, commmercialization, cubic boron nitride, cutting tools, CVD, diamond, diamond films, diamond technology, diamond-like carbon, doping, electronics, epitaxial growth, epitaxy, hard materials, heat conduction, heat sinks, machine tools, nucleation, optics, physical properties, polishing, thermal management 


\section{ACKNOWLEDGMENTS}

We wish to thank Takayuki Shirao of the Science and Technology Agency, Office of Materials Science and Technology for the invaluable assistance he provided us in planning and implementing our visit. The visit was deemed to be very worthwhile and his help assured the success of the trip.

We thank Dr. Asakura of the Rockwell International Overseas Corporation for acting as translator and guide.

We wish to thank all of our Japanese hosts for the excellent hospitality and courtesy extended to the members of our delegation.

The support of the National Science Foundation for the expenses of our university delegates was greatly appreciated.

We thank Ken Gordon of the NIST Office of International Affairs for his assistance and advice, and Michael McCabe and R. Hyams of the State Department for assistance with hotel arrangements in Japan.

We thank Verla Weaver of the National Technical Information Service for organizing the debriefing seminar.

\section{DISCLAIMER}

The opinions expressed in this report are those of the authors of the report and do not necessarily represent the views of the National Institute of Standards and Technology, the Department of Commerce, or the Government of the United States.

COVER DESCRIPTION

Microwave reactor for chemical vapor deposition (CVD) of diamond developed in Japan at the National Institute for Research in Inorganic Materials (NIRIM). 
FOREWARD

"Recent success in deposition of diamond and diamond-like coatings on a variety of substrates at practical growth rates is one of the most important technological developments of the last decade. It places within the reach of science and industry an opportunity to exploit many desirable extreme properties of these materials. Indeed, the ultimate economic impact of this technology may outstrip that of high temperature superconductors. Consequently it is imperative that the United States take a leading role in the commercialization of diamond technology."

Opening paragraph from STATUS AND APPLICATIONS OF DIAMOND AND DIAMOND-LIKE MATERIALS: AN EMERGING TECHNOLOGY, published by the National Materials Advisory Board of the National Research Council (NMAB-445, 1990) 


\section{CONCLUSIONS}

1. Japanese companies have made a strategic commitment to support diamond technology. They have committed to diamond technology without knowing exactly what the markets will be. Small markets are seen at present, but larger markets are expected to develop with the evolution of the technology. They have faith that new applications will develop for a material with such superior properties.

2. Diamond technology in Japan has grown beyond the need for governmental incubation as evidenced by this industrial commitment. Many companies stated that they do not receive and are not interested in government funding.

3. Japanese companies consider each other their main competition; however, there is good communication among companies, except for information about production technology.

4. The Japanese effort is directed predominantly to processing and applications. In these areas the Japanese consider themselves to be ahead of the United States. Most Japanese consider the United States stronger in basic research; however, the results of basic research are rapidly disseminated and serve all competitors equally, including companies in Japan.

5. It is probable that the United States trails Japan in production scale capability with relatively few U.S. based manufacturers investing in this technology. Several U.S. based companies appear ready to commit to an initial product and it is likely that they have prototype systems with deposition rates as high as those of Japanese companies. However, many more large Japanese companies with a wider range of interests appear to have made such a commitment.

6. Overall, the Japanese are leading in the new diamond technology. No specific applications of diamond technology were identified in which the Japanese have a dramatic advantage except high rate deposition of diamondlike carbon films. Announcements of commercial tool inserts made with chemical vapor deposited (CVD) diamond suggest that they may lead in this important application as well.

7. CVD diamond products are reaching the market sooner than high temperature superconductor products and are likely to have a comparable ultimate economic impact. In Japan, this has led to comparable investment in these two developments by industry and government, while in the United States, a significant imbalance exists in $R \& D$ expenditures in favor of high temperature superconductors. 


\section{RECOMMENDATIONS}

1. As part of its effort to support precompetitive research in support of emerging technologies, government should significantly increase funding for generic CVD diamond process development, for training facilities at universities and national laboratories, and for internships for learning to use and apply the new diamond technology. This should include increases in government funding for fundamental studies likely to be critical to future technological development.

2. To be competitive, U.S. companies should significantly increase funding for CVD diamond processing and applications. To facilitate these efforts, the government should make companies aware of technology transfer opportunities that exist at government and university laboratories, and should encourage companies to take advantage of these opportunities.

3. An interagency committee to coordinate government funded $R \& D$ in CVD diamond and related materials should be established by the Committee on Materials (COMAT) under the Office of Science and Technology Policy (OSTP). Topics for immediate consideration by such a coordinating committee should include:

a. Support of several nationally recognized 'centers of excellence' in CVD diamond and related materials research to ensure the development and maintenance of a publicly accessible technology base in the United States and identification of long term ( $>5$ years) funding for these centers.

b. Exploration of mechanisms to enhance information transfer among members of the U.S. diamond community.

c. Acceleration of translation of relevant Japanese journals and patents.

d. Encouragement and/or subsidization of closer United States-Japan collaboration in diamond technology.

e. Development of calibration standards and standard measurement methods for characterizing chemical and physical properties of CVD diamond. Possible examples include standards for Raman spectroscopy, optical quality, thermal conductivity, electrical conductivity, and doping level (e.g., boron concentration).

4. The U.S. government should sponsor similar visits to assess Japanese technology using the mechanism our delegation has established on the basis of the 1988 United States-Japan Agreement on Cooperation in Research and Development in Science and Technology.

5. While not specific to the current study, the committee recommends more broadly that the government should identify and eliminate those institutional and structural impediments that make it unattractive for U.S. companies to invest in longterm $R \& D$. 



\title{
U.S. ASSESSMENT OF THE NEW DIAMOND TECHNOLOGY IN JAPAN
}

\author{
INTRODUCTION
}

\section{IMPORTANCE OF DIAMOND TECHNOLOGY}

The properties of diamond make it desirable for numerous applications. Diamond has several extreme properties, that is, properties with values exceeding those of any other materials; these are hardness, thermal conductivity at room temperature, Young's modulus, and free carrier saturation velocity. Other important properties of diamond include low friction coefficient, high chemical stability, low permeability to diffusion, high $\mathrm{x}$-ray transmission, high resistance to radiation damage, high electrical resistivity, semiconducting properties with doping, high dielectric strength, transparency to electromagnetic radiation from DC to the ultraviolet (except for a small region in the infrared), and high refractive index. It is the combination of superior properties that make diamond such a desirable material.

The areas of potential application are mechanical, thermal, electronic, optical, optoelectronic, medical, and chemical. Within each of these areas specific applications include cutting tools, electronic substrates, semiconductor devices, windows, ultraviolet detectors, prosthetics, and chemically resistant containers. See the recent National Materials Advisory Board report for a more detailed listing of potential applications.[1]

The development of chemical vapor deposition (CVD) methods to produce diamond has now made it possible to consider diamond for all of those applications that were previously inaccessable due to the limited sizes of previously available diamond raw material or due to the high cost of the material. New unforseen applications will arise with the expected wide availability of diamond material in large sizes and at reasonable cost.

While projections for the sales of products made of diamond and other related superhard materials [2] are very large (approximately $\$ 6 \mathrm{~B}$ by the year 2000 [3]), these figures ultimately may underestimate the potential economic impact that these materials can make. This is because the new diamond technology is an enabling technology which makes possible other technolgies. For example: $\mathrm{x}$-ray masks of CVD diamond may enable the production of larger scale integrated circuits than would be possible without diamond; CVD diamond substrates for integrated circuit packaging may enable a new generation of high speed computers; and, inexpensive diamond tooling may enable new production methods as well as new levels of production efficiency.

Although the scientific bases for CVD diamond deposition were discovered in the U.S. and in the Soviet Union, it was in Japan at the National Institute for Research in Inorganic Materials (NIRIM) that practical methods for deposition of CVD diamond were developed. The hot filament [4] and the microwave plasma [4] methods form the foundation of the new diamond technology and it was the discovery of these diamond deposition methods that galvanized the drive in Japan toward commercialization of CVD diamond. A sign of the seriousness of the Japanese effort in CVD diamond technology was the formation 
of the Japan New Diamond Forum (JNDF) in 1985, a consortium or trade association of companies sharing a common interest in diamond technology. The JNDF encourages active participation by government and university researchers. It publishes New Diamond, a publication devoted entirely to the new CVD diamond technology, and it sponsors technical conferences on this subject.

Belatedly, U.S. scientists and engineers recognized the significance of the Japanese effort on CVD diamond. Some U.S. companies began efforts in CVD diamond research and several new companies were formed to pursue CVD diamond products. Sometimes the research occurred at the grassroots level, without active management encouragement. In other cases, full scale development projects were undertaken with full management support. At this stage it is difficult to know whether U.S. industry has caught up to Japanese industry in the drive toward commercialization. However, it appears that many more Japanese companies are poised to exploit the technology.

Because of the potentially enormous economic impact the new diamond technology is expected to make, it is important for the U.S. to seek a leadership position in the commercialization of this technology. Technological leadership in this arena will contribute significantly to the future economic well being of this country.

\section{BACKGROUND OF STUDY}

This assessment was undertaken at the request of the joint committees for implementation of the 1988 United States-Japan Agreement on Cooperation in Research and Development in Science and Technology under the auspices of the Committee on Materials, Office of Science and Technology Policy. The purposes of the study were to assess the level of scientific activity, areas of intended commercialization, progress in commercialization, the role of the Japanese government in assisting industry to exploit the new diamond technology, and the relative positions of Japan and the United States in all aspects of synthesized diamond technology. Japanese efforts were chosen for assessment because Japan is the apparent world leader in the drive for commercialization of this technology. The principal focus of the study was CVD diamond technology with a peripheral investigation of cubic boron nitride $(\mathrm{cBN})$ and diamond-like carbon.

The delegation, which was chosen from government, universities, and industry, was composed of experts in diamond technology and managers with a direct interest in diamond technology. The researchers and managers we visited in Japan at company, university, and government sites are leaders in the new diamond technology. The visit to Japan took place between May 28 and June 5, 1990.

This report summarizes the findings of our committee. It discusses the status in Japan of generic research, applications, manufacturing technology, commericializaton and the role of the Japanese government. The discussion includes information about $\mathrm{cBN}$ and diamond-like carbon research and products. Our Conclusions and our Recommendations are presented at the beginning of the report. 
Several appendices present details regarding our visit. Appendix A discusses the planning and implementation of the assessment. In order to give a wider perspective on the new diamond technology, a brief review of related work in the rest of the world is presented in Appendix $B$. Reports describing the site visits are given in Appendix C. Appendix D describes the administration of science and technology in Japan. Appendices E lists the members of our delegation and Appendix $F$ presents the biographies of the delegates. The itinerary of our visit is given in Appendix $G$ and the organizations visited are listed in Appendix H. A listing of abbreviations is given in Appendix I.

In several parts of this report, monetary values are given. An exchange rate of 150 Japanese yen ( $¥$ ) per U.S. dollar was used, which was the approximate rate of exchange during our visit.

\section{REFERENCES AND NOTES}

[1] Status and Applications of Diamond and Diamond-like Materials: An Emerging Technology, Report of the Committee on Superhard Materials, National Materials Advisory Board, Commission on Engineering and Technical Systems, National Research Council (NMAB-445, National Academy Press, 1990).

[2] By superhard materials we refer to materials such as diamond, diamond-like carbon and $c B N$.

[3] S. Kurita "A Summary of the Report of Studies on the Plausible Policies for Promoting the New Diamond Industry," in New Diamond 1990, M. Yoshikawa, editor (The New Diamond Forum, c/o Tokyo Liaison Office, Japan Fine Ceramics Center, \& F Nishikan Toranomon Building, 1-22-13 Toranomon, Minato-ku, Tokyo 101 Japan) pp. 113-118.

[4] S. Matsumoto, Y. Sato, M. Kamo, and N. Setaka, "Vapor Deposition of Diamond Particles from Methane," Jpn. J. App1. Phys. 21, L183 (1982).

[5] M. Kamo, Y. Sato, S. Matsumoto, and N. Setaka, "Diamond Synthesis from Gas Phase in Microwave Plasma," J. Cryst. Growth 62, 642-4 (1983). 

GENERIC RESEARCH

\section{DEPOSITION TECHNOLOGIES}

\section{Introduction}

The Japanese effort to advance the technology of diamond deposition from the vapor phase is very impressive. Various new techniques and modifications to established techniques are under development, although not always reported at international gatherings. Many of these techniques are sometimes simple first generation systems, but the concepts are technologically very creative and are continually opening up new areas of diamond research. It appears that the most dramatic advances have been made at the government laboratories and at universities, whereas more subtle advances have been made in the industrial laboratories. It is quite probable that some of the most important industrial advances were not openly discussed. However, it is interesting that the university and government laboratory advances are very quickly transferred to industry both through general and specific agreements. Three examples of such transfers are the microwave plasma technique developed at the National Institute for Research in Inorganic Materials (NIRIM), the combustion technique developed at the Nippon Institute of Technology, and electron assisted CVD method developed at Aoyama Gakuin University, all of which have been duplicated by numerous industrial laboratories. This innovation process appears to occur more quickly and more often than in the United States possibly because of the established collaborative technological interaction between government, universities and industry. Thus, the research is much more directly applicable to industrial goals.

There was a general impression during discussions with the Japanese in Japan that Japan was significantly ahead of the United States in deposition method technologies, but were probably behind the United States in the fundamental understanding of the deposition process. The present section of this report will attempt to summarize these technological advances and their impact on diamond technology, as well as to give an overview of the issues that appear to be of greatest concern in Japan.

Cold Plasma Methods

Throughout our visits to the various laboratories conducting research and development on diamond deposition, the impact of the initial NIRIM research was evident. Many laboratories have sent researchers to study at NIRIM, usually for periods of 3 to 6 months, and have installed NIRIM-type microwave plasma CVD reactors which consist of a quartz tube placed perpendicularly through a rectangular waveguide. Thus, historically, this type of microwave system has had significant impact despite its limitations in deposition area, growth rate, and film purity. It has also led to the development of microwave reactors with different configurations that overcome some of these limitations.

The NIRIM type reactor has been utilized in many diamond deposition studies. For example, it has been used to control surface morphology by modification of deposition conditions, to enhance film quality by addition of oxygen to the feed gas mixture, and to achieve doping with boron. However, the only 
significant technological advance in deposition based directly on this original configuration was observed by the committee at Kobe Steel. Three NIRIM type microwave reactors were coupled together to allow for independent depositions of pure diamond, $\mathrm{p}$-type diamond, and $\mathrm{n}$-type diamond on a single substrate without cross contamination or autodoping. The sample may be transferred from one chamber to the next without exposure to atmospheric contaminants.

A derivative technique based on the original NIRIM design involves coupling of a rectangular waveguide to a cylindrical waveguide which acts as a resonant cavity that allows for depositions over much larger areas. The cylindrical waveguide either acts as the deposition chamber or is coupled to a separate cylindrical deposition chamber. Idemitsu Petrochemical anticipates that $25 \mathrm{~cm}$ diameter depositions will be achievable with such microwave plasma techniques by 1992. Kobe Steel showed the committee a microwave reactor of this type capable of $10 \mathrm{~cm}$ diameter depositions. This reactor consists of two rectangular waveguides coupled to one cylindrical chamber.

Osaka University is responsible for another significant advance utilizing magnetically enhanced microwave plasma deposition. This system allows for depositions over larger areas than most conventional systems. Due to plasma confinement by a magnetic field, depositions can occur at lower than usual pressures. However, this is not a true electron cyclotron resonance deposition because the cyclotron resonance condition is not utilized. Two systems are in operation. The newer system was a joint effort with Shimadzu Corporation. This system has achieved diamond growth at chamber pressures as low as 0.01 Torr; however, the growth rate and film quality tend to be low. The plasma area is fairly uniform up to $5 \mathrm{~cm}$ in diameter, although limitations in substrate heating have prevented verification of uniform diamond deposition.

Finally, the desire to achieve higher growth rates and better efficiencies has led to research involving very high power input (tens of kilowatts) to create thermal plasmas, which are discussed below. Microwave sources have not been used in high power depositions due to unavailability of commercial sources at reasonable cost. Currently, $5 \mathrm{~kW}$ is the maximum power easily obtainable from a microwave generator and is typical of microwave powers utilized in reactors being placed into operation. It is likely that higher power microwave generators will become available in the future.

In Japan, cold radio frequency (RF) and direct current (DC) plasmas rarely have been utilized in diamond deposition according to the people in the laboratories visited. This appears to be due to historical precedence rather than to technical merit.

Thermal Plasmas and Combustion Synthesis

A new area of technological development receiving widespread attention in Japan is diamond deposition with thermal plasmas. These are systems in which plasmas are maintained by very high input powers resulting in electron and ion temperatures that are approximately equal. Both RF and DC are used to generate these plasmas. 
The most impressive results utilizing thermal plasmas were observed at the Tokyo Institute of Technology; a DC arc plasma jet was used to grow diamond at a rate of $920 \mu \mathrm{m} / \mathrm{hr}$. Although the deposition area was small, the efficiency of gas use was claimed to be very high. Thus, the technique is expected to be very cost effective. The heart of the system is a nozzle, equipped with a series of gas inlets, that allows for various input configurations of $\mathrm{Ar}, \mathrm{H}_{2}$, hydrocarbons, and oxygen containing organic molecules. The entire system, including the substrate, must be water cooled. This DC plasma jet is thought to be more stable than the RF torch discussed below. However, electrode wear introduces a low level of impurities into the films which is a concern for some applications. Such jets have also been utilized by Fujitsu and NIRIM. Fujitsu has deposited diamond on areas $3 \mathrm{~cm} \times 3 \mathrm{~cm} \times 2 \mathrm{~mm}$ thick by scanning the substrate under the jet. Growth rates in this case were greater than 200 $\mu \mathrm{m} / \mathrm{hr}$.

The other major thermal plasma technique observed was an inductively coupled RF plasma torch at NIRIM. Deposition rates with this technique are about 200 $\mu \mathrm{m} / \mathrm{hr}$. The RF generator operated at a frequency of $4 \mathrm{MHz}$ with a power output in the range $10 \mathrm{~kW}$ to $50 \mathrm{~kW}$. Gas mixtures of $\mathrm{Ar}, \mathrm{H}_{2}$ and methane are utilized at flow rates of tens of liters per minute. To avoid deposition on the side walls of the chamber, a gas sheath containing hydrogen is employed.

Instabilities of the plasma, inefficiencies in power transfer, and nonuniform depositions are the major concerns with this technique. However, the high growth rates and potential for scale-up make it a very promising technique for the commercial deposition of diamond.

A modification of the RF plasma torch technique, currently under development at NIRIM, involves the use of variable RF frequencies. An RF generator with power output believed to be between $70 \mathrm{~kW}$ and $100 \mathrm{~kW}$ and tunable between $15 \mathrm{Mhz}$ and $100 \mathrm{Mhz}$ is being installed. The higher frequencies are expected to enable RF plasmas to be stably maintained without the use of Ar in feed gas mixtures. When this system is completed, it should provide additional insight into the growth of diamond from high density thermal plasmas.

Combustion synthesis of diamond is receiving increased attention in Japan. Combustion synthesis provides a similar environment for diamond growth as hot plasma sources. This technique was developed at the Nippon Institute of Technology (NIT) and is now being examined in numerous laboratories, including Showa Denko, Kobe Steel, and NIRIM. This is probably due to the simplicity of the method and the small cost for its implementation. The major obstacles that must be overcome in combustion synthesis are the small growth areas which are about $5 \mathrm{~mm} \times 5 \mathrm{~mm}$ and the nonuniformity of growth. To improve the uniformity and increase the area of deposition, NIT is working on a system to scan the flame over the substrate. Showa Denko has developed a low pressure combustion flame system that is enclosed in a chamber. Using this method, they have increased the growth area to approximately $9 \times 9 \mathrm{~mm}$, but uniformity still remains a problem.

One advantage for the combustion synthesis of diamond is the large volume of background information about combustion flames that is available. Much of this information predates the development of low pressure diamond synthesis. Thus, the study of combustion synthesis of diamond rests on a foundation of scientific knowledge and measurement techniques which can be applied to 
optimizing the process. For example, NIT is utilizing emission spectroscopy to understand the growth environment.

The combustion flame method has two other problems that will impede its commercial use. First, the cost of the feed gas is high because the combustion process consumes the hydrocarbons; recirculating the hydrocarbons is not feasible. Second, the thickness of films is limited to about $200 \mu \mathrm{m}$, presumably due to substrate temperature effects. No significant solutions to these problems were observed by the committee.

Hot Filament CVD (HFCVD)

Most Japanese laboratories have worked with HFCVD to some extent, although some believe it may not be feasible for commercial production. Major advances in this area have involved increased growth area, growth rate, and film quality. Aoyama Gakuin University has shown that electric field biasing enhances growth rate and this concept is being pursued by Sumitomo Electric, Kobe Steel, and probably others. New systems appear to use a high electric field biasing deposition process that combines features of hot filament and DC plasma deposition. If growth parameters are properly optimized, such a combination appears to improve film quality and increase growth rates simultaneously. NIT was the first to show that feed gases containing various organic compounds, especially alcohols, also enhance the growth rate and film quality. Perhaps the most interesting new result was observed at Sumitomo Electric where the deposition area appeared to have been increased to as large as 10 inches square by using multiple filaments made of long wires. Sumitomo also stated that this and other systems were run continuously for numerous days in order to achieve thick films for various applications. NEC has also constructed a similar large area HFCVD system. Both the NEC and Sumitomo Electric systems utilize a tensioning system to keep the hot filaments from sagging during growth.

Another interesting advancement in HFCVD was the coating of nonflat surfaces at Showa Denko. Researchers were able to coat the inside of a crucible by conforming a filament to the approximate cross-sectional shape of the crucible and then rotating the crucible to obtain dome shaped diamond films for speaker diaphragms. Free-standing diamond cylinders and disks were also observed at Showa Denko.

Miscellaneous

The use of carbon monoxide instead of methane in the feed gas enhances deposition rates by a factor of ten in conventional microwave plasma CVD reactors. Idemitsu Petrochemical claims to hold a patent for this process. Idemitsu will identify other additives that aid diamond growth at an upcoming professional meeting.

At Aoyama Gakuin University, two interesting deposition results have recently been reported. The first is the heteroepitaxial growth of diamond on cubic boron nitride ( $\mathrm{CBN}$ ) crystals as verified by electron diffraction and Raman spectroscopy. Although the cBN crystals were small (100 $\mu \mathrm{m}$ sized crystals prepared by the high temperature/high pressure process) and thus not commercially viable, this work proves that heteroepitaxial growth of diamond is possible. Second, small diamond particles have been grown from carbon 
evaporated by an electron beam coupled with a molybdenum cracker. Results were interpreted as indicating the importance of a $C_{1}$ species for the growth of diamond.

An interesting advance in the growth of diamond powder was reported by Showa Denko. A crucible containing a fluidized bed of ceramic powder was placed in a hot filament reactor to allow the ceramic particles to be coated with diamond. Cross sectional images of the particles revealed the success of this technique. Fluidization of the particles was maintained by vibration of the crucible. By varying the deposition parameters, the surface morphology could be accurately controlled to be cubo-octahedral, mirror-ball, or rounded ball.

A problem of concern to commercialization of diamond is adhesion. NIT has developed an apparatus to measure adhesion of diamond to a substrate by measuring the displacement of a hard wedge placed at the diamond/substrate interface as a function of the applied load. However, there was minimal information about how the problem of adhesion was being addressed, presumably due to its proprietary nature. Toshiba-Tungaloy indicated that surface pretreatment of cobalt free sintered tungsten-carbide permitted deposition of adherent diamond coatings. The reliability of these coatings was not discussed. Several pretreatments, especially those to decrease surface cobalt concentration in sintered carbide substrates, or the use of interfacial layers are gradually yielding successful results.

It now appears relatively routine to control surface morphology from smooth with microcrystalline grains to rough with large-grained polycrystals. Even the type of faceting [(100) vs. (111)] can be chosen, depending on growth conditions. Scanning electror microscopy remains the primary technique for observing such surface morphology while Raman spectroscopy is used for determining diamond film quality.

Several companies (including Fujitsu, Kobe Steel, Ltd., and NEC) are conducting their diamond depositions in a clean room, possibly in anticipation of commercialization in the future.

An interesting observation about patents related to growth techniques should be noted. Many companies are working on techniques that have been patented in their fundamental form elsewhere; however, the investigators do not believe that patent infringement will be a problem. It was stated that the patent problem will be addressed as products approach the commercialization stage. Some companies felt that they had made significant modifications that will allow them to obtain their own patents. Others stated that they would cross-license the desired technology. Obviously, numerous companies will require licensing of the original NIRIM patents; however, there appears to be some disagreement regarding how encompassing the NIRIM patents are. Some companies believe their techniques do not fall under these patents, but these views may be challenged.

\section{Summary}

Laboratories in Japan are quite advanced in the technology of diamond film deposition. New approaches and modifications to existing technology continue to be developed by the leading laboratories. The United States appears to lead Japan in fundamental investigations and understanding of the deposition 
process, but lags in diamond deposition technology, especially in the high growth rate techniques. Gas species analysis is of interest to many laboratories in Japan, but measurement techniques are less advanced than those used in the United States Low temperature deposition may be one area in which the United States has a significant advantage at the present time. The Japanese can control surface morphology and film roughness, but adhesion remains a major concern. However, advances in adhesion have allowed prototype cutting tools to be marketed. (Since our visit, Dr. Kawarada of Fujitsu has reported that adhesion can be controlled at his company.) The state-of-the-art in deposition area appears to be somewhere between $15 \mathrm{~cm}$ diameter disks and $10 \times 25 \mathrm{~cm}$ plates, although the ability to achieve these dimensions is limited to two or three laboratories.

Most Japanese companies with a significant effort in diamond have approximately 10 deposition systems in operation and have experience with several different deposition techniques. The initial work of NIRIM, which spawned this field in the early 1980s, still has a significant impact on current research. The microwave plasma technique seems to be the method of choice for controllable, high quality, pure diamond depositions that can be monitored for process control. Hot filament deposition appears to be the leader in terms of growth area, but within the next two years it is expected that microwave plasmas will be very competitive. Microwave plasma and HFCVD are limited to low deposition rates, but can be run continuously over long periods of time to achieve thick films.

The Japanese are rapidly gaining experience in the use of thermal plasma techniques for depositing diamond at high deposition rates. DC plasma jets and RF plasma torches have been the primary advances, but these methods are have limited deposition areas. Scanning the substrate in the deposition region is one method that allows for increased growth areas, but this method has not yet been fully developed. The DC plasma jet appears to have the greatest economic efficiency of all the deposition methods. Economically efficient diamond growth appears to be a goal of several research groups.

Most of the systems observed were not commercially available, but were custom built, sometimes through collaborations between universities and industry. Commercially available systems targeted specifically for diamond growth are now becoming available.

\section{NUCLEATION}

There is a recognition by Japanese research groups, as in the United States, that control of nucleation is essential for many applications. The Japanese effort in control of nucleation and progress being made appear to be similar to that in the United States. For example, substrate pretreatment with diamond powder or other abrasives is necessary to promote nucleation in microwave and hot filament reactors. Nucleation promotion is not required with the high deposition rate thermal plasma or combustion methods.

Some Japanese groups are taking fundamental approaches to the nucleation problem. Yoichiro Sato and his colleagues at NIRIM are developing a capability for fundamental in situ surface science studies during nucleation and growth. This work has a high probability of unraveling some of the 
complexities of nucleation and growth mechanisms. Seiichiro Matsumoto, also at NIRIM, is explicitly studying homogeneous nucleation processes in diamond chemical vapor deposition. Matsumoto was the first to propose high molecular weight compounds as the precursors to diamond formation. Few details of his current work are available.

At Matsushita Electric, silicon surfaces are being implanted with carbon as a pretreatment for subsequent diamond nucleation and growth. Details of the process and specific results were not available. Also, several Japanese groups are nucleating and growing diamond on nondiamond substrates within fluidized beds. Silicon carbide particles are being used as seed crystals in some of these experiments.

One important goal of diamond research in the United States is heteroepitaxial deposition of diamond over large areas. We observed no evidence for successful large area diamond heteroepitaxy in Japan. Several Japanese laboratories are working in this research area.

A particular advance in diamond nucleation should also be noted. Osaka University, Kobe Steel, and Canon Inc. have used a photolithographic technique to deposit diamond on selected areas of a substrate while leaving the remaining substrate area diamond free. This technique, called SENTAXY, employs an ion beam to damage a selected region of the substrate surface, preventing nucleation of diamond in the damaged region. The technique has been used at Kobe Steel to fabricate various circuit elements made of diamond, such as thermistors and Hall effect devices. This selective area deposition technique also may help us gain insights about the mechanisms for diamond nucleation.

\section{CHEMICAL AND PHYSICAL PROPERTIES}

Specifications for physical and chemical properties of diamond depend on the application for which the material is intended. After a practical set of specifications has been defined, direct measurements must be made to confirm that the material complies with the specified properties. Such qualifications of CVD diamond requires not only reliable measurement methods, but also appropriate protocols for executing sequences of complementary characterizations that examine the interdependence of physical and chemical properties. Since the important chemical and physical properties of CVD diamond can vary considerably with growth parameters, exact knowledge of and control of growth conditions are imperative. Parameters such as feed gas composition, feed gas flow rate, deposition pressure, substrate temperature, filament temperature, filament geometry, plasma temperature, and plasma electric field strength can influence deposition rate, morphology, grain size, hardness, surface roughness, thermal conductivity, electrical resistivity, film adhesion, color, optical transparency, $\mathrm{sp}^{3}$ to $\mathrm{sp}^{2}$ carbon level ratios, and impurity content. Consequently, only by detailed characterizations of deposited films and definitive correlation of measured properties with growth conditions can films be tailored reproducibly for specified properties.

Measurement techniques for determining specified properties of diamond are as well developed in Japan as in the United States. In both countries there is a need to systematize the characterization of diamond to ensure that 
investigators use a universal protocol for determining physical properties such as thermal conductivity, hardness, resistivity, thickness, adhesion, stress, and surface roughness. While chemically related measurements such as Raman frequencies, NMR chemical shifts, hydrogen content etc., can be easily compared, few investigators report accurate and reproducible physical property measurements that permit interlaboratory comparisons. A need continues to exist for investigators to establish a specification for combinations of measurement techniques that totally characterize a diamond specimen for a specific application. The data from such characterizations are likely to be retained as proprietary information. However, these measurement protocols are critical for the technical exploitation of diamond.

\section{Chemical properties}

The identification of a material as diamond is based largely on the characteristic Raman vibration at $1332 \mathrm{~cm}^{-1}$. This is the most widely used confirmation tool, which also indicates the purity of the deposited films with respect to $\mathrm{sp}^{2}$ contaminants. Several Japanese laboratories, for example Fujitsu, have also used NMR for characterization of CVD diamond. Diamond has a well defined resonance peak with a chemical shift of $35 \mathrm{ppm}$ relative to the standard carbon reference, tetra-methyl-silane. Three-fold coordinated (aromatic or graphitic) environments have chemical shifts in the 70 to $150 \mathrm{ppm}$ range and are readily distinguishable. Thus NMR spectroscopy can provide a quantitative breakdown of the carbon bonding environments in both diamond and diamond-like material.

The measurement of the hydrogen content in diamond materials is also important to correlate with property measurements. This is especially true for diamond-like carbon (DLC) where it is important to correlate hydrogen content with density. Matsushita Electric has prepared DLC with a density of 1.8 $\mathrm{g} / \mathrm{cm}^{3}$, a hardness of $2800 \mathrm{Kg} / \mathrm{mm}^{2}$, and containing less than $5 \%$ hydrogen. The hydrogen content was determined by an unnormalized SIMS techniques.

Hydrogen in DLC has also been measured by Rutherford backscattering (RBS) and by recoil methods at NEC. DLC films containing $24 \%$ to $32 \%$ hydrogen had been fabricated. Detailed thermal decomposition studies at NEC showed that the DLC films lose $\mathrm{CH}_{3}$ and $\mathrm{CH}_{2}$ groups as the temperature is raised above $200{ }^{\circ} \mathrm{C}$. At $400{ }^{\circ} \mathrm{C}$ the films begin to graphitize and at $430{ }^{\circ} \mathrm{C}$ they become unstable. DLC films prepared by glow discharge showed high electrical resistivity of $2.8 \times 10^{13} \mathrm{ohm}-\mathrm{cm}$, a dielectric constant of 3.5 and densities of $2 \mathrm{~g} / \mathrm{cm}^{3}$. The location of hydrogen in diamond still remains an unresolved question. Does it reside predominantly at the grain boundaries or within the crystal structure?

At Seiko Instruments Inc., Akixa Nishikawa [1] showed a significant correlation between the Raman spectra of diamond films deposited by microwave plasma CVD, the methane/hydrogen ratios used in the feed gas and thermal conductivity. This work had been reported previously by ono et al. [2]. The sharpness of the diamond Raman peak showed a correlation with increasing thermal conductivity, and an anticorrelation with increasing methane/hydrogen ratio.

At the Semiconductor Energy Laboratory (SEL), the electron cyclotron resonance (ECR) process for diamond deposition has been optimized by use of atomic emission spectroscopy. Control of the levels of atomic hydrogen during growth 
has been accomplished. By inserting a light probe into different regions of the ECR discharge, SEL has determined the parameter space in power, pressure, and substrate bias whereby one can obtain uniform $656 \mathrm{~nm}$ atomic hydrogen emission over a $100 \mathrm{~mm}$ diameter wafer. This is an example of the high quality engineering characterizations performed at SEL [3].

At NEC, the dependence of surface roughness of films on the methane fraction in the feed gas was studied by SEM examination. At methane fractions of $1 \%$, rough faceted growth was observed. Increasing the methane fraction to $3 \%$ gave significantly reduced surface roughness due to the decreased size of the diamond crystallites. These films, which were $5 \mu \mathrm{m}$ thick, were translucent and had a thermal conductivity of $500 \mathrm{~W} / \mathrm{m} / \mathrm{K}$. Films were characterized by Raman spectroscopy and $\mathrm{x}$-ray diffraction. Morphology, roughness and transmittance were also assessed.

Another valuable measurement process was claimed by Asahi Diamond. While no details were provided, they indicated that it was using in situ thickness monitoring of diamond film growth.

Physical Properties

Many Japanese companies have made significant investments in characterization methods for supporting their diamond programs. Facilities are available for determining nucleation density, hardness, thermal conductivity, Young's modulus, and resistivity. Analytical techniques include, scanning electron microscopy, reflection high energy electron diffraction (RHEED), ESCA, Auger spectroscopy, cathodoluminescence, optical spectroscopy, transmission electron microscopy, $x$-ray diffraction, NMR, Raman spectroscopy, and Rutherford backscattering.

Determinations of the thermal conductivity or thermal diffusivity of polycrystalline diamond are made by relatively few laboratories. The radiant cooling method was developed by Seiko in collaboration with the National Research Laboratory of Metrology. This approach described by Akira Ono and co-workers measures the thermal conductivity of thin films ( 7 to $30 \mu \mathrm{m}$ ) in a direction parallel to the surface [2]. Measurements are made between $100{ }^{\circ} \mathrm{C}$ and $130{ }^{\circ} \mathrm{C}$ by a thermograph providing a visual display of temperature distribution along an unsupported diamond film in the form of a thin ribbon. Samples of oxygen-free copper and pure silver were used to calibrate the apparatus to an accuracy of several percent. Some difficulty was experienced with fracture of unsupported diamond films during measurements. Thermal conductivity of diamond films versus methane/hydrogen ratios in the feed gas showed an inverse relationship. Films prepared at 0.1 methane fraction had the highest thermal conductivity, $1000 \mathrm{~W} / \mathrm{m} / \mathrm{K}$. The thermal conductivity decreased rapidly with increasing methane/hydrogen ratios. Thermal conductivity also showed an inverse correlation with graphitic or DLC content in the films as indicated the Raman spectra. Similar studies of thermal diffusivity versus methane/hydrogen ratios have been done by NEC. The AC calorimetric instrument used by NEC to measure thermal conductivity is available commercially [4].

Stress is another important property that must be controlled in diamond film preparation. This is especially important in the production of diamond membranes for $\mathrm{x}$-ray lithography. Direct measurements of stress were not 
widely reported during our visits. Only one group, at Tokyo Institute of Technology, is examining the influence of microwave power on stress in the films. The change of stress in the deposited material is determined by shifts in the characteristic Raman peaks for diamond.

Other physical measurements are useful for characterizing diamond films. For example, density measurements provide information about the relative content of non-diamond components in the film. Density measurements are not commonly performed because the measurement method employed uses liquids that have toxic properties.

\section{ADHESION, BONDING AND HARDNESS}

The strength of the adhesive bond of diamond films to the substrate is a very important property for many applications. For diamond cutting tool inserts this is the most important property. Only limited information on adhesion and bonding was provided by our Japanese hosts. Detailed scrutiny of Japanese patents may be needed to obtain more information about their progress in these proprietary areas.

Adhesion of diamond received the most attention from corporations interested in exploiting diamond as a cutting tool material. Although Fujitsu listed the development of the methods for improving the adhesion of CVD diamond to substrates as a major accomplishment over the past year, details on how this was accomplished were not provided. Adhesion of diamond as a function of substrate thickness was shown by Professor Tadao Inuzuka at Aoyama Gakuin University. Diamond adhesion to a given substrate as a function of film thickness is also important, but no information about this measurement was revealed during our visits.

Researchers at Idemitsu Petrochemical indicated that they were not successful in preventing the delamination of CVD diamond from the surface of tungsten carbide. Close examination revealed that WC and diamond had a strong bond, but fracture occurred during use of the tool bits due to the disparate thermal expansion between $W C$ and diamond. By using $\mathrm{Si}_{3} \mathrm{~N}_{4}$, a material whose thermal expansion closely matches that of diamond, instead of WC, excellent adhesion of diamond was obtained.

Kobe Steel has fabricated CVD diamond coated WC-Co tool inserts in a microwave plasma. However, the adhesion was believed to be insufficient for marketing a practical product. In contrast, Mitsubishi Metals reports the direct coating of diamond onto specially prepared cemented carbide inserts. Adhesion problems have been largely solved by control of the cobalt layer and by proper surface treatment methods [5]. Toshiba Tungaloy has also improved the adhesion strength of diamond to WC by eliminating the use of cobalt. The surface is first roughened before diamond deposition. Decarbonization is then achieved by etching the surface in a $2 \% \mathrm{O}_{2}$ in $\mathrm{H}_{2}$ microwave plasma. Electron micrographs of the treated surface indicate that the surface morphology of the WC influences adhesion. X-ray diffraction results indicate that the treated surface is very fine grained compared to the untreated one. The surface after plasma etching is also rich in metallic tungsten. TEM micrographs of the interface indicate that good adhesion is due partly to filaments of WC interwinded with diamond. 
The most definitive experimental measurements of adhesion were detailed at Toshiba Tungaloy and at the Nippon Institute of Technology. At Toshiba Tungaloy, the results of a $60 \mathrm{~kg}$ drop weight and scratch test were used to examine the hardness and adhesion of diamond to the WC interface. Although the wear resistance of the diamond is excellent, adhesion strength still needs further improvements. As mentioned earlier, a lateral scraping device was demonstrated for measuring film adhesion, at NIT. A unique shearing wear tester was developed in-house. This machine measures the rate of wear of a diamond cutting edge by repeatedly cutting slivers of carbide abrasive tape. This instrument has been used to demonstrate quantitative correlation between film adhesion and cutting edge lifetime.

At NEC a micro-indenter method has been applied to determine the hardness of DLC [5]. The distance of penetration of a loaded microtip was measured by measuring interference fringe movement as a function of applied load with an electrobalance. Both the hardness and Young's modulus of the diamond films were determined by comparison with measurements performed on materials with known hardness used as reference standards.

\section{DOPING OF DIAMOND FILMS}

Idemitsu Petrochemical, Osaka University, Sumitomo Electric, and Kobe Steel have active research programs in doping of diamond films. Sumitomo Electric is working on doped homoepitaxial diamond films. These are doped CVD diamond layers deposited on single crystal diamond substrates. All of the laboratories are doping and characterizing polycrystalline diamond films. No work was being done on doping diamond at NIRIM because of their emphasis on first understanding undoped diamond. NIRIM expects to begin working on doped diamond films soon.

Kobe Steel probably has the largest investment in equipment for the development of polycrystralline diamond device technology. The work at Kobe Steel is based on microwave plasma deposition; their deposition system has been described above. Boron is the dopant of choice, and prototype Hall devices are being fabricated to determine carrier concentrations and mobilities. Secondary nucleation of the doped diamond on the undoped layer has been avoided by initiating a hydrogen discharge prior to introducing the methane for the doped diamond deposition.

Osaka University has been doping SYNTAXY produced diamond films with boron. Doping was accomplished by use of $\mathrm{B}_{2} \mathrm{H}_{6}$ in the feed gas with concentrations not exceeding 1000 parts per million (ppm). Exceeding $1000 \mathrm{ppm}$ resulted in degradation of the diamond quality. Nitrogen, introduced as $\mathrm{N}_{2}$ in the feed gas, is being tested a dopant source. Electron spin resonance is being used to measure the nitrogen concentrations in the films.

Idemitsu Petrochemical has been studying the electrical conductivity of B-doped diamond films as a function temperature at different doping levels. The conductivity is measured over the temperature range 300 to $650 \mathrm{~K}$ on films grown on (111) diamond substrates. 
Sumitomo Electric reported significant information on dopant incorporation in homoepitaxial films. B, S, P, C1, As, and Se were evaluated as dopants. Phosphorous doping did result in $n$-type behavior but the conductivity of the films was very poor. The activation energy of the boron doped samples was observed to be a function of the dopant concentration in the gas phase. Table 1 gives values for the activation energy for various boron gas concentrations for homoepitaxial growths on (100) growth surfaces.

The boron concentration in the (100) films was determined by SIMS analysis. The results are shown in Table 2 .

The hole mobility as a function of temperature was reported for one of the boron doped films. The hole concentration at room temperature was $10^{13} \mathrm{~cm}^{-3}$ increasing to $10^{18} \mathrm{~cm}^{-3}$ at $600{ }^{\circ} \mathrm{C}$. The hole mobility at room temperature was $960 \mathrm{~cm}^{2} / \mathrm{V} / \mathrm{s}$ declining to $70 \mathrm{~cm}^{2} / \mathrm{V} / \mathrm{s}$ at $600{ }^{\circ} \mathrm{C}$. Sumitomo has fabricated some devices from B-doped films.

TABLE 1. Carrier activation energy vs, boron concentration in the feed gas for diamond films deposited on diamond substrates [6]

\begin{tabular}{|c|c|c|c|}
\hline Substrate orientation & \multicolumn{3}{|c|}{ carrier activation energy } \\
\hline & $\begin{array}{l}\text { boron } \\
20 \mathrm{ppm}\end{array}$ & $\begin{array}{l}\text { tration } \\
100 \mathrm{ppm}\end{array}$ & $\begin{array}{l}\text { ed gas } \\
1000 \mathrm{ppm}\end{array}$ \\
\hline $\begin{array}{l}(100) \\
(110)\end{array}$ & $\begin{array}{l}0.43 \mathrm{eV} \\
0.43\end{array}$ & $\begin{array}{l}0.34 \mathrm{eV} \\
0.35\end{array}$ & $\begin{array}{l}0.22 \mathrm{eV} \\
0.11\end{array}$ \\
\hline
\end{tabular}

Table 2. Boron concentration in deposited diamond films vs boron fraction in the feed gas [6]

\begin{tabular}{|l|c|c|c|}
\hline B in feed gas (ppm) & 40 & \multicolumn{3}{|c|}{100} & 1000 \\
\hline $\begin{array}{l}\text { Boron concentration } \\
\text { in film }\left(\mathrm{cm}^{-3}\right)\end{array}$ & $4.0 \times 10^{17}$ & $6.0 \times 10^{18}$ & $1.0 \times 10^{20}$ \\
\hline
\end{tabular}

\section{DIAMOND EPITAXIAL GROWTH}

Few Japanese companies or universities appear to be involved in diamond epitaxial growth. This is probably because the Japanese are interested in processes that are expected to produce more immediate practical results and 
polycrystalline diamond films may suffice in some electronic applications. The most notable exception is Sumitomo Electric where considerable research in the growth of homoepitaxial diamond films has been performed. This is probably because Sumitomo's capability to produce high pressure diamond substrates allows its researchers to select, cut and polish high quality substrates for epitaxial growth. This capability gives Sumitomo a significant advantage in CVD homoepitaxial studies.

Sumitomo uses microwave systems of its own design for diamond growth. Microwave reactors are preferred over hot-filament reactors for the growth of epitaxial layers because of impurity incorporation during the hot filament process; 20 to $30 \mathrm{ppm}$ of $\mathrm{W}$ have been found in diamond films grown in hot-filament reactors. The microwave systems operate at pressures between 40 and 100 Torr using methane/hydrogen mixtures. The highest quality diamond growth is found to occur on (100) diamond surfaces at a substrate temperature of $830{ }^{\circ} \mathrm{C}$ and with a surprisingly high methane fraction (6\%) in the feed gas. This assessment was made on the basis of surface topography examination, RHEED analysis, and Raman spectroscopy. The homoepitaxial films deposited with $6 \%$ methane had smoother surfaces and contained less amorphous carbon bonding than films deposited with lower or higher methane fractions in the feed gas.

Besides homoepitaxy, Sumitomo also showed results on the heteroepitaxial growth of diamond on high-pressure synthesized cBN crystals. RHEED data was shown for heteroepitaxial growth on both (111) and (100) faces of cBN. Details of the growth were not given and no characterization methods other than RHEED were mentioned.

Workers at Aoyama Gakuim University have also grown diamond on cBN. Professor Inuzuka has imbedded $c B N$ crystals into $\mathrm{Ta}$ and has studied the growth of diamond on various faces of the $c B N$. The films grown on the cBN crystals are under considerable stress as evidenced by the shift in the diamond Raman line from $1332 \mathrm{~cm}^{-1}$ to $1325.6 \mathrm{~cm}^{-1}$. After depositing $10 \mu \mathrm{m}$, a smooth (111) diamond film was obtained.

A variety of substrates are being tested for heteroepitaxy by different groups in Japan. These substrates include $\mathrm{MgF}_{2}, \mathrm{MgAl}_{2} \mathrm{O}_{4}, \mathrm{AlN}, \mathrm{SiC}, \mathrm{CaF}_{2}$, and $\mathrm{Al}_{2} \mathrm{O}_{3}$. Only the work on $c B N$ has been successful.

\section{POST DEPOSITION PROCESSING}

Most applications for CVD diamond require some form of processing of the deposited material. In this report, post deposition processing is taken to include, polishing, etching, and brazing. Many Japanese companies realize that these technologies are essential in applications of CVD diamond, and have devoted considerable resources into these areas.

To illustrate the enabling nature of post deposition processing, consider a CVD diamond film with a surface roughness of 1 to $3 \mu \mathrm{m}$; it will be unsuitable as an optical window material due to optical scatter. Similarly, the surface roughness of CVD diamond films can limit their use as heat sinks and tribological coatings due to poor thermal contact and sliding friction, respectively. Polishing offers a way of reducing surface roughness, and thereby enables optical, heat sink, and tribological applications of CVD 
diamond. An alternate approach to reducing surface roughness is to synthesize the CVD diamond with controlled, small (relative to the wavelength), uniform grain size, independent of film thickness. Modifying the as-grown properties of CVD diamond films will be discussed in later section.

Laser cutting and planing

Lasers are routinely used to cut diamond synthesized with high pressure/high temperature techniques. Recently, Tezuka and Yoshikawa at the Tokyo Institute of Technology reported using a Nd:YAG laser to cut and plane diamond films grown with a DC Plasma Jet [7]. Their technique uses a repetitively pulsed Q-switched Nd:YAG laser with a peak power of $23 \mathrm{~kW}$ and a pulse repetition rate of $1 \mathrm{kHz}$. An oxygen atmosphere was needed to remove the graphite (through conversion to $\mathrm{CO}_{2}$ ) which accumulated during laser irradiation. The planing operation begins with a focussed laser beam aligned approximately parallel to the surface of a diamond film. The beam is then traversed at a $1 \mathrm{~mm} / \mathrm{sec}$ rate across the surface. The focus is gradually advanced along the beam direction and down into the film with successive passes. Roughness averages of $3 \mu \mathrm{m}$ have been achieved. Cutting of diamond films deposited by plasma jet was also demonstrated.

Ion etching processes

Etching of diamond films has been studied at Kobe Steel, at NIRIM, and at other institutions. At Kobe Steel, etching has been accomplished in a specially tailored DC plasma discharge containing oxygen and helium between parallel electrodes. Etch rates between 1 and $2 \mu \mathrm{m} / \mathrm{hr}$ have been achieved. The NIRIM work used an oxygen plasma in a microwave reactor to reveal the columnar structure of microwave plasma synthesized CVD diamond films. Work in smoothing CVD diamond films with a Penning discharge micro-sputtering system was recently reported by Seiko [8]. Their procedure uses an $\mathrm{Ar} / \mathrm{O}_{2}$ plasma at 0.001 Torr for reducing the surface roughness of CVD diamond films. They have achieved etching rates of $0.07 \mathrm{~mm} / \mathrm{min}$.

Chemical polishing

Numerous groups in Japan are researching chemical and abrasive techniques for polishing CVD diamond. Yoshikawa at the Tokyo Institute of Technology (TIT) has developed a novel technique for polishing CVD diamond which is based on the poor performance of diamond tools when cutting and grinding ferrous metals $[9,10]$. His technique places the CVD diamond sample on a hot iron surface rotating near a tungsten filament in a hydrogen atmosphere. The standard operating conditions are: iron plate temperature, $700-900{ }^{\circ} \mathrm{C}$; filament temperature, $2000{ }^{\circ} \mathrm{C}$; hydrogen flow rate, $100 \mathrm{sccm}$; chamber pressure, 40 torr; rotation rate of iron plate, $5 \mathrm{rpm}$ (the sample was also rotated about its center at a slower rate); and pressure of sample against iron plate, $60 \mathrm{kPa}$. To obtain a peak to valley surface roughness of between 2 and $3 \mu \mathrm{m}$ required 4 hr of polishing under these conditions, giving a material removal rate of about $0.5 \mu \mathrm{m} / \mathrm{hr}$. Yoshikawa indicated [11] that the mechanism for polishing is diffusion of carbon into the iron to form a carbide, and subsequently removal of the carbon from the iron surface by methanation. Recently, Yoshikawa has observed polishing in vacuum environments, polishing rates of $6 \mu \mathrm{m} / \mathrm{hr}$, and preliminary evidence of polishing (111) faces of natural diamond with this technique [12]. 
Showa Denko is working with Dr. Murakawa at the Nippon Institute of Technology (NIT) on a very similar process which can produce a surface roughness of 0.01-0.05 $\mu \mathrm{m}$ in 10-20 min.; Showa Denko has applied for a U.S. patent on this process. Fujitsu and other Japanese companies have set up systems similar to Yoshikawa's and are beginning to use this technique for polishing CVD diamond.

Abrasive polishing

Several groups in Japan are studying more conventional abrasive polishing techniques for CVD diamond. At NIRIM, a low speed cast iron wheel impregnated with diamond grit has been used to polish a microwave plasma grown diamond film to a specular finish in the visible. The polishing took many hours to complete. Osaka Industrial Diamond Company has used a diamond wheel to polish fairly large area CVD diamond films $(1 \times 2 \mathrm{~cm})$ to a specular finish in the visible. The polishing rate was reported to be very fast. Thick (100 $\mu \mathrm{m})$ diamond films were polished at Sumitomo's research laboratory by conventional abrasive techniques.

Brazing

While brazing appears to be the technique for fabricating the first generation of CVD diamond tools, we did not observe any research related to brazing. Sumitomo is manufacturing a small end mill cutter and a TAB bonder by brazing thick CVD diamond coatings to the underlying support material. Cutting tests observed at NIT were being performed with a brazed CVD diamond insert. Asahi Diamond claims to have patented a superior brazing process for CVD diamond. Brazing produces a more reliably adherent CVD diamond coating compared to direct CVD diamond deposition onto a substrate. 
[1] A. Nishikawa, "Measurement for Thermal Conductivity of Diamond Films", in New Diamond, Japan Reviews in New Diamond 1990, Japan New Diamond Forum, pp. $70-72$.

[2]. A. Ono, T. Baba, H. Funamoto, and A. Nishikawa, "Thermal Conductivity of Diamond Films Synthesized by Microwave Plasma CVD," Jap. J. Appl. Phys. 25, 1986, pp. L 808-L810.

[3] See Appendix C, site visit report for Semiconductor Energy Laboratory, p. 65 .

[4] I. Hatta, Y. Sasuga, R. Kato, and A. Maesono, Rev. Sci. Instrum., 56, 1643 (1985).

[5] S. Hoshino, K. Fujii, N. Shohata, H. Yamagucki, Y. Tsukamoto, and M.Yanagsawa, "Mechanical Properties of Diamond-like Carbon Films," J. Appl.Phys., 65, 1918-1922 (1989).

[6] N. Fujimori, H. Nakahata, and T. Imai, "Properites of Boron-Doped Epitaxial Diamond Films," Jpn. J. Appl. Phys. 29, 824-827 (1990).

[7] S. Tezuka and M. Yoshikawa, "Cutting and Surface Planing of CVD Diamond Films by YAG Laser," New Diamond 17, 36 (1990) [in Japanese].

[8] H. Funamoto, O. Koseki, T. Sugita, Y. Yoshida, and E. Nishikawa, "Planing of Diamond Film by Penning Discharge Micro-etching," Spring Japanese Applied Physics Meeting, Program and Book of Abstracts, p. 27, p-E-12 (1990).

[9] C.F. Yang, H. Tokura, and M. Yoshikawa, "Polishing of Diamond Film With Metal," Program and Book of Abstracts, 1st International Conference on the New Diamond Science and Technology (Tokyo, 1988) p.138.

[10] M. Yoshikawa, "CVD Diamond Film Polishing," in SPIE Proceedings Vol. 1325 -Diamond Optics III (1990), pp. 210-221.

[11] M. Yoshikawa, "Applications for Mechanical Characteristics" Diamond Thin Film Technology, Ch. 6 (in Japanese), N. Setaka, editor (Sogo Gijutsu Center, 1988).

[12] Personal communication, M. Yoshikawa, May 1990. Yoshikawa also indicated that the higher polishing rates were obtained without a filament and with an iron temperature of $900^{\circ} \mathrm{C}$. 
APPLICATIONS

\section{INTRODUCTION}

The market for CVD diamond and DLC products is not well defined yet; however, Japanese companies are focussing on several main applications including machine cutting tools, tool coatings, TAB bonding tools, electronic devices, heat sinks (thermal conductors), and optical windows and coatings. Many large Japanese companies have research and development efforts on CVD diamond of between 5 and 15 researchers, with significant equipment capitalization programs. Although mass produced CVD diamond products are not expected in the near future, companies seem willing to devote significant resources to develop technologies for patenting, commercial products, and in-house expertise. Due to the rapidly accelerating pace of scientific research in this field, any report on applications of CVD diamond is bound to be dated. It is also expected that new discoveries will fuel new applications and markets, and that the focus of research teams may shift to accommodate these changes. Companies with an in-house capability to synthesize, process, and characterize CVD diamond will be most able to adapt and respond to new developments in the field.

The following sections of this report discuss Japanese CVD diamond research efforts in the following areas: machine tools and abrasives, heat sinks (thermal conductors), semiconductor applications, and optics. Little or no research was observed on wear coatings, chemically protective coatings, and masks for $x$-ray lithography.

\section{MACHINE TOOLS AND ABRASIVES}

Almost all of the products common to industrially developed nations require, at some stage of their fabrication, various machining and surface finishing operations. Examples include dimensioning and planing of lumber for the construction industry, surface milling of engine and transmission components in the automobile industry, and finishing and polishing computer disc drive read/write heads for the computer industry. It is generally recognized that material removal operations form a substantial part of the processing technology base for a modern industrial economy. No less important is the control of wear and friction. Much of the use of vapor deposition technology in the United States is for the preparation of cutting tools and the coating of wear surfaces. No reliable market projection for the impact of CVD diamond or cubic boron nitride ( $\mathrm{cBN}$ ) on U.S. industry are presently available; however the market for diamond and cubic boron nitride tools and wear surfaces in Japan has been estimated and is expected to grow to approximately 2.7 billion U.S. dollars by 1995 compared to a 1988 volume of slightly over 600 million dollars.[1] The 1988 volume was of course almost entirely dependent on high pressure/high temperature (HPHT) synthetic diamond and cBN powders.

These estimates do not reflect the likely impact of diamond tools on the total national economy. This is because CVD diamond tools and coatings for high temperature wear resistance are quintessential enabling technologies. For example, enormous increases in machining speeds over the last century have resulted in tremendous increases in manufacturing efficiency. This was made 
possible due to the development of new cutting tool materials such as tungsten carbide, silicon nitride, cubic boron nitride, and polycrystalline diamond compacts. While CVD diamond is postulated to replace polycrystalline diamond compacts, the greatest impact may well be in tooling and wear applications not yet anticipated. It is axiomatic that the development of new materials for manufacturing processes often leads to new processes not previously anticipated by the original pioneers in the field.

A simple example to illustrate this is the development and introduction in the early 1970s of fuse-quench zirconia/alumina abrasives which were expected at the time to serve primarily as improved products for the grinding of low carbon steels. It was rapidly discovered that with the improved performance and reliability of these products, computer controlled abrasive machining operations were possible. This in turn resulted in significant improvements in the manufacture of lumber with the replacement of steel knives by abrasive planing machines and the design and construction of computer controlled abrasive machining units to replace more conventional milling of transmission cases and engine heads.

A similar, but likely more profound effect can be expected in the present case of CVD diamond with many new operations becoming feasible. It is this anticipation that appears to drive much research and development in Japan. In 1987, Dr. Akio Hara of Sumitomo Electric Industries presented data on the development and performance of high frequency diamond coated speaker diaphragms for use by the Sony Corporation [2]. In the course of his presentation he remarked that the major improvement in audio fidelity afforded by the diamond coating was well outside the range of human perception so that "... your dog is likely to appreciate it more than you are." The joke was well received by the audience, but, the point was that sumitomo judged the strategic implications of CVD diamond sufficiently important to justify exploiting any opportunity for developing a quality product in the effort to develop a high quality manufacturing technology base for CVD diamond based products. Sumitomo, along with others, has subsequently introduced other products, including small end mills for various cutting operations. Whereas many North American and European tool manufacturers tend to await the development of an economically viable production scale technology, prior to the limited introduction or test marketing of new products, at least some Japanese manufacturers appear to view their initial product introductions as important elements in the process/product development program itself. Close ties between customer and vendor are considered critical to successful process/product development.

This view of Japanese product/process development is consistent with an overall pattern of traditional Japanese industrial organization or keiretsu, in which close, almost familial, relationships are maintained between industrial consumers and suppliers. It is expected that this strategy will also be pursued in the development and exploitation of CVD diamond technology for tooling and wear applications.

\section{Initial Products and Production Processes}

One of the current problems limiting product design at present is satisfactory adhesion of CVD diamond to many substrate materials of interest. Numerous 
strategies are being pursued by different manufactures to overcome this problem. A major current item of manufacture is the powdered diamond compact or PDC which is viewed by many as a potential material for the CVD diamond to replace. This product is produced by a process in which diamond powder, a metal binder or catalyst, and usually some graphite powder are combined, often with a substrate in place, and sintered together at high pressure with some transformation of the graphite to diamond to produce a high density composite structure with many of the properties of diamond. There are several variations of this process with the original work [3] having been accomplished within a decade after the invention of the HPHT process for diamond manufacture.

With the development of a process technology for rapidly depositing relatively thick layers, CVD diamond products might be more economically manufactured with some promise of improved performance. Although some crystal-crystal bonding is obtained in many PDC products, the necessary presence of a binder phase or the retention of some of the metal catalyst limits their hardness and performance. It is expected that with the absence of a binder or catalyst metal at the cutting surface, and coupled with the higher anticipated thermal conductivity of a pure diamond layer, much superior performance can be obtained from a CVD diamond surface on the tool.

An approach being pursued by some Japanese companies, notably Asahi Diamond and Sumitomo Electric, is to grow relatively thick layers of CVD diamond, where good crystal-crystal bonding is obtained without the need for a binder phase. The dummy substrate, used only for the growth of the diamond, is then removed to produce a free standing thick layer. This layer is then machined, typically with powerful lasers, to the desired shape and bonded to a suitable tool substrate. The fabrication of a multiplicity of shapes then becomes possible through laser machining of the free standing "slab" of diamond without the need for specialized dies and presses for each product shape or type. High nucleation densities on the growth substrate ensure that one surface of the free standing diamond layer is smooth and the typically rough surface on the growth side of the layer would contribute to adhesion to the tool base.

Critical to success in this approach is the process technology for growing relatively thick free standing layers of CVD diamond and its brazing to suitable tool base materials, notably 8 to 12 weight per cent cobalt cemented tungsten carbide (WC-Co). Almost all of the pioneering work reported for the high rate growth of thick diamond layers has come from Japan and in the interviews conducted as a part of this study, both Sumitomo Electric and Asahi Diamond exhibited considerable confidence in their ability to use a variety of techniques to accomplish this. Asahi Diamond reports that they hold or have exclusive licenses to U.S. patents covering both electron assisted hot filament CVD methods and superior bonding or brazing technologies. In addition, many more patent applications are reported to be pending in both the United States and Japan. It should be noted that with the ability to grow thick free standing diamond layers economically, and the ability to laser machine these layers to precise shapes, numerous other products, including potentially high thermal conductivity substrates for electronic packaging and various medical devices, become feasible. 
Ideally, an ultimate objective is to grow dianond directly on the desired tool support. However, the number of materials on which diamond can be grown with good adhesion is limited. The tool support of greatest interest is WC-Co because of its excellent hardness, toughness and strength at relatively high temperature. Many Japanese companies are aggressively pursuing different strategies to coat this material with CVD diamond in order to obtain sufficient adhesion. To date, consistently high adhesion on high cobalt containing tool bases remains an elusive goal. Consequently, several organizations have opted to use other tool base materials, while continuing their investigation of different approaches to coating WC-Co.

Idemitsu Petrochemical Inc. has announced the introduction of diamond coated silicon nitride based lathe inserts for the machining of high silicon aluminum alloys in the automotive industry, an important machining problem to this industry. Samples of these inserts were given to different members of the study group. Alternatively, Toshiba Tungaloy, Inc. has pursued several different strategies for enhancing diamond adhesion to WC. The most successful strategy has been to eliminate the cobalt binder normally used and make a sintered tool of $100 \%$ WC which is then decarburized at the surface. The carbide is subsequently reformed in the diamond deposition process to give a very fine grained structure with high diamond nucleation density. Researchers report that this approach is successful in producing good adhesion.

Some of the most extensive test data on prototype products has been provided by Mitsubishi Metal Corporation. It is one of the few organizations reporting satisfactory adhesion of diamond coatings on WC-Co through the use of proprietary surface pretreatments. [4]

Several of the manufacturers visited indicated considerable interest and activity in the synthesis of $\mathrm{CBN}$. The expectation was that the range of cutting and machining applications might be extended to ferrous metals by applying a layer of $\mathrm{cBN}$ to the diamond at the cutting surface. This would effectively inhibit the accelerated wear of the cutting edge normally observed on ferrous metals with an untreated diamond surface. However the study group was repeatedly told by several companies visited that developments with cBN were still too immature to be discussed freely.

CVD coatings for cutting and machine tool applications have evolved from relatively simple single layer coatings to multiple layer coatings for different applications as the deposition processes and coating materials have matured [5] and it is likely that similar evolution will occur in the development of CVD diamond coatings as the understanding of how to achieve satisfactory material and process combinations is developed. Among those developments that one might anticipate coming from Japan in the foreseeable future are the design of multilayers to control residual coating stresses and to ensure a broader range of applications and the design of material composite coatings with CVD diamond as an element in the composite design.

\section{THERMAL MANAGEMENT}

Diamond's superior thermal conductivity makes it very attractive for heat transport and thermal management applications. While several industrial 
organizations believed this application of CVD diamond would be realized, a few did not. Those pursuing it included Fujitsu, Idemitsu, Asahi Diamond, Seiko Instruments, and Kobe Steel. Fujitsu is interested in diamond heat sinks for laser diodes and VLSI supercomputer chips, and has made CVD plates as large as $3 \mathrm{~cm} \times 3 \mathrm{~cm} 2 \mathrm{~mm}$. Idemitsu is concentrating on depositing thick diamond films on silicon nitride substrates due to the excellent match in thermal expansion up to $1000{ }^{\circ} \mathrm{C}$. Seiko Instruments thinks a technological barrier to commercializing CVD diamond heat sinks is the inability to deposit diamond films of sufficiently high quality to have the highest possible thermal conductivity. They believe heat sink applications are 2 to 3 years away. Seiko has a highly developed method for measuring thermal conductivity. It should be noted that to our knowledge only NEC, Seiko, and Asahi diamond measure thermal conductivity.

Semiconductor Energy Laboratory, while having no activity in heat sinks at the present time, sees potential for them as heat transport aids for other semiconducting devices.

While Kobe Steel is growing diamond films on silicon for heat sink applications, they anticipate a low probability of successful economic commercialization of thick CVD diamond films for this application. Sumitomo Electric did not yet see a CVD process for making thick diamond films for heat transport that could compete with bulk diamond heat sinks fabricated from diamond crystals made by the HPHT process.

Finally, the New Diamond Forum predicts the following market size for diamond heat sinks: 1995 - $\$ 150 \mathrm{M} ; 2000$ - $\$ 360 \mathrm{M} ; 2010$ - $\$ 700 \mathrm{M}$, assuming 150 yen to the dollar, the exchange rate during our visit.

\section{ELECTRONIC AND OPTOELECTRONIC DEVICES}

The combination of diamond's high band gap, high mobility, high thermal conductivity, and high carrier saturation velocity makes diamond a likely candidate for high power, high speed electronics. A number of Japanese institutions and companies are fabricating electronic devices from polycrystalline and single crystal diamond films. Sumitomo Electric, Osaka University, Kobe Steel, and Matsushita Electric are active in device fabrication research.

The devices are typically test structures such as Schottky diodes, MESFETs, light emitting devices, and thermistors. Outstanding performance from these devices has not yet been observed. Sumitomo has fabricated a variety of devices. Diamond MESFETs have been fabricated from boron doped CVD diamond deposited on single crystal HPHT diamond substrates. The gate length and width were $80 \mu \mathrm{m}$ and $150 \mu \mathrm{m}$, respectively. Ti was used for ohmic contact to the source and drain while $W$ was used for the Schottky barrier metal. When 1 $\mu \mathrm{m}$ p-type layers were deposited on the substrates followed by the metalization, transistor behavior was observed, but the source to drain currents were extremely small. Improvements in the source to drain current have been obtained by depositing a $0.90 \mu \mathrm{m}$-type layer and then a $0.23 \mu \mathrm{m}$ intrinsic layer before the metalization. The operation of these transistors at elevated temperatures was not reported. 
Besides MESFETs, thermistors and light emitting electroluminescent devices have been fabricated at Sumitomo Electric. The light emitting devices were fabricated from boron doped epitaxial films using $W$ as the Schottky barrier metal. A whitish emission was observed when 40 to $100 \mathrm{~V}$ were applied. The spectrum of the electroluminesence was similar to the spectrum of

cathodoluminescence observed on this film. Thermistors were fabricated from boron doped polycrystalline diamond deposited on silicon nitride substrates. A thermistor device fabricated from CVD diamond doped with boron changed resistivity by two orders of magnitude with a temperature change from room temperature of $500{ }^{\circ} \mathrm{C}$. The $\mathrm{B} / \mathrm{C}$ ratio in the feed gas phase was $200 \mathrm{ppm}$.

Osaka University has fabricated light emitting devices from polycrystalline films deposited in magneto-microwave plasma and conventional microwave plasma systems. Some of the equipment was supplied by Semiconductor Energy Laboratory and by the Shimadzu Corporation. Boron doped films, 1 to $5 \mu \mathrm{m}$ thick, were deposited on p-type Si substrates and then were metalized with Al, $\mathrm{W}, \mathrm{Au}$, or Pt. Electroluminescence was observed when the forward bias exceeded $25 \mathrm{~V}$ or when the reverse bias exceeded $20 \mathrm{~V}$. The electroluminescence spectrum coincided with the cathodoluminscence spectrum that had been observed from the specimen. The emission spectrum showed a peak at $2.35 \mathrm{eV}$ with a shoulder at $2.7 \mathrm{eV}$.

In parallel work at Osaka University, Schottky barrier heights of diamond on various metals are being studied. Researchers have found that treatment of the CVD diamond surface with a solution of chromate in sulfuric acid produced consistent Schottky barrier heights with different metals. X-ray photoemission studies of the acid treated surface revealed a substantial amount of oxygen, a small amount of sulfur and no detectable chromium. To determine the effects of oxygen on the Schottky diode formation, diamond surfaces were exposed to oxygen discharges in the absence of wet chemistry prior to metallization. The barrier heights were similar to the heights found on those samples that had received the acid treatment.

A major goal of Kobe Steel's diamond effort is to develop a diamond electronics technology. The work on diamond devices is still evolving. Specifically, researchers are targeting polycrystalline diamond as an electronic material. They are actively involved with doping, broad area deposition, selected area deposition, reactive ion etching, electrical characterization, and fabrication of simple test structures. No results from the test structures were reported. It seems likely that, given the level of effort, diamond devices will be forthcoming soon.

OPTICAL APPLICATIONS: COATINGS, LENSES, WINDOWS AND X-RAY WINDOWS

Introduction

A combination of superior properties make diamond highly desirable as an optical material. Diamond is transparent over wide ranges of wavelengths from the ultraviolet through the visible and most of the infrared. Great hardness makes diamond desirable as a protective optical coating that would be useful on missile domes, aircraft windshields, or supermarket scanners. High thermal conductivity makes diamond useful in applications requiring rapid dissipation of heat, such as windows in high power laser systems. High refractive index 
of diamond makes this a choice material in specialized laser applications such as resonant stack reflectors used in polarizers. Electronic properties make diamond and/or doped diamond potentially useful as an ultraviolet detector and as an electroluminescence emitter.

State-of-the-art CVD diamond may soon be usable as an optical material due to progress in reducing optical scatter and defect induced absorption. While other applications of CVD diamond films, such as machine tool and abrasive applications are tolerant of the presence of impurities and graininess in polycrystaline films, nearly all optical applications require extreme material homogeneity, smooth optical surfaces, minimum impurity content, and negligible optical absorption.

Recent Developments

Progress over the past year on different fronts of CVD diamond film research is expected to advance new optical applications of diamond films. Significant progress has been reported in three major areas of the technology, polishing polycrystalline diamond, depositions over large complex shapes, and high deposition rates. Polishing of polycrystalline diamond films to average surface roughness less than $3 \mathrm{~nm}$ has been demonstrated by TIT using a newly developed fast and efficient polishing method. (See Post Deposition Processing/Chemical Polishing on page 23.) This method could be extended to polish large surface areas and also non-flat surfaces.

The new hot plasma deposition methods allow for deposition of diamond films over large areas and over complex shapes, such as domes, at deposition rates two to three orders of magnitude higher than the microwave and hot filament CVD methods. Unfortunately these methods produce diamond films that are not yet suitable for most optical applications. The challenge remains to deposit high optical quality diamond at high deposition rates and at reasonable cost.

Progress also has been made in the deposition of diamond films that show preferential orientation of the individual grains. The SENTAXY technique for selected area depositions offers the promise of oriented diamond grain.

In the United States, an important development has been the deposition of thin, smooth, transparent diamond films over areas greater than two inches in diameter. The films remain in tension after etching away the central region of the silicon substrate, leaving a large unsupported diamond membrane. The great stiffness and large $\mathrm{x}$-ray transparency make these diamond membranes an ideal material for $x$-ray lithography. The diamond provides the support for the $x$-ray mask material which can be etched to the desired pattern by electron beam lithography. Orily Seiko Instruments reported an interest in this type of work.

A most important breakthrough for optical and electro-optical applications, as it would be for electronic applications, would be development of a method for heteroepitaxial growth of thin and thick single crystal diamond films.

Optical Applications of Diamond in Japan

Of the many possible applications of diamond films, optical applications appear to have low priority in Japan. This is probably because the high 
material quality deemed necessary for optical applications has not yet been achieved by any of the current film deposition processes. The best film quality from the point of view of optical applications is achieved by microwave plasma enhanced CVD methods. Low methane concentrations and the presence of oxygen in the feed gas are preferred for enhanced optical transparency. Deposition conditions that promote grain sizes that are small compared to the optical wavelength of the application, are preferred because the smaller grains sizes lead to smoother surfaces, thus minimizing the need for optical polishing. Small grain size is desirable for self supporting optical membranes and for optical hard coatings. Large grain films, which usually have the highest thermal conductivity, must be polished before they are usable at all except the longest infrared and microwave wavelengths.

None of the Japanese organizations visited were observed to have activities in optical applications. Several of the research groups, however, have been involved in optical characterization of diamond films. These characterizations included measurements of optical absorption in different portions of the electromagnetic spectrum. Of most interest are studies of the visible and near infrared transmission spectra of films that were deposited by a variety of methods. Surface and volume scattering measurements were also of considerable interest to these groups. Progress in optical polishing of polycrystalline films was tracked by measuring optical surface scatter.

According to researchers at Sumitomo Electric, the market is too poorly defined for projecting the commercial markets for optical applications of CVD diamond at this time. Success in deposition of crystal diamond films for electronic applications is expected to benefit optical applications as well.

Seiko Instruments is currently working on optical applications of diamond and DLC films. The films are used as scratch resistant protective layers on watch lenses. The company is also interested in $x$-ray windows and diamond membranes for $x$-ray lithography applications. Researchers optically characterize their microwave plasma CVD films.

Kobe Steel is not working on optical products directly; however, they are actively involved in improving diamond film quality for electronic applications. This company also believes that improved diamond film processing methods will eventually benefit the optical applications areas.

Showa Denko has no specific optical component development efforts at present; however, they are very much interested in diamond film polishing technology and its advancements. They were the first company to demonstrate the deposition of CVD diamond domes, tubes, and other complex shapes.

NEC and Sumitomo Electric are currently conducting synchrotron lithography research. Neither indicated ongoing work on diamond membrane development which is considered to be important for $x$-ray lithography. This area of research is probably highly proprietary.

Osaka University uses optical characterization of their diamond films to monitor film quality.

The polishing work being done by Professor Yoshikawa's group at TIT is probably the most important post deposition processing technology for optical 
applications. Very low optical scatter from these newly polished surfaces show exciting evidence that optical applications for diamond films are not far away.

\section{REFERENCES}

[1] New Diamond 1990, Japan New Diamond Forum, Ohmsha, Ltd., Tokyo, Japan, 1990 .

[2] A. Hara, N. Fujimori and S. Yazu, "Research and Development of Diamond and Diamond-like Carbon Coatings in Sumitomo Electric Industries," Paper N4.1, 1987 Fall Meeting of the Materials Research Society, Boston, MA, Dec. 2, 1987.

[3] A. Blainey and J. H. Custers, U. S. Patent no., 3,239,321 (1966).

[4] N. Kikuchi and H. Yoshimura, "Diamond Coated Inserts," New Diamond 1988, Japan New Diamond Forum, Ohmsha, Ltd., Tokyo, Japan, 1988.

[5] D. T. Quinto, J. Vac Sci. Technol, A6 (3), 2149 (1988). 
Probably because of its proprietary nature, little information was made available to us on manufacturing technology. For example, regarding specific equipment development for manufacturing, nothing was revealed. Regarding scale-up, however, there were a number of views depending on the application. For electronics, it was generally concluded that the microwave-assisted CVD process would be used because of its cleanliness and the ability to control depositions. For large area sources, some would favor the hot filament CVD because of the ease with which it can be scaled up in size. For thick parts, some favored the DC plasma jet. A summary of product-dependent scale-up approaches is given in Table 3 .

For process controls, nothing unique was described. The controls that were mentioned included only those for flow, pressure, and power. For sensors, the situation was similar. Sensors mentioned were optical pyrometers for temperature, and standard gas pressure sensors. Asahi stated that they measured in situ film thickness but did not say how. NIRIM plans to explore the use of RHEED to assess film quality. As an indirect sensor application, the Semiconductor Energy Laboratory used an optical sensor to measure the hydrogen-alpha line emission in the microwave discharge in order to adjust, refine, or make a more uniform discharge.

Automation of DLC film deposition has been achieved by NEC. Disks are loaded from a multiple substrate holder into the reactor by machines. Matsushita has developed a continuous DLC film Coater. 


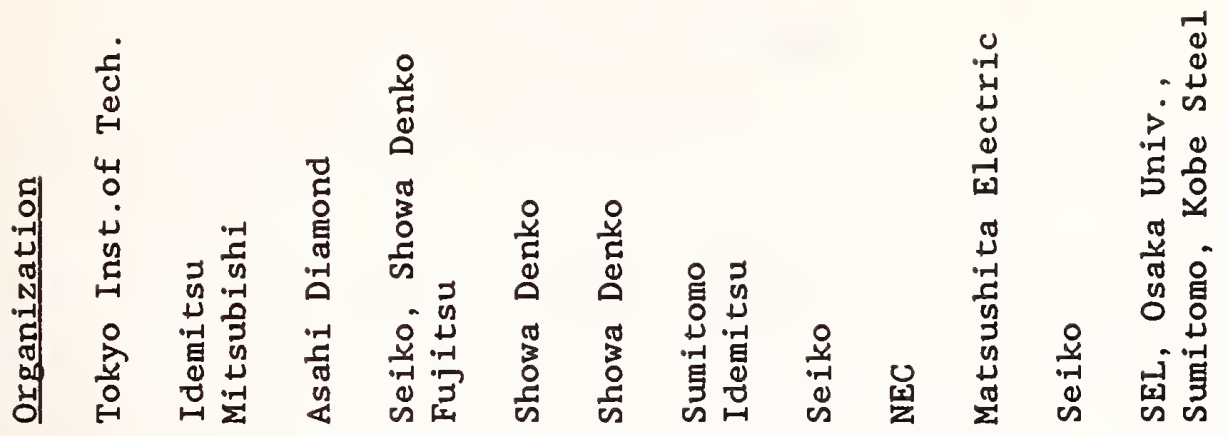

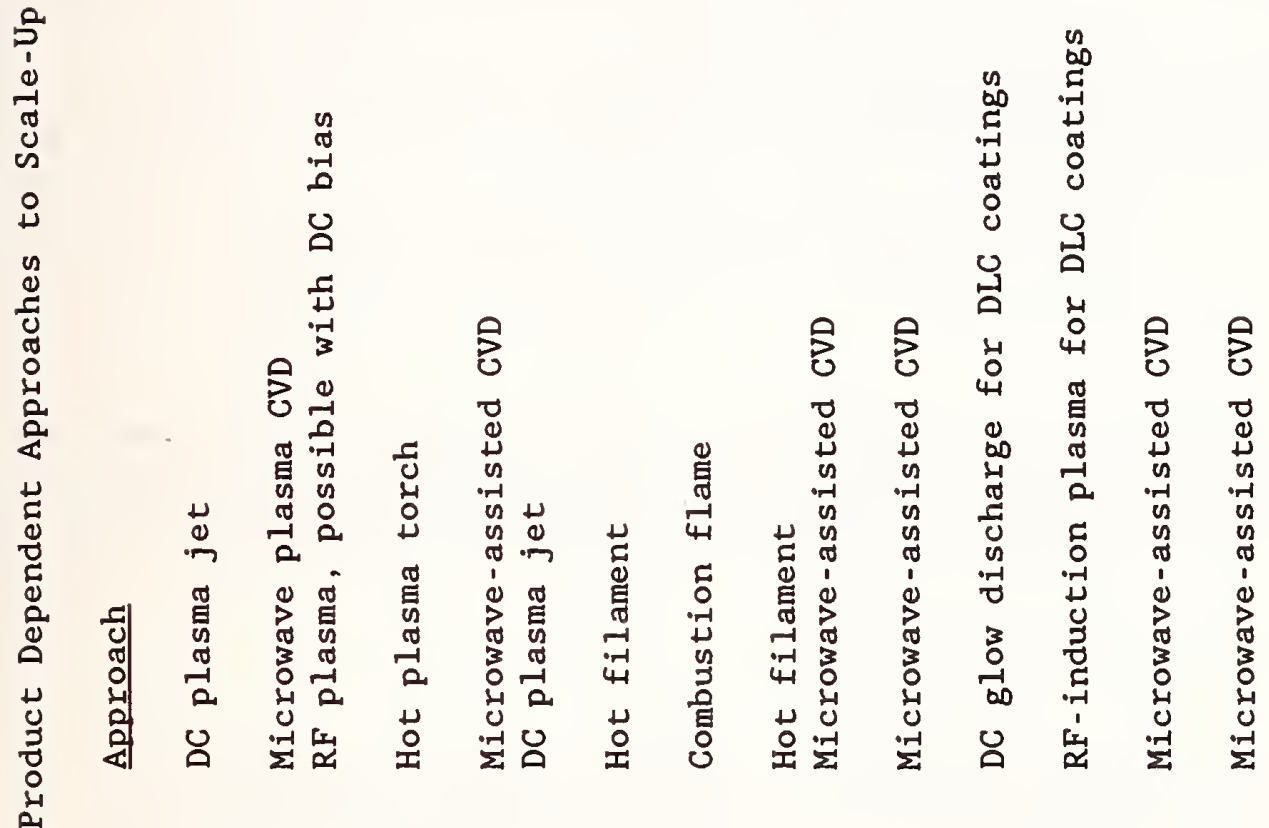

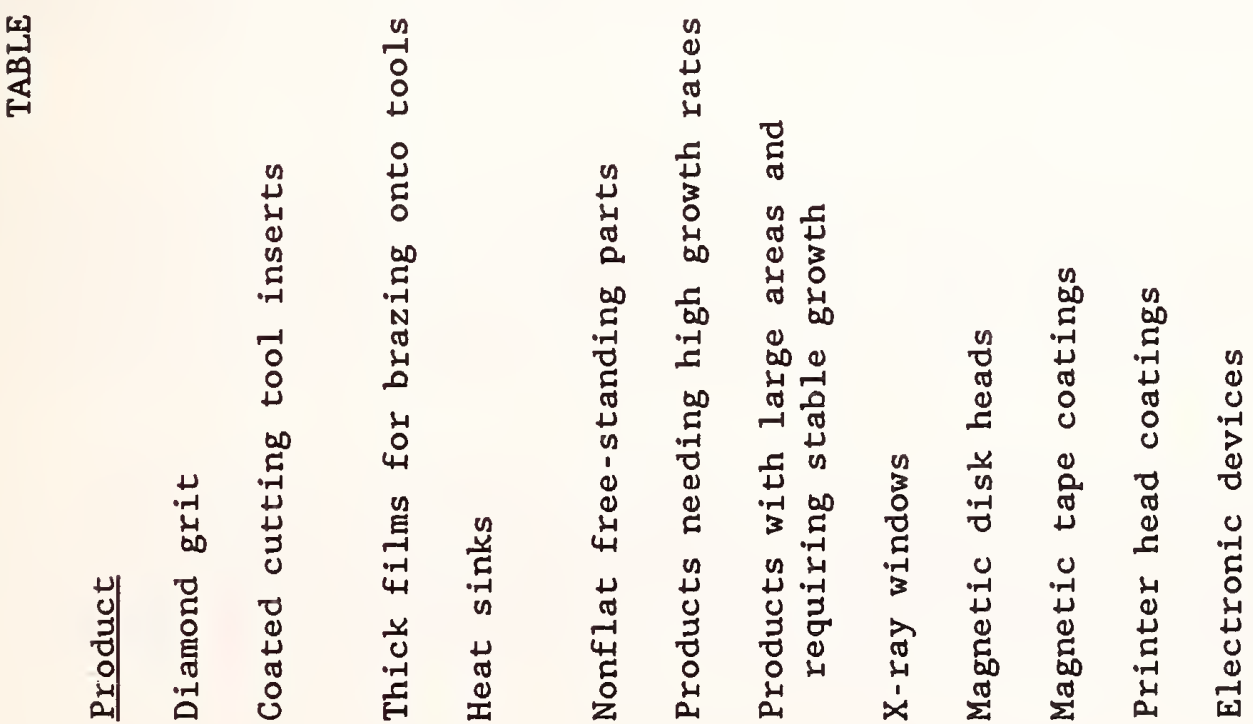




\section{COMMERCIALIZATION}

\section{PATENTS AND LICENSING}

It is well known that the Japanese patent system differs from the U.S. system. A Japanese inventor need only to submit a summary of an idea without reducing the idea to practice. The submission date is the date of the patent.

Every group we visited mentioned their patents on CVD diamond processing. The only relevant answer to a direct question on patents was given by people at Kobe Steel and at Showa Denko, who were very matter-of-fact about the answer. They said that if and when they needed to get patent protection they would seek cross-license agreements with other companies. All governmental, university and industrial organizations in Japan seek patent positions in Japan, and also in the United States and in Europe.

PRODUCTS NOW ON THE MARKET OR EXPECTED TO BE ON THE MARKET SOON

Heat sinks

Heat sinks are made of thick diamond films (thickness greater that $50 \mu \mathrm{m}$ ) on Mo, SiC or silicon substrates. This activity was discussed at Showa Denko K.K., Sumitomo Electric, and at Kobe Steel. A particular application is a heat conducting substrate for laser sources to be used for fiber-optic communications.

Free-standing Cones, Domes, and Speakers

Loud speaker diaphragms were the first CVD diamond products to reach the market. These free-standing diamond film parts also have application to optical domes. These products were discussed at Showa Denko and at Sumitomo. At Sumitomo, $2 \mu \mathrm{m}$ of diamond and $0.5 \mu \mathrm{m}$ of $\mathrm{SiC}$ are deposited onto an $\mathrm{Al}_{2} \mathrm{O}_{3}$ speaker cone. The upper limit of the frequency response of the speaker shifts from $50 \mathrm{KHz}$ to $100 \mathrm{KHz}$.

\section{$\mathrm{TAB}$ Bonding Tool}

Diamond deposited on metal or ceramic substrate is used as a TAB bonding tool. This tool is used to surface-mount electronic devices. The diamond acts as a heat transport medium that provides a non-wetting surface for solder. This application was discussed at Sumitomo Electric, Showa Denko, and Kobe Steel.

\section{Cutting Tools}

Diamond is being used as a coating on $\mathrm{SiC}$, WC, and $\mathrm{Si}_{3} \mathrm{~N}_{4}$ tool substrates. Companies with products on the market or expected to be on the market soon are Idemitsu, Mitsubishi Metal, Toshiba Tungaloy, Sumitomo, Showa Denko and Semiconductor Energy Laboratory. Sumitomo has a brazed CVD diamond end mill cutter on the market. 
Sales of Diamond Deposition Equipment

Semiconductor Energy Laboratory indicated that they would sell their magnetic field enhanced ECR system. These systems are constructed by Osaka Vacuum and Seiko Instruments. One of these systems was observed in operation at Osaka University.

Another magneto-microwave plasma deposition system was also observed at Osaka University. This reactor system was built by the Shimadzu Company. Such systems are available for purchase with a wide variety of optional accessories.

$\mathrm{X}$-ray Lithography Masks and $\mathrm{X}$-ray Windows

Seiko Instruments had an interest in $x$-ray lithographic masks although nothing was revealed about what they are doing in this area. There were no other 'discussions about $x$-ray lithography masks except in discussions between Sumitomo and one of the members of the team who obtained price quotes for coatings on silicon substrates for this purpose.

Seiko Instruments manufactures an $x$-ray window for instrumentation. 
The role of the Japanese government in promoting science, technological infrastructure, and the eventual commercialization of products is generally complex and multi-faceted. Many national government agencies play roles including the Ministry of International Trade and Industry (MITI), The Science and Technology Agency (STA) and the Ministry of Education, (MOMBUSHO) which funds research at universities. These national agencies are often complemented by local government activities which assist in funding and/or organization, working with individual companies, consortia of industries and counterpart research programs in universities and government laboratories. No single pattern characterizes all developments leading to commercialization and the system is best characterized by its flexibility and adaptability to circumstances. In the instance of thin film artificial diamond technology, the story is relatively straight forward and one may readily discern the role of government agencies and, in particular, the government laboratory, the National Institute for Research on Inorganic Materials (NIRIM).

The national institutes of the STA, and indeed much of Japanese science, operates on the "Research Group" system. It is instructive to quote NIRIM's printed brochure on the rationale and structure.

"Research Group System

Specialists of various fields form a research group in order to attain a project target. They investigate inorganic compounds which meet practical requirements, with particular attention to properties, composition, structures, and synthesis.

The group research period is usually set at five years. At the end of the period, it is determined whether the research project is to be terminated or to be extended for an additional specific period of time. When a research project is completed, the research group is dissolved and a new research group is organized to undertake a new project."

The concept of a finite number of targeted research objectives is central. There are about 120 research scientists divided into groups. Typically, each group has some eight researchers formed around topics such as "diamond," "tantalum carbide," "zinc oxide." The facilities are on a par with any equivalent laboratory in the United States.

Research on thin film synthesized diamond began at NIRIM in 1972 in parallel with work on high pressure synthesis. These programs have met with success after success, and so, although the specific research agenda has evolved, both

*Based on visits to Science and Technology Agency (Dr. T. Shirao, Director of Materials Science and Technology, Bureau of Research and Development); Japan Research and Development Corporation ( $\mathrm{Dr}$. M. Goto, Senior Vice President and former Director General of the National Institute for Research on Inorganic Materials); and the Ministry of International Trade and Industry ( $\mathrm{Dr} . \mathrm{M}$. Sonai, Director, Fine Ceramics office). A more complete discussion of the organization of national support for $R \& D$ in Japan may be found in Appendix $D$. 
thin film and high pressure synthesis continue as part of the current NIRIM research agenda. By 1977 the NIRIM group began to have significant results worthy of publication. From 1977 through 1984 their work led to process patents of three kinds, all based on the chemical vapor deposition of diamond film using $\mathrm{CH}_{4} / \mathrm{H}_{2}$ mixtures: a) hot filament; b) low-frequency; and c) highfrequency (microwave). These patents have become the base for a developing industry in structural applications of diamond. Improvements in the technology and development of new processes have continued at NIRIM, with application interest shifting toward the use of diamond as a semiconductor. Focus has now centered on understanding nucleation, controlling doping and on the growth of single crystal heteroepitaxial films. They believe that success in this area could lead to commercial possibilities rivaling those of the more highly touted high-temperature superconductors. More details about the technical program at NIRIM may be found in Appendix D.

The role of transfer of government developed technology to industry in Japan is shared by two agencies, the Agency of Industrial Science and Technology (AIST) of MITI which focusses on MITI-developed patents, and the Japan Research and Development Corporation (JRDC), an area of the STA which works with STA initiated programs, but also acts as manager of government-developed patents initiated by other agencies.

In 1984, the NIRIM patents on artificial diamond were transferred to JRDC which developed the business plan designed to stimulate commercialization. It sought industrial applications and from among these selected two companies for initial development programs. Exclusive, but limited, licenses were granted to Mitsubishi Metals for application of patents a) and b) to cutting tools and to Seiko Electronics for application of patent c) to heat sinks for semiconductor packaging. These licenses expired in 1990. In addition, recognizing that further development would be required before commercialization was possible, JRDC granted these companies zero-interest, forgivable loans for the first 3 years of development. If no profit is made from use of these patents, no return of funds to the government will be required.

[JRDC has several functions, but in FY 1989 nearly $¥ 6 \mathrm{~B}$ (approximately $\$ 40 \mathrm{M}$ ) was allocated for the development of new technology. In that same year, repayment of loans for development funds and revenues from licensing brought $¥ 5.1 B$ to JRDC for further dispersal. This is a highly successful program with a history extending back 28 years.]

Throughout this development period, NIRIM has acted as a technical resource for Mitsubishi and Seiko as well as for other companies which were stimulated by NIRIM's success (and in several cases frustrated by their failure to be chosen by JRDC) and initiated their own R\&D efforts on CVD diamond. The Visiting Research Officer program at NIRIM was effective in this regard. Scientists from industries, paid for by industry, spend time at NIRIM working with the government scientists and carrying back NIRIM technology to their companies. (This is similar to the Industrial Research Associates program which operates at the NIST in the United States.)

It is somewhat surprising to find that in this sequence of events leading to commercialization, no significant role was played by MITI, the Ministry of 
International Trade and Industry. In fact, MITI's role as usual, was arrived at by consultation with industry. It appears that the efforts by the JRDC followed so quickly by strong competitive pressures from many companies left no significant role to be played by MITI and that agency was advised by its industrial consultants to concentrate its efforts on other priorities. In fact, the only role played by MITI has been their minimal funding in assistance of The New Diamond Forum, a trade association with membership including about one hundred producers and potential users of artificial diamond (both CVD and high pressure). The MITI funding of about $¥ 5 \mathrm{M} / \mathrm{yr}$. (approximately $\$ 32 \mathrm{~K} / \mathrm{yr}$. ), used primarily to defray publication costs, will cease in 1992 and the association will be on its own.

In recent years, JRDC has extended further limited licenses to other companies including Shingitsu Chemical Industries (patent c) for surgical knives - they are already paying royalties] Yamaha [patents a), b), and c)] for high fidelity speaker cones, and Sumitomo Electric [patent c) for cutting tools]. At the same time, other companies have developed their own processes and are moving towards commercialization.

In these structural applications areas, intense competition is now setting in with each company producing or readying itself for production of specific marketable products. The government role was to carry out basic research and then, as appropriate, stimulate commercialization through licensing, technology transfer, and forgivable loans. This successful process is used over and over in Japan in other technologies as part of the Japanese success story. 


\author{
APPENDIX A \\ Planning and Implementation of the Assessment
}

The initiative for this assessment was taken by the office of International Affairs in conjunction with the Materials Science and Engineering Laboratory of NIST, in response to requests for such activities from various committees overseeing the United States-Japan Agreement on Cooperation in Research and Development in Science and Technology.

The decision to conduct this assessment was made in January, 1990. It became necessary to compose a calendar of actions required for implementing the assessment. The key phases of the assessment were: selecting the members of the delegation; composing the agenda for the assessment including sites to be visited in Japan; conducting the assessment by visiting Japan; and presenting the results of the assessment.

The visiting delegation was selected from government, universities, and industry. All members received letters of appointment from D. Allan Bromley, Director of the Office of Science and Technology Policy.

The government delegates were from NIST, which was leading the delegation, and from the Naval Research Laboratory, which has the largest in-house governmental program in CVD diamond research. The university delegates were all widely recognized pioneer researchers in the field.

In order to promote the greatest openness from our Japanese hosts, we chose delegation members from companies that would be users of CVD diamond products; we did not choose members from companies that were potential competitors in diamond production.

An agenda for the visit was set at a planning workshop held at NIST on March 27, 1990. In addition to attendance by the delegates, people from government and industry with an interest in diamond technology were also invited. At this workshop, a questionnaire that provided the basis for the questions asked during our site visits was composed. Finally, a preliminary outline of this report was prepared. Team members were assigned the responsibility for writing subsections of the report. For each of the two major sections of the report, a cordinator was chosen to assemble the material provided by the writers of the subsections.

By fortunate coincidence, Dr. Takayuki Shirao of the Science and Technology Agency in Japan had been visiting NIST during the early planning stages of our assessment. He offered to assist us in arranging our itinerary and this assistance proved to be invaluable in assuring the success of our visit. On the basis of frequent communications by FAX with Dr. Shirao, we devised the itinerary for the visit.

The sites to be visited in Japan were selected on the basis of recommendations from the delegation members. In order to visit all of the sites, the delegation was divided into several teams so that several site visits were conducted in parallel. Although every member of the team could not visit every site, we were able to visit many more sites. One team member was assigned to prepare a site report for each place visited. The site reports, 
which appear in Appendix B, provided the information needed for preparing the main part of the report.

The visit took place between May 28 and June 5, 1990. At the conclusion of the visit, a meeting was held at the American Consulate in Osaka where we wrote our preliminary conclusions and recommendations and where we refined the outline of our report.

The prelimary results of our assessment were presented to government and industry representatives at a seminar held September 13, 1990 in Crystal City, Virginia. This Seminar was organized by the National Technical Information Service. In this report we present the results of our assessment. 


\author{
APPENDIX B \\ Brief Assessment of the New Diamond Technology in Europe and in \\ Other Countries
}

Significant research efforts in CVD diamond are underway in countries other than the United States and Japan. The recent initiation of an annual Diamond Films conference in Europe is a reflection of the great increase in interest in the new diamond technologies in other parts of the world. A very brief review of these efforts is given in this appendix.

Some of the most significant findings in CVD diamond research have been achieved in the Soviet Union, most notably by members of the research team at the Physical Chemistry Institute in Moscow. This research group was initially under the direction of Dr. Boris Deryagin. Contributors to this effort include, among others, Dr. Boris Spitsyn, Dr. A. Fedoseev and Dr. Valentin Varnin. Both crystalline diamond and diamondlike materials are being investigated. Apparently, the crystalline diamond work is primarily associated with Dr. Spitsyn and the diamondlike research with Dr. Fedoseev and his co-workers. Little is known about the scope and scale of this research effort, although the recent surge of interest in the United States and Japan have led to greater efforts in the Soviet Union as well. Details of reactor types and methods of deposition have not yet been revealed in the open technical literature.

Another significant diamond effort in the Soviet Union is centered at the Institute for Hard Materials in Kiev, under the direction of Dr. N.V. Novikov. The group in Kiev has a long history in high pressure diamond synthesis and is now expanding its efforts into low pressure CVD as well. Again, the scope and scale of this effort are not available.

In western Europe, a major center of CVD diamond research appears to be that of Dr. Benno Lux at the Technical University of Vienna. Dr. Lux has been actively pursuing low pressure diamond growth since the early 1980s. His efforts are concentrated heavily in the production of diamond coated tool inserts. Very fundamental and important studies of nucleation and growth processes during diamond CVD have also been undertaken by this group. This is a major and significant research program.

Another major center of research in Europe is at the Fraunhofer Institute in Freiburg, under the direction of $\mathrm{Dr}$. Peter Koidl. This group has been working on diamond-like films since the early 1980 s and has more recently switched its attention to crystalline diamond as well. Other important centers of diamond research in Germany include: the Institute for Plasma Physics at Julich, the University of Frankfurt, the Institute for Physical Chemistry at Heidelberg, the Institute for Nuclear Physics at Karlsruhe, Phillips Laboratories, and the University of Hamburg among others.

In France, significant research papers have appeared from several institutions including the Paul Pascal Research Center, The University of Nantes, and at Grenoble. Theoretical studies of diamond-like hydrocarbons have been reported by J.L. Bredas, University of Notre Dame, Namur. 
There has been a very long and distinguished tradition of diamond research in Great Britain. An annual "Diamond Conference" supported by DeBeers is a focal point of these research efforts. There has been a concentration of effort on the detailed study of defects in natural diamonds and the friction and wear characteristics of diamond surfaces. Leading figures in these efforts include, but are not limited to: Sir Charles Frank and Sir Andrew Lang at Bristol University; Dr. Moreton Moore at the Royal Holloway and Bedford New College; Judith Milledge and Monica Mendelssohn of the University College, London; Dr. Dennis Tabor of the University of Cambridge; Dr. R. Berman, Dr. Eileen Wilks and Dr. John Wilks of Oxford University; Dr. Robert Jones of the University of Exeter. In the last several years, interest in low pressure diamond growth has been evident among British workers. However, it appears that much of this research is supported by DeBeers and the results and methods are inaccessible at the present time.

One of the major research centers in Britain has been under the direction of Dr. A.H. Lettington at the Royal Signals and Radar Establishment, Malvern. His work has primarily concentrated on diamond-like films as protective coatings for infrared optics. Important theoretical studies of diamond-1ike materials have been conducted by $\mathrm{Dr}$. John Robertson of the Central Electricity Research Laboratories and E.P. O'Reilly of Surrey University. In addition, a consortium of several university groups has been assembled in the United Kingdom to work on carbon films.

A very significant research and development capability exists at the Drukker Diamond Corporation in the Netherlands. Dr. Michael Seal has been the leading research figure in this company for many years. He has, however, very recently retired from his position as Director of Research. Drukker has maintained close affiliations with universities in the Netherlands, e.g., University of Nijmegen, and researchers from this group have recently published papers on diamond CVD. The Drukker company has perhaps the most broadly based experience with the high tech uses of diamond of any company in the world. Their U.S. representatives are the Dubbledee Harris Diamond Company in New Jersey.

The ASEA Corporation in Sweden has had a long standing history of high pressure diamond synthesis. In fact, its synthesis of diamond at high pressures predated that of General Electric. Some CVD diamond work is being done currently at Uppsala University.

Both high pressure and low pressure synthesis of diamond has been studied for some time in Poland at the Warsaw Technical University, the Institute of Electronic Materials Technology in Warsaw and at the Lodz Technical

University. Significant studies of hard carbon films was carried out for many years by $\mathrm{Dr}$. Christian Weissmantel in the German Democratic Republic. How much the recent death of Dr. Weissmantel will influence this effort is not known. J.P. Hirvonen, A. Antilla, and J. Koskinen at the University of Helsinki have reported extensive studies on diamondlike carbons.

Theoretical studies of the thermochemistry of CVD diamond and DLC film growth is carried out by Dr. P. Deak, Dr. I. Biczo and others under the direction of Professor J. Giber, head of the Department of Atomic Physics at the Technical University of Budapest Hungary. 
The Republic of South Africa has an obvious interest in diamond, both natural and synthetic. The DeBeers company has entered the CVD diamond field much later than the leading diamond producers in Japan and the United States. Nevertheless, their sophisticated and wide ranging capabilities in diamond research will certainly make them a significant factor in low pressure diamond growth in the future. Research is now being conducted at the University of the Witwatersrand, under the direction of Professor Friedel Sellschop and by Dr. J.F. Prins. Dr. Robert Caveney, Director of Research at DeBeers, has done work in low pressure diamond growth in the 1970s.

In Australia there are important efforts in diamondlike carbon underway at the University of Sidney under the direction of David McKenzie and at CSIRO under P.J. Martin. 
APPENDIX C
Site visit Reports

AOYAMA GAKUIN UNIVERSITY

Date of visit: May 30, 1990

Visiting Delegation: J. J. Cuomo, J. T. Glass, L. H. Schwartz, and C. M. Stickley

The visit was hosted by Professor Tadao Inuzuka. Also present were three researchers from Toshiba Corporation, Dr. Atsuhito Sawabe, Dr. Hisakazu Izuka, and Dr. Shinji Arai.

Professor Inuzuka indicated that he started his work on CVD diamond in 1981 with Dr. Atsuhito Sawabe as a student. They used methane because they believed its tetrahedral coordination was important. First they produced amorphous carbon and then diamond. Together they developed the electron assisted CVD method (EACVD) which consists of a hot filament CVD system with a voltage applied between the filament and the substrate. They found the film surface morphology was smoother when a voltage was applied than when no voltage was applied. The current was several $\mathrm{mA}$ over a $15 \mathrm{~mm}^{2}$ area.

Substrates used were Si, SiC, Mo, and garnet. The deposition rate is several $\mu \mathrm{m} / \mathrm{hr}$. Nuclei are used to initiate growth. At $0.5 \%$ methane the diamond Raman line is observed with little background signal; however, at $2 \%$ methane the diamond Raman line is observed in the presence of a large background signal. Nucleation of diamond has also been observed without surface scratching.

Deposition conditions for the EACVD process were: applied voltage, 600-800 V; electrical current, 400-600 ma; current density, 4-5 a/cm ; substrate temperature, 800 to $1000{ }^{\circ} \mathrm{C} ; \mathrm{CH}_{4} / \mathrm{H}_{2}, 0.5 \%, 1 \%, 2 \%, 3 \%, 5 \%$; total gas pressure, 180 Torr; gas flow rate, $300 \mathrm{sccm}$.

Depositions employing evaporation of carbon and atomic carbon beams were described. Graphite was deposited. It was stated that the monomer $C_{1}$, the dimmer $\mathrm{C}_{2}$ and the trimmer $\mathrm{C}_{3}$ concentrations change according to the evaporation conditions of the melt. By choosing the evaporation conditions so that $C_{1}$ predominated, an atomic beam is produced and when hydrogen is introduced into the chamber at a pressure of $10^{-4}$ Torr, particles of diamond were found. SiC was present during this process.

The adhesion of diamond films to silicon substrates was measured. In a pull test, fracture took place at the diamond/silicon interface. An adhesion force per unit area of $27 \mathrm{~kg} / \mathrm{mm}^{2}$ was measured on one film. We were shown unpublished data that displayed an effect of substrate thickness on adhesion.

Epitaxial growth of diamond on $\mathrm{CaF}_{2}$ and $\mathrm{Al}_{2} \mathrm{O}_{3}$ in a hydrogen plasma were tried without success. Epitaxial diamond was successfully grown on single crystal $c B N$. Small cBN substrates were prepared by a high pressure process similar to the process for HPHT synthesis of diamond. The diamond begins to grow as particles, similar to what is observed in conventional CVD of polycrystalline diamond. However, all of the crystallites are similarly oriented so when the particles merge into a film at a thickness of between 0.2 and $1 \mu \mathrm{m}$, the 
resultant film shows an epitaxial relationship with the substrate. Epitaxial growth occured on the $\{111\},\{100\}$ and $(221)$ faces of cBN.

ASAHI DIAMOND INDUSTRIAL COMPANY, LTD.

Date of visit: May 29, 1990

Visiting delegation: A. Feldman, R. A. Rudder, M. A. Tamor and W. A. Yarbrough.

The visit to Asahi Diamond took place at the company headquarters in Tokyo. Discussion were held with Dr. Kazuo 0-oka, Director and General Manager of the Research and Development Division, Y. Yamauchi, Director and General Manager of the Foreign Trade Department, and Kinichi Goya, Director and General Manager of Marketing and Engineering. Because of the proprietary nature of the work at Asahi Diamond, we were not able to see any facilities or talk directly to research staff. However, we were able to learn about the philosophy of the company and its view regarding diamond technology.

Asahi diamond was established in 1937 and is a manufacturer of diamond and superabrasive tools and related precision equipment. However, they have not been a producer of diamond. As a gage of the size of the company, net sales in 1989 were 34.8 billion yen or $\$ 232$ million (at 150 yen per $\$$ ). They believe that marketing controls the stream of technology flow.

Because of its strong interest in diamond tools, Asahi diamond has been working on CVD diamond for over 5 years. It has started to introduce prototype products of CVD diamond. We were told that all of the work is internally funded with no assistance from the Japanese government. There has been collaboration with Professor Inuzuka of Aoyama Gakuin University who developed the electron assisted CVD process for producing diamond.

The company holds 20 patents related to diamond with two patents in the United States, electron assisted CVD, developed by Professor Inuzuka, and a method of brazing diamond for cutting tools.

Asahi diamond has had a long term commercial relationship with General Electric (GE). GE has been supplying diamond to Asahi Diamond for over 30 years. This long relationship has resulted in a cooperative agreement between $G E$ and Asahi to form a jointly controlled company called Gena systems. The company is expected to come out with a major product within several months, and this accounts for the reluctance of Asahi Diamond to reveal any information regarding the methods they are using to produce diamond and the nature of the products they are working on. Initially, production of the product will be done both at Asahi Diamond in Japan and at GE in the United States; however, production with be done eventually at Gena systems in the United States.

Listed below are the views of Asahi Diamond on several topics related to CVD diamond:

Deposition: In their estimation, microwave deposition offers the best control of deposition and has the greatest possibility for process control. They are investigating the use of hot plasma torch deposition for making thick films 
which are then attached to the substrate by brazing. They believe CVD is not a practical method for producing diamond powders at present. However, in several years the method may prove to be competitive with the high-pressurehigh-temperature diamond. They are not interested in producing diamond powders by CVD. They are studying low temperature deposition processes and coatings for sliding surfaces. The company has interest in diamond-like carbon, and this activity is part of the agreement with GE.

Characterization: They have a large effort in characterization. These include measurements of nucleation density (they have achieved $10^{11} / \mathrm{cm}^{2}$ ), hardness (8000-10000 Vickers), thermal conductivity (600-800w/m), in-situ thickness monitoring, adhesion, analysis of hydrogen content, and Raman spectroscopy.

Semiconducting diamond: Semiconductor use of diamond is a long way off. Doping is presently being done, however n-type doping is a problem. Another problem is heteroepitaxial growth.

Diamond quality: A major emphasis of their work on diamond is diamond quality rather than growth rate and size of deposition area. This implies that growth rate and size of deposition area are not impediments for them at this time.

Nature of Research at Asahi Diamond: Asahi diamond has 10 people working on CVD diamond. They have excellent scientists. The work at Asahi Diamond is principally in applications. It takes 6-7 years to convert basic research to an application. They are working on cBN but could not discuss this work with us.

Relative position of United States and Japan in diamond technology: Japan is ahead in applications while the United States and Japan are about equal in basic research. Japan is believed to spend about 4 times the amount spent in the United States. However, this number is highly speculative.

The Future: Asahi Diamond considers itself a world leader in CVD diamond. Its short term interest is in brazed tools of CVD diamond. In the long term, it is interested in all aspects of diamond technology. The company believes in a good future for CVD diamond. 
FUJITSU LABORATORIES, LTD.

Date of visit: May 29, 1990

Visiting delegation: J. C. Angus, S. Holly, J. W. Mitchell, and K. A. Snail

The visit was hosted by Takahiko Misugi, Managing Director of Fujitsu Laboratories and Dr. Motonobu Kawarada, Senior Researcher in the Electronics Packaging Laboratory, Fujitsu Laboratories.

Fujitsu is interested in using CVD diamond as a heat tranport material for laser diodes and VLSI supercomputer chips. The use of diamond as a tool coating is also of interest. They are also interested in active diamond electronics for the future.

Using a DC Plasma Jet, Fujitsu was the first to demonstrate very high diamond growth rates (greater than $200 \mu \mathrm{m} / \mathrm{hr}$ ). They have synthesized large plates $(1 \times 1 \mathrm{~cm} \times 2 \mathrm{~mm}$ thick) of CVD diamond and have built prototype laser diode assembles on these plates. The plates were fabricated by scanning the substrate below the plasma jet during the deposition. We were shown one DC plasma jet in operation in a clean room and were told that two others were located in a separate lab.

Currently they are using NMR to characterize the composition of their deposits. We didn't see how they were measuring thermal conductivity, and they seemed surprised to hear about the thermal conductivity results reported by the General Motors research laboratory.

They have also duplicated the polishing apparatus developed by Professor Yoshikawa at TIT and have begun experiments in polishing diamond, although most of their polishing has been done with a skeif, a diamond cutters polishing wheel.

A major accomplishment during the last year was the development of methods for improving the adhesion of CVD diamond to substrates, presumably for tools.

IDEMITSU PETROCHEMICAL COMPANY, LTD.

Date of visit: May 30, 1990

Visiting delegation: J. C. Angus, S. Holly, J. W. Mitche11, and K. A. Snail

The visit was hosted by Mr. K. Ito, Manager of Planning of High Tech Materials, Planning and Development Department and Dr. Nariyuki Hayashi, Diamond Project Leader, Planning and Development Department. The visit took place at the corporate headquarters so that no laboratory facilities were seen.

Now one of the world's leading oil companies, Idemitsu Petrochemical began business in 1911 as a petroleum retailer. The company expanded substantially in 1957 by acquisition of its first oil refinery in Tokuyama. Since then, Idemitsu has continued to grow and has become one of Japan's leading industrial groups. Last year gross sales reached almost 3 trillion 
yen ( $\$ 20$ billion). The Idemitsu group of companies now include many domestic (in Japan) and overseas companies.

The Idemitsu Research Group is a group of research establishments with strong emphasis on the fields of energy, biotechnology, electronics and new materials. Research and development work on diamond and related materials are conducted at the New Materials Department at its Research Laboratories in Chiba. Seven researchers are currently employed in CVD diamond film research and development work. These researchers are supported by 9 technicians and up to 5 people at a university. There are approximately 1000 people at the Research Laboratories in Chiba.

Idemitsu was one of the first companies in Japan to start research in CVD diamond film technology (1982). Initial work at Idemitsu followed the lead provided by NIRIM in Tsukuba. The microwave plasma deposition technique including details of hardware design was borrowed from NIRIM and is still in use today.

Idemitsu considers the use of carbon monoxide instead of methane as a their major contribution to CVD diamond film technology. Subsequently, they have secured a strong patent position on the use of CO gas. Carbon monoxide has the advantage of being usable at much higher percentages (up to $50 \%$ and higher) in the feed gas without interfering with the deposited diamond film quality. With increased $C O$ percentage the film growth rate increases; thus, diamond film growth rates in a microwave reactor can be up to 10 times higher than growth rates based on methane. Growth rates up to $4 \mu / \mathrm{hr}$ have been achieved.

Idemitsu has chosen to deposit diamond on silicon nitride substrates because of the good thermal expansion match over a large temperature range (from room temperature to $1000^{\circ} \mathrm{C}$ ). That may explain, why they have not spent much effort on developing techniques to deposit diamond film at reduced substrate temperatures.

Areas of current research interests include:

1. Nucleation and growth studies, gas phase chemistry (calculations by Professor Nishimoto and his associates at Osaka City University) and doping studies for potential semiconductor applications. The delegation was shown the results of electrical conductivity vs. temperature ( 300 to $650 \mathrm{~K}$ ) measurements on boron doped diamond films at different dopant levels.

2. Development of a deposition reactor for coating large areas. The target is deposition of CVD diamond films on substrates up to $25 \mathrm{~cm}$ diameter by 1992 . The two most challenging goals to be achieved over these large areas are the deposition of films with uniform characteristics and maintainance of high growth rates recently demonstrated on $1.25 \mathrm{~cm}$ square substrates. It is hoped that sophisticated electronic monitoring techniques will help overcome these difficulties.

3. Development of technologies for producing diamond coated tool bits. This includes studies of cutting, bonding, polishing, and interface layer development. Idemitsu understands the importance of $c B N$ to the development of cutting tools for machining ferrous materials, which accounts for an estimated 
$80 \%$ of all machining done, and recognizes its importance to their future business. They did not discuss their work on cBN; however, progress is being made on this material.

Idemitsu has no HPHT diamond synthesis capability. They showed samples of diamond films deposited on silicon nitride. The substrates were polished $12 \mathrm{~mm}$ $\times 12 \mathrm{~mm} \times 2 \mathrm{~mm}$ silicon nitride coated with uniform diamond films approximately $10 \mu \mathrm{m}$ thick.

KOBE STEEL, LTD.

Date of visit: June 5, 1990

Visiting delegation: Visited by all members of the U.S. Delegation

Researchers in Kobe Steel's Electronics Research Laboratory, Materials Research Center, and Mechanical Engineering Laboratory are currently working on diamond produced from the vapor phase. Major goals are electronic devices and tool coatings. The total effort consists of approximately five researchers, but is expected to expand by one or two in the near future. Presently, $80 \%$ of their effort is on understanding and relatively fundamental research with $20 \%$ on applications, but this latter percentage is increasing. Their electronics oriented research has involved a surface morphology and microstructural investigation, oxygen addition to improve film quality, large area ( 5 to $10 \mathrm{~cm}$ ) deposition, p-type $B$ doping and $n$-type Si doping (although not clear n-type), electrical properties and contacts measurements, reactive ion etching, selected area deposition, and fabrication of simple device structures. Although there was some interest expressed in optoelectronic devices, current emphasis appears to be on the fabrication of Hall devices, thermistors, and MESFETs. The electrical characteristics of these devices have not yet been measured. The substrate material of interest is $\mathrm{Si}$ and no homoepitaxial research is underway. Thus, all of the aforementioned devices are made in polycrystalline diamond films.

The deposition techniques of interest for the electronics area are EACVD and microwave plasma CVD (both NIRIM type and large area type reactors). Growth rates are up to $3 \mu \mathrm{m} / \mathrm{hr}$, but need to be improved for applications such as heat sinks. They are concentrating on microwave plasma CVD due to its scalability and cleanliness. The NIRIM type reactor developed at Kobe Steel has three systems connected together to allow p-type, n-type, and undoped material to be grown without cross contamination, as well as multilayer depositions without exposure to atmosphere. The large area deposition systems involve a high power microwave source ( $5 \mathrm{KW}$ ) split into two waveguides connected to a single chamber. This system is expected to give higher growth rates than the NIRIM type system they are now using.

Etching has been accomplished in a specially designed D.C. plasma discharge in oxygen and helium gas mixture, utilizing "focused parallel plate" electrodes. Etch rates between 1 and $2 \mu \mathrm{m} / \mathrm{hr}$ have been achieved.

When depositing doped layers on undoped layers of diamond, they have avoided secondary nucleation by introducing $\mathrm{H}_{2}$ into the chamber prior the deposition and then slowly increasing the methane content in the feed gas. 
In their study of boron doping, they have examined numerous doping levels by measuring Hall mobility and current-voltage characteristics. They expressed no interest in lowering deposition temperatures, but are trying to obtain smoother surfaces for the fabrication of devices.

A prototype MESFET device is expected within one year, however, this device is not expected to perform well. As a first generation device, it will provide a baseline for further developments.

Although there is some work on thick diamond films for heat sink applications, Kobe Steel researchers are discouraged by the low probability of economical commercialization and are much more interested in thin film applications such as active electronic devices.

Kobe Steel's effort in tool coatings and other non-electronic applications involve microwave plasma CVD and combustion growth. They are interested in enlarging the deposition area and want to understand gas flow and reaction chemistry in their combustion growth research. There did not appear to be any specific applications in mind for this study. Tool bits utilized in drilling printed circuit boards (WC-Co inserts) were coated with diamond via microwave plasma CVD. Films were prepared by depositing an intermediate buffer layer between the insert and the diamond. Surface morphology and interfacial structures have been evaluated but practical testing of the bits has not yet been accomplished. It is believed that the adhesive bond is inadequate at the present time and they do not know when they will supply such tools to potential customers.

Kobe Steel is also interested in cBN coatings and has deposited seemingly high quality polycrystalline $\mathrm{cBN}$ on $\mathrm{Si}$ by means of a reactive ion plating technique. However, it has not been possible to deposit the same films on nonsilicon substrates.

Kobe Steel's diamond effort began in 1985 via interaction with the National Institute for Research in Inorganic Materials (i.e., a Kobe Steel researcher spent several months at NIRIM). Since that time they have been studying diamond for electronics whereas tool coatings have only been under investigation for approximately 1 year. They have applied for several patents but have not licensed the basic technology from NIRIM or others yet. However, they feel that when a clear product path and the required processing techniques are determined, it will not be a problem to cross license the necessary technology. They have not completed a thorough market study for diamond because they believe that markets will develop as the material and processing techniques improve.

Amost all of the funding for Kobe Steel's diamond research is internal, however, a small fraction is derived from a MITI/NEDO joint international research grant. This project is a collaboration between Kobe Steel, Harwell Laboratories (England) and North Carolina State University. It involves research and development of electronic devices in polycrystalline diamond and results will be published in the open literature. The level of effort is approximately one researcher at each institution.

Kobe Steel has a major company wide goal of globalization. As such, they have recently established research laboratories on the East and West coasts of the 
United States and in England. Combined with their laboratories in Japan, they refer to this expansion project as "24 hour research" because there will be Kobe Steel laboratories conducting $R \& D$ "around the clock" somewhere in the world. A laboratory recently established in the Research Triangle Park (the Electronic Materials (enter) will concentrate on diamond thin films for electronics. This laboratory will serve to increase Kobe Steel's collaboration with U.S. companies and universities. An ongoing relationship with North Carolina State University is one reason for the choice of location of this laboratory. They have also established ties with some U.S. companies by supplying films deposited in their Japanese laboratories and are seeking more opportunities of this kind.

Finally, diamond is viewed as part of a broader context at Kobe Steel. The company is currently diversifying from its traditional metal products and heavy machinery into "high tech" materials. One area that has been targeted is electronic materials; thus, a background base in electronics needs to be developed. Diamond is serving as one vehicle for building up this expertise in electronics. From this standpoint, the sizes of current markets for diamond are not critical at the present time.

\section{MATSUSHITA ELECTRIC CORPORATION}

Date of visit: June 5, 1990

Visiting delegation: J. C. Angus, J. J. Cuomo, M. A. Tamor

Matsushita has a long history of research in the area of diamondlike carbon (DLC), and recently started work on CVD diamond for electronic applications. This work is in part stated interest in deposition of high temperature materials by "energetic atom" processes. The company is interested in diamond, DLC, SiC, $B_{4} C$, and $c B N$. Their diamond and DLC group is comprised of eight scientists, five at the Central Research Laboratory, and three at the Device Laboratory. Discussions were quite open and collegial.

DLC work at Matsushita began in 1976 with deposition of hard films in an RF diode sputtering reactor. These films were found to be hydrogenated by water vapor, and no film was formed when the experiments were repeated in an ultrahigh vacuum system. In 1985, this reactor was modified to include a proton beam for direct hydrogenation. Hard films with scattered microcrystallites believed to be diamond were formed. This work is similar to work reported by Weissmantel and others.

A very impressive accomplishment is the development of a high rate reactor for deposition of hydrogenated DLC onto a $15 \mathrm{~cm}$ wide magnetic tape in a reel-toreel web-coating apparatus. The reactor uses RF induction to excite a plasma of $\mathrm{CH}_{4}$ and $\mathrm{Ar}$ in a $50 / 50$ ratio ( $100 \mathrm{~m}$ Torr pressure) and includes an anode to provide a bias voltage of 700 to $2000 \mathrm{~V}$ with respect to the substrate. DLC with a density of $1.8 \mathrm{~g} / \mathrm{cm}^{3}$, hardness of $2800 \mathrm{~kg} / \mathrm{mm}^{2}$, and less than $5 \%$ hydrogen content (by an unnormalized SIMS analysis) is deposited at deposition rate of $0.3 \mu \mathrm{m} / \mathrm{min}$. For a desired film thickness of $10 \mathrm{~nm}$, the tape speed is quite high. The DLC coating is protective against both wear and oxidation of an metal thin film magnetic layer and provides dramatic reductions in tape and tape-head wear. The economics of the process are under evaluation. 
Diamond work at Matsushita Electric is aimed entirely at development of single crystal films and contact metallizations for electronics. Both hot filament and biased microwave plasma reactors are in use. In diamond CVD, the effort has been to develop new nucleation techniques to promote heteroepitaxial growth on silicon. One novel experiment has been to use low energy ion implantation followed by annealing to produce a very thin SiC layer on a Si [111] surface. Diamond was then grown on this surface without the usual scratch pretreatment. Along with a few scattered diamond crystallites, a smooth layer with scattered triangular pits appeared. The company expressed confidence that diamond film is epitaxial, but it must be determined if the triangular indentations are simply etch pits in the carbide layer. Whatever the final result, this type of experiment demonstrates a willingness to try new ideas.

Researchers at Matsushita felt that although Japan leads in tool applications of CVD diamond, the United States enjoys a significant lead in basic research and in some electronic applications. They were keen to exchange ideas, and even entertained the possibility of collaboration in the area of heteroepitaxy.

\section{MITSUBISHI METAL CORPORATION}

Date of visit: May 30, 1990

Visiting delegation: A. Feldman, R. A. Rudder, M. A. Tamor, and W. A. Yarbrough

The team met with personnel from the Mitsubishi Metal Corportion to discuss diamond technology. Mitsubishi Metal manufactures cemented carbide tools and other products for the machine tool industry. Mitsubishi Metal Corporation will officially merge with the Mitsubishi Mining and Cement Corporation in December 1990. Mitsubishi Electric Company remains an independent company and there is no joint research or other collaboration between Mitsubishi Electric and Mitsubishi Metal. Mitsubishi Mining and Cement currently does not have a CVD diamond program, but it can be expected to do such product development as might be decided upon using resources available to it through its merger with Mitsubishi Metals.

Mitsubishi Metal began work on hard carbon coatings approximately 12 years ago and, with the successful synthesis of diamond at NIRIM, shifted to the study of diamond in preference to DLC. Mitsubishi Metal has work in CVD diamond technology not only because of its potential impact on many of its existing products and business, but also because of activity and interest in electronic materials. Mitsubishi is also interested in the vapor phase synthesis of $c B N$, but no activity was discussed and this field was perceived as not nearly as well developed at the company as CVD diamond.

Diamond deposition equipment was not shown to the visiting delegation because of its proprietary nature. Extensive characterization and clean room facilities are available and considerable characterization data on CVD diamond produced by the company was shared with us.

The synthetic methods used to produce CVD diamond include both plasma and hot filament deposition; however, Mitsubishi Metal held exclusive licenses from 
JRDC to develop hot filament and plasma deposited CVD diamond for cutting tool applications. These expired in the summer of 1990 and will not be renewed. The company at present manufactures approximately 5,000 cutting tool inserts per month for domestic consumption and cooperating in a test marketing program with selected Japanese customers (presumably automobile manufacturers). The deposition method of choice is believed to be a RF plasma technique, possibly with a DC bias. The R\&D team at the company consists of 8 to 10 people, five of whom are research scientists, and it appears that with the establishment of pilot scale production, additional personnel are likely to be involved with production, process engineering, and quality assurance functions.

The tools are prepared by the direct coating of diamond onto specially prepared cemented carbide inserts, and the company reports that adhesion difficulties have been sufficiently resolved to permit the use of diamond coated tools for the face milling of high silicon aluminum alloy engine heads. The solution to the adhesion problem includes the use of less cobalt and improved surface treatments; much of this work has been discussed and reported in both the United States and Japan. Delegation members were given an English language copy of Mr. Kikuchi's paper in the publication New Diamond 1990, the most recent of the annual English language publications of the Japan New Diamond Forum.

Work at Mitsubishi Metal is internally funded, with evidence of major management commitment to the development of the technology and its application to numerous existing and potential products. Government involvement is significantly less now than in the inceptual stages; however, close communications and some collaboration with Universities and Government laboratories (e.g., Prof. Yoshida of Tokyo University and NIRIM) continues.

The perception of Mitsubishi Metal management is that although researchers in the U. S. and Japan are approximately even with each other in the scientific work, technological development, particularly the preparation of prototype products and processes, is more advanced in Japan than in the United States. The leader in Japan is believed to be Sumitomo Electric Industries and in the United States, General Electric. The question was raised as to when Mitsubishi Metal would be willing to supply U.S. auto manufacturers with test samples for testing and qualification. No direct response was received but an interest in the North American market was apparent. The delegation's impression was that a wider field test and qualification program would come after a substantially more cost effective production technology had been developed.

NATIONAL INSTITUTE FOR RESEARCH IN INORGANIC MATERIALS

Date of visit: May 30,1990

Visited by all members of the U.S. Delegation

Background.

The major developments that catalyzed the world wide pursuit of a practical low pressure diamond technology were made at NIRIM. These were the invention of hot filament and the microwave plasma reactors for CVD of diamond. 
The full U.S. delegation visited the National Institute for Research in Inorganic Materials (NIRIM) on May 31, 1990. After arriving at the nearby train station, we were met by Dr. Kamo who escorted us to the NIRIM site at Tsukuba. NIRIM, one of six government institutes, was established in 1966 and funded by the Science and Technology Agency (STA). NIRIM's annual budget is $\$ 25 \mathrm{M}$ dollars with $\$ 10 \mathrm{M}$ available as disposable funds for purchase of plant equipment, supplies, expenses, etc. The Institute consists of 170 people divided into 15 groups, each specializing in the research and development of a single material. Investigations of the most fundamental kind are the primary objectives of the Institute's work.

In the case of diamond, two primary activities are ongoing, Technology For Synthesis of High Pressure Diamond Materials and High Temperature Plasma Jet Techniques.

Diamond Growth At High Pressure And High Temperature.

Currently, NIRIM has the most advanced high pressure facilities in Japan for diamond growth. We were shown a 1,500 and a 30,000 ton press, the latter capable of attaining 80,000 bars and $2500{ }^{\circ} \mathrm{C}$. Since the initiation of this program in 1974, considerable progress has occurred in growing large single crystal diamonds and in determining and controlling the incorporation of impurities. New catalysts have been discovered for diamond growth and new methods have been perfected that use carbonate, hydroxide and sulfate salts rather than conventional metal fluxes such as $\mathrm{Ni}$ or Co. Using alternating carbonate and graphite layers between which diamond seed crystals are sandwiched, the group has succeeded in growing large diamonds. Recently NIRIM has succeeded in growing small colorless diamonds using magnesium hydroxide/graphite matrices and calcium hydroxide/graphite matrices at high temperature and pressure. Work is underway to investigate whether diamonds can be grown at lower temperatures and pressures.

Progress has been made in $c B N$ synthesis by high pressure techniques in which hexagonal material is converted to cubic material. We were not provided with the details of this method, although we were shown crystals of the material.

In Seiichiro Matsumoto's laboratory we were shown the most advanced systems to date for high temperature plasma arc synthesis of diamond. RF powered $70 \mathrm{KW}$ systems and a DC plasma $100 \mathrm{KW}$ system operating utilizing a $\mathrm{CH}_{4}-\mathrm{H}_{2}-\mathrm{Ar}$ feed gas mixture provided depositions of diamond in a $1.27 \mathrm{~cm}$ diameter area at a deposition rate of $2 \mu \mathrm{m} / \mathrm{min}$. In addition, an acetylene torch deposition system was present in this well equipped laboratory.

\section{Microwave Plasma CVD Facilities}

Four $1.5 \mathrm{KW}$ microwave plasma systems were available for CVD synthesis. On these reactors no separate control of the substrate temperature was done. Two more advanced units that looked larger, were being constructed in a laboratory that we did not enter.

Surprisingly, using no substrate preparation other than washing the silicon substrate with alcohol, Dr. Sato claimed to obtain excellent nucleation of diamond. One inch diameter areas of film had been grown. Under microscopic examination, both large and small distinct diamond crystals were visible on 
samples where growth had been interrupted before formation of the continuous film. The growth temperature, which was monitored with an optical pyrometer that sampled the reactor by a prism coupling through the top of the reactor, was determined to be between 700 and $900{ }^{\circ} \mathrm{C}$.

\section{Characterizations}

NIRIM's facilities for growth of diamond vastly outstripped its facilities for characterizing the materials. SEM is done, but no thermal conductivity measurements are done. This paucity of characterization tools will soon be rectified by the addition of new capabilities that are being set-up. Plans to acquire surface reflection FTIR exists. A new UHV system equipped with excimer laser assisted photodeposition, in situ RHEED, and Auger spectroscopy is under construction. A Raman spectrometer is already in operation.

NIRIM needs to collaborate more closely with other groups in order to obtain comprehensive characterizations of the diamond coatings deposited in its high deposition rate systems.

NEC

Date of visit: June 1, 1990

Visiting Delegation: A. Feldman, J. Mitchell, and M. Tamor

Background. NEC is a large corporation established in 1899 and subsequently owned $42 \%$ by Western Electric Corporation following World War II. NEC, now partially owned by Sumitomo, had net sales of $\$ 23$ billion dollars and included 104,022 employees in 1989. Within its nine research divisions are 1000 employees mostly located at the Kawasaki central research facility. Three departments reside at the Tsukuba location, where most of the semiconductor work is done. NEC is expanding with a research laboratory specializing in artificial intelligence at Princeton, New Jersey and a new laboratory planned for Osaka.

Within the Materials Research Laboratory at Kawasaki a broad range of research is conducted. Ten researchers work on Josephson junction computers, while fifteen researchers are investigating high $T_{c}$ superconductor materials. Two thirds of their device work includes silicon electronics, while one third is devoted to II-V's.

NEC had a rather impressive area displaying products and technology. A computer system that does translations into six languages was demonstrated. High clarity, brightly colored liquid crystal displays on miniaturized TV screens were shown. Technology for networking of supercomputers was diagrammed. A complete 8 in diameter $\times 4 \mathrm{ft}$. long single crystal boule of $\mathrm{Si}$ was displayed. These were only a few of the items on display.

The Diamond Program. Dr. Shohata, Manager, Materials Research Laboratory, presented a technical seminar on diamond materials for applications, possibilities including high fidelity speaker membranes, ultraviolet sensors, and magnetic disc coatings. NEC's diamond program is two years old and involves seven people investigating diamond and diamond-like carbon (DLC) materials. No semiconductor diamond work is underway. However, Sumitomo 
(NEC's partial owner) is heavily engaged in such investigations. NEC and Sumitomo are conducting synchrotron lithography research. NEC operates a 10 meter system while sumotomo has a 3 meter synchrotron. It is quite curious that neither of these corporations indicated that they are working on X-ray mask applications for diamond. In view of the fact that the Japanese have been committed for a long time to the diamond materials for $\mathrm{x}$-ray masks. Their work is likely to be considered highly proprietary.

An elegant hot filament reactor is in operation. With this specially designed multiple $W$ wire hot filament reactor, 3 inch silicon wafers had been coated successfully. Deposition at $0.5 \mathrm{micron} / \mathrm{hr}$ at $850{ }^{\circ} \mathrm{C}$ substrate temperature in $\mathrm{Ch}_{4} / \mathrm{H}_{2}$ (1-5 vol \%) had been achieved. The temperature of the substrate holder in the filament reactor ( 6 in $\times 6$ in) was controlled by separate infrared heaters. Four $0.3 \mathrm{~mm}$ W wires were suspended $10 \mathrm{~mm}$ above the substrate surface and kept in tension by specially designed metal posts.

Characterizations. Investigation of the dependence of surface roughness of films on $\mathrm{CH}_{4}$ concentration have been carried out. It was observed by SEM that a $1 \% \mathrm{CH}_{4}$ fraction in a $\mathrm{CH}_{4} / \mathrm{H}_{2}$ feed gas gave crystalline surfaces that improved in smoothness. When the $\mathrm{CH}_{4}$ fraction was increased to $3 \%$, very smooth translucent diamond films of 5 micron thickness were obtained. One could read through these films. Their thermal conductivity was $500 \mathrm{~W} / \mathrm{m} \mathrm{K}$. Films were well characterized by Raman spectroscopy, and x-ray diffraction. Morphology, roughness and transmittance were assessed. Thermal diffusivity measurements were made on thick free-standing diamond films with a commercially available apparatus .

The NEC group had analyzed comprehensively their diamond-like materials and had developed advanced facilities for depositing DLC materials. Thermal studies of DLC showed that these materials continuously lost $\mathrm{CH}_{3}$ and $\mathrm{CH}_{2}$ radical groups as the temperature was heated to $700{ }^{\circ} \mathrm{C}$. Rapid graphitization occurred at temperatures $\geq 400{ }^{\circ} \mathrm{C}$ and the upper temperature limit for DLC was determined to be $430{ }^{\circ} \mathrm{C}$. DLC materials were further characterized by Rutherford backscattering and recoil methods and found to contain 24 to $32 \%$ hydrogen. An impressive (but perhaps not unequivocal) micro-indenter method had been applied to determine the apparent "hardness" of DLC. The distance of penetration of the micro tip was measured by an interference fringe technique and the applied load was determined by an electrobalance. Both the Vickers hardness and Young modulus of the films were measured versus the $\mathrm{CH}_{4} / \mathrm{H}_{2}$ ratios used in deposition. Other characterizations included electrical resistivity $\left(2.8 \times 10^{13} \mathrm{ohm} \mathrm{cm}\right.$ ) and dielectric constant (3.5). The density of the film prepared in a DC glow discharge reactor was $2 \mathrm{~g} / \mathrm{cm}^{3}$.

The NEC DLC system had a very large chamber, $14 \times 14 \times 10$ in. Plastic holders in a stacked assembly could be loaded into the chamber. It appeared that each disk could be automatically transferred from this holder and positioned in the reactor for sequential coating without opening the vacuum chamber. This was a production type DLC system for coating magnetic disk heads, an application NEC is about to commercialize. The entire DLC apparatus was housed within semiclean space. This prototype system was considered proprietary. Thus, it was viewed from a distance of 15 to 20 feet. In contrast, we were able to look inside the hot filament reactor. 


\section{NIPPON INSTITUTE OF TECHNOLOGY (NIT)}

Date of visit: May 30, 1990

Visiting delegation: A. Feldman, R. A. Rudder, M. A. Tamor, and W. A. Yarbrough

The diamond effort at NIT is over 5 years old, but it has expanded recently. Five faculty members ( 3 senior, 2 junior) and five graduate students are working on diamond research. Salaries and overhead are funded by the Ministry of Education. Some major equipment is obtained from the Ministry of Education, but most is provided by industrial sponsors. All funding for studies of coating and testing cutting tools was provided by industrial sponsors. The sponsors were unnamed, but are likely to be automotive as evidenced by the interest in super-eutectic silicon/aluminum alloys.

Professor Y. Hirose had been on sabbatical at North Carolina State University during the 1989-1990 academic year. Ironically, the NIT faculty pointed out that Japanese industry prefers to fund U.S. universities because they are more reliable in performing and reporting the desired research.

Diamond research at NIT is focussed in two areas: chemistry of CVD; and tool performance and tribology. Approximately $20 \%$ of the effort appeared to be devoted to CVD studies, with the remainder devoted to tool applications. In the area of CVD chemistry, both hot filament (HFCVD) and combustion flame reactors are in use. In HFCVD, after demonstrating diamond deposition from a wide variety of hydrocarbon liquids, including sake and bourbon, ethanol was selected as the carbon source of choice. Two large area reactors (approximately 3 in. diameter) have been built for tool coating, while smaller reactors ( 1 in. diameter) are used for deposition research. Professor Hirose was the first to demonstrate deposition of diamond by an oxy-acetylene combustion flame. This work is being extended with demonstration of a scanned flame reactor for coating larger areas and the initiation of studies of optical emission spectral from the flame.

The facility for evaluation of tool tribology at NIT was unique and quite impressive. This included a rather conventional lateral scraping device for measuring film adhesion, and a unique shear tester developed in house for measuring tool wear. The latter measures the rate of wear of a cutting edge by repeatedly cutting slivers from the end of a carbide abrasive coated tape. This instrument has been used to demonstrate quantitative correlation between film adhesion and cutting edge lifetime. NIT is also involved in fabrication and testing of tools formed by brazing of CVD diamond plates to conventional tool inserts. Tools brazed with diamond plates more than 15 microns thick exhibited performance equal to that of diamond compacts in cutting supereutectic (18\%) silicon/aluminum alloy.

NIT also has a somewhat smaller project in cBN. They have deposited thin films of pure nanocrystalline $c B N$ in a hybrid reactor. This reactor uses a magnetically stabilized, capacitively coupled RF plasma of argon and nitrogen, along with electron-beam evaporated boron to deposit cBN on a 2 in. diameter substrate. 
NIT faculty indicated that in basic research on CVD diamond and in some applications the United States may enjoy a small lead, but that Japan leads in most applications by a large margin.

\section{OSAKA UNIVERSITY}

Date of visit: June 4, 1990

Visiting delegation: Visited by all members of the U.S. Delegation

The visit was hosted by Professor Akio Hiraki and Dr. Hiroshi Kawarada.

The scale of effort on CVD diamond at Osaka University is impressive. In addition to Professor Hiraki and Dr. Kawarada, there are 10 graduate students and post doctoral researchers. The research is directed towards applications in electronics and luminescent emitters.

The group has been working on CVD diamond for 3.5 years. Their major support comes from government research grants. A significant portion of the support for diamond is apparently spin off from a major program on silicon. The Osaka University group is collaborating with Kobe Steel on electronic properties of diamond and with Shimadzu Corporation on the development of ECR diamond deposition sources. The Osaka group, together with Shimadzu, is apparently selling an ECR source developed and designed at Osaka University. In addition, the group has coauthored joint papers with researchers from Idemitsu and Canon. Professor Hiraki has many contacts in the United States stemming from two prior extensive stays in this country.

The research at Osaka University addresses a number of fundamental issues including: nucleation and growth, gas phase chemistry, doping, film morphology, interface properties, and defect structures. They are primarily interested in the electrical and optical properties and do not make thermal conductivity measurements.

The group at Osaka University has developed an interesting and novel process which they call SENTAXY. This process uses a combination of masking, abrasion with diamond, and ion sputtering to provide diamond nucleation sites at selected substrate locations. Beautiful arrays of single crystallites of diamond can be achieved by this method. However, the individual crystals are not oriented with respect to the substrate.

The group is also focusing on the problems of obtaining deposition of high quality diamond films over wide areas. To accomplish this they are using low pressure, magnetically confined plasmas. Operation at lower pressures gives a more diffuse, widespread plasma which leads to more uniform deposition over wider areas. However, the low pressure deposition process is accompanied by much lower growth rates. The growth rate problem was addressed by use of different chemistry in the plasma, most notably using $\mathrm{CO}$ and $\mathrm{CO}_{2}$ instead of methane. The source gases can be, for example, $85 \% \mathrm{H}_{2}$ and $15 \% \mathrm{CO}$ by volume. Growth rates of 0.3 to $0.5 \mu \mathrm{m} / \mathrm{hr}$ have been accomplished using a $5 \mathrm{KW}$ microwave source operating at $2.45 \mathrm{GHz}$ to generate a low pressure plasma in the presence of a confining magnetic field; however, the electron cyclotron resonance (ECR) 
condition is not utilized. The feed gas flow rate was $100 \mathrm{sccm}$ and pressure was as low as 0.1 Torr.

Substrate temperatures have been reduced to $500{ }^{\circ} \mathrm{C}$ and they hope to further reduce these temperatures to $400^{\circ} \mathrm{C}$ and lower. The delegation was shown a 4 inch diameter silicon substrate with a diamond film $1 \mu \mathrm{m}$ thick covering the entire surface. The deposition was not completely uniform, because

interference fringes were clearly visible. This film was deposited from a gas mixture of $5 \% \mathrm{CH}_{4}, 10 \% \mathrm{CO}_{2}$, and $85 \% \mathrm{H}_{2}$ at a feed gas flow rate of $100 \mathrm{sccm}$. Doping of the deposited diamond films was achieved by addition of $\mathrm{B}_{2} \mathrm{H}_{6}$ to the source gas.

The Osaka University group is highly committed to the use of microwave ECR deposition reactors although they usually use fields greater than those needed to fulfill the ECR condition. They believe that this method has good potential for scale-up and use in production applications.

Some efforts on heteroepitaxial growth of diamond on silicon carbide were attempted, but without success. Growth of diamond films from beams of $\mathrm{CH}_{3}$ radicals is also being attempted.

The characterization capabilities at Osaka University are extensive. These include Raman spectroscopy, $x$-ray diffraction, electron microscopy, Auger spectroscopy, cathodoluminescence, photoluminescence, and Rutherford backscattering. Hydrogen content in diamond films is determined by forward scattering in the Rutherford backscattering facility, which is equipped with a $3.5 \mathrm{MeV}$ ion accelerator. This apparatus is also used for ion channeling experiments.

The visiting team was greatly impressed by the quality of the entire effort at Osaka University. This is a world class research team under the direction a very energetic and capable leader.

\section{SEIKO INSTRUMENTS INC.}

Date of visit: May 30, 1990

Visiting delegation: J. C. Angus, S. Holly, J. W. Mitchell, and K. A. Snail

Dr. Kohji Asakura, Senior Engineer at the Rockwell International Overseas Corporation acted as interpreter and guide.

Mr. Hiroyuki Funamoto, Manager of the Process Development Section, met us at the train station and served as a contact person throughout our visit. Mr. Yoichiro Sakami, Director of the Technology and Project Administration Department was our primary host.

Each of the visiting team give a very brief overview of our own diamond efforts. Mr. Funamoto then gave a very informative and extended discussion of the Seiko effort in diamond and diamondlike materials.

Seiko has been working on CVD diamond since 1984. The goals of their research are specific products. These include: heat sinks, protective coatings, 
printer head coatings, and x-ray windows. Three full time research employees work on CVD diamond at Seiko.

Seiko believes itself to be a relatively small player in the CVD diamond field, and, therefore, relies heavily on cooperative efforts with other institutions. Initially, they cooperated with on NIRIM and on the Japan Research and Development Corporation. They are also cooperating with universities, including the Tokyo Science University. They spoke very highly of their joint venture with Air Products and Chemicals Corporation for the development of diamond-like films for protective coatings. (NOTE: A new company, Diamonex has been formed to carry on the diamond and DLC work formerly done at Air Products and Chemcials.) The positive nature of this relationship was emphasized several times during our visit.

The research effort at Seiko is very heavily weighted toward applications rather than fundamental research. They have strong efforts in measuring the mechanical, thermal, and optical properties of the diamond films. They are also concerned with film morphology and surface finish. They are investigating ion etching and other processes for polishing the films.

Seiko is using only microwave plasma CVD processes for depositing diamond films. Ion beam processes for deposition of diamondlike materials are being conducted in the United States by their partner, Air Products Corporation. They indicated that their substrates were prepared by scratching. Deposition temperatures range from 700 to $900{ }^{\circ} \mathrm{C}$. Film characterization measurements include thermal conductivity, density, Raman spectroscopy, x-ray diffraction, scanning tunneling microscopy, and hardness. They did not mention any work on $\mathrm{cBN}$.

Seiko apparently will be using microwave deposition for its scaled up commercial processes. It believes that an important technological barrier still to be overcome is the deposition of high quality films with the highest possible thermal conductivity. Heat sink applications for CVD diamond are still two to three years away according to Seiko. However, applications of diamondlike films are expected very shortly. The first applications of the diamondlike films will be coatings for scratch resistant watch faces. This could be a significant market, since Seiko makes 55 million watches per year. The seiko representatives indicated that the diamondlike film coating work would be done by their partner, Air Products and Chemicals, in the United States, while any CVD diamond application work would be conducted in Japan.

The visiting delegation was taken on a very interesting tour of the Seiko facilities. We saw two robotic, pilot production lines for the production of watches. These automated production facilities were most impressive. We then were taken to the laboratory areas were the CVD diamond was produced and also saw their highly developed method for measurement of thermal conductivity of diamond films. The deposition system appeared to be what is now called the standard NIRIM microwave system.

The entire visiting team came away with a very great respect for the competence and energy with which Seiko Instruments is pursuing research and development in CVD diamond. Their level of effort and sophistication is especially noteworthy because they are not a giant corporation with exceedingly large resources. 
Date of visit: June 1, 1990.

Visiting delegation: J. C. Angus, J. J. Cuomo, S. Holly, and R. A. Rudder

The visit was hosted by Dr. Shumpei Yamazaki, President of SEL, who briefed the delegation on the history of SEL and its current business. Dr. Yamazaki has applied for more than 1700 Japanese and $600 \mathrm{U} . S$. Patents. Yamasaki is one of the three founders of electronically programmable read only memories (EPRDM). His application for a diamond CVD patent in 1981 using RF or microwave plasmas is dated several months prior to NIRIM's hot-filament application. His company demonstrated diamond CVD growth in 1984. Despite this auspicious diamond start, SEL sought business opportunities other than diamond. Today, of its 130 employees, only 4 or 5 work on diamond CVD development. Its major business areas are solar cells, image sensors, photo sensors, large size liquid crystal displays, and photo-enhanced or plasmaassisted CVD apparatus.

Before discussing the diamond technology at SEL, it is worthwhile to discuss the SEL business strategy. Our visiting delegation found the concept of SEL and its management as intriguing as the diamond technology. SEL is a research and development warehouse. It uses revenues returned from patent licenses and royalties along with income from contractual sale of technology to industry to seed research and development in new technologies. As these technologies develop, patents are applied for to establish SEL's position. The processing technology or materials technology are marketed to industrial clients. SEL sees itself as a global company willing to export its technology around the world. SEL's product is its technology for a particular process. It delivers to industry primarily equipment and instruction but will undertake to have SEL personnel assist people at the clients location. SEL has no government contracts. SEL is in a position to market its technology world-wide.

Dr. Yamazaki perceives the world economy divided into three sectors: agricultural and raw materials; services; manufacturing. By this segregation, he describes his company as a "2.5" company, providing research and development services to manufacturing companies around the world. SEL entered the diamond CVD technology by delivery of a prototype low pressure ECR system to Osaka University. SEL currently offers for sale a mixed cyclotron resonance diamond CVD apparatus for deposition onto $100 \mathrm{~mm} \mathrm{Si}$ wafers. It currently has delivered 5 units to customers. Diamond CVD equipment is not the only CVD equipment marketed by SEL. It currently sells photochemical CVD equipment for silicon nitride deposition.

Diamond research and development at SEL is not the major product at SEL. SEL stated that it had one person devoted to diamond R\&D and that it had 5 people active in DLC R\&D. The committee perceived perhaps 2-3 people active and conversant with the diamond CVD effort. Besides activities in diamond, DLC, silicon nitride, SEL has activities in high $T_{c}$ superconductors and solar cells. Areas other than diamond constitute a larger market for SEL.

Yamasaki does not foresee immediate development of electronically active devices. He does see the potential for diamond heatsinks for other 
semiconducting devices. He is not optimistic about diamond light-emitting devices. He does foresee diamond technology for cutting tool coatings, wire dies, protective coatings on windshields, and for photomasks on UV exposure systems. Diamond n-type doping must be achieved if there is to be significant electronics application.

For large area coatings greater than $100 \mathrm{~mm}$ in diameter, a microwave source with power output greater than $5 \mathrm{KW}$ must be designed in order to maintain the plasma density necessary for diamond deposition. Currently, SEL can deliver systems to clients which grow diamond films uniformly over a $100 \mathrm{~mm}$ Si water. The rates are approximately $0.5 \mu \mathrm{m} / \mathrm{hr}$. The substrates are subjected to a diamond ultrasonic treatment prior to deposition. The lowest deposition temperature for diamond occurred between 330 and $470{ }^{\circ} \mathrm{C}$ using methanol in the feed gas. The films are characterized by SEM, Raman, XRD, electroluminescence, and cathodoluminescence. The optimization of their process has occurred both through the aforementioned external characterizations and by use of atomic emission spectroscopy. By inserting a light probe into different regions of the ECR discharge, SEL has determined the parameter space in power, pressure, and substrate bias whereby one can obtain uniform $656 \mathrm{~nm}$ atomic hydrogen emission over a $100 \mathrm{~mm}$ diameter. While not basic research, this is an example of the high quality of engineering research performed at SEL. Results of this study, while not yet published, were openly discussed and displayed to the visiting delegation.

The delegation received a laboratory tour of facilities, copies of Japanese patents on diamond processing, product literature and prices, SEL publications on diamond, and corporate charter and financial status information. We were very impressed with the company. Its intrepreneurial nature makes certain that as diamond technology develops at SEL, it will be immediately available to the diamond industry. 
SHOWA DENKO K. K.

Date of visit: May 30, 1990

Visiting Delegation: J. J. Cuomo, J. T. Glass, L. H. Schwartz, and C. M. Stickley.

The visit was hosted by Dr. Junichi Sato, Chief Staff Manager of Ceramics Division. Also present were Dr. Kunio Komaki, Deputy Chief Researcher of the Central Research Laboratory, Shingo Morlmoto, Deputy Chief Researcher of the Central Research Laboratory, and Masataka Yamamoto, Deputy Chief Manager of the Ceramics Division. We met at their corporate offices and thus we saw no facilities nor were we shown pictures of facilities.

Showa Denko (SD) is a producer of olefins, plastics, organic chemicals, inorganic chemicals, gases, biotechnology products, electronic materials, carbons, ceramics, nonmetallurgical aluminas, aluminum, and metallic materials. The company had 1989 total sales of $\$ 3.6 \mathrm{~B}$ and 5000 employees. Its current 5 year plan (1989 to 1994) calls for achieving an annual sales level of $\$ 4.5 \mathrm{~B}$ by 1994 and to have invested over the five year period, $\$ 0.96 \mathrm{~B}$ in $\mathrm{R} \& \mathrm{D}$ and $\$ 1.72 \mathrm{~B}$ in plant and equipment. Assuming a constant fraction of $R \& D$ investment to sales over this five year period implies a $4.8 \%$ R\&D to sales ratio. Only internal funds are used for $R \& D$ (i.e., MITI, etc., funds are negligible). Their interest in diamond is broadening from producing diamond powders (with varying particle shapes) to objects closer to finished products such as free-standing parts, including cones for high frequency speakers.

Dr. Komaki gave a presentation which summarized a publication they had published in the 1990 New Diamond Forum proceedings entitled "Multi-shaped and Hybrid Diamond Particles by Vapor Phase Method." The article reports that "using (the) hot-filament method we have developed several ways to control diamond particle morphology by nucleation and growth conditions, resulting in large single crystal-1ike and multi-shaped particles. We have also produced diamond-ceramic hybrid particles in a continuous process." SD has licensed the patent for this deposition process from NIRIM. The company is utilizing the combustion flame method to produce particles of different shapes. Dr. Komaki stated that SD owns the patent for this process having paid for the development of it with Prof. Hirose at the Nippon Institute of Technology.

For the hot filament approach to making diamond particles they used a feed gas of ethanol mixed with $\mathrm{H}_{2}$ and a filament temperature of $2800^{\circ} \mathrm{C}$ to produce cubo-octahedral particles. They have modified their process by adding a fluidized bed to suspend other ceramic particles (SiC typically) for coating with diamond films. SD has U.S. and Japanese patents on the fluidization process.

Further, they have modified the combustion flame method, which normally operates in the open atmosphere, to operate in a chamber (the chamber flame method) in which $\mathrm{C}_{2} \mathrm{H}_{2}$ and $\mathrm{O}_{2}$ (in the ratio of 1 to 0.87 ) burn at a pressure ranging from 760 Torr down to 300 Torr. The diamond growth area is $60 \mathrm{~mm}^{2}$ at 470 Torr. The thickness is typically $50 \mu \mathrm{m}$ and independent of specimen length (up to $10 \mathrm{~mm}$ ); one hour is required to grow the film, which is densely packed and will stand alone. The film will grow thicker with time; they have grown films as thick as $0.2 \mathrm{~mm}$. 
Using SiC chips coated with diamond by the chamber flame method, they have machined Al-18\%Si alloys at turning speeds up to 1500 RPM. These chips show good durability having turning distances of $60 \mathrm{~km}$. The chip lifetime is 100 times the lifetime of uncoated chips. Adhesion strength, variations in adhesion strength, surface roughness, and development of a production capability are improvements that are needed.

With regard to other materials, they state that titanium nitride coatings show excellent cost/performance ratios. They are just beginning to work on $c B N$ coatings and have developed a laboratory-level process to make these coatings. They state that $c B N$ coatings have problems similar to those of diamond - poor surface finish and inadequate adhesion. SD seems to be pursuing surface preparation and pre-coating techniques to control nucleation and growth.

Mr. Morimoto presented a review of their work on "Free Standing Diamond Films - Plates, Tubes, and Curved Diaphragms." This was presented at the Diamond Optics SPIE meeting in San Diego in August 1989. By shaping (curving) the hot filament and rotating the substrate (silicon) they have made bowl-shaped parts as large as $6 \mathrm{~cm}$ in diameter and pipes $10 \mathrm{~mm}$ in diameter. Microwave CVD is used to make plates $1^{\prime \prime}$ in diameter and 20 microns thick; diameters are expected to increase to from 2 to 6 inches. The bowls are principally diamond as seen by Raman spectra; However, they appear darker then other parts indicating a higher graphite content. With this technique they make speaker cones for Pioneer; they are close to a production process. They will develop their own equipment for production.

SD has worked with Professor Yoshikawa of TIT on a polishing technique and have applied to patent the technique in the United States. It involves rubbing the surface to be polished against a rotating iron plate heated to $700-800{ }^{\circ} \mathrm{C}$ in 30 Torr of $\mathrm{H}_{2}$. With this process they can achieve a surface roughness of 0.01-0.05 microns in 10-20 minutes; the more conventual techniques (diamond paste and unheated iron in $\mathrm{H}_{2}$ ) yields a roughness of 1-2 microns after several hours of polishing. They claim this easy to accomplish on a laboratory scale.

The patent for this process is the only one they have appiied for due to the high cost of patenting involved. They have 10 applications in Japan for patents on the combustion method, and several have been granted already.

Each department administers its own $R \& D$, but long term $R \& D$ ( 5 to 10 years) is done by the Central Research Laboratory. Related divisions cooperate in advising the Central Research Laboratory about its program. The commercial departments at SD have a 3-5 year perspective. 
SUMITOMO ELECTRIC INDUSTRIES, LTD.

Date of visit: June 4, 1990

Visiting delegation: Visited by all members of the U.S. Delegation

The visit was hosted by $\mathrm{Dr}$. Akio Hara, Managing Director of the Sumitomo Electric Itami Works. Dr. Hara explained the functions of their corporate division as well as the company's strategy for developing new areas of business through research and development. Sumitomo's commitment to research is reflected in its budget; $4 \%$ of it's operating budget and $10 \%$ of its manpower are dedicated to research and development. Sumitomo makes strategic choices of research areas to pursue when it envisions developing commercial markets in those areas. It also recognizes that the size of the commercial market cannot be forecast at the time the R\&D decisions are reached. It depends on the developing technology to spawn new products and ideas that will expand the commercial market. Sumitomo then maintains a long-term commitment in support of the research.

Diamond R\&D at Sumitomo is an excellent example of this selection process. CVD diamond work began at Sumitomo in 1980. Today, more than 10 people are involved with diamond CVD. Five hot filament and 7 microwave plasma CVD systems are in operation. No CVD diamond products had been introduced to the marketplace until 1987. The following is a list of CVD diamond products produced by Sumitomo Electric and the dates they were introduced to the market.

$$
\begin{aligned}
& 1987 \text { - diamond-coated loudspeaker diagrams } \\
& 1989 \text { - diamond-coated endmills } \\
& 1990 \text { - tape automatic bonding tools (TAB bonders) }
\end{aligned}
$$

A new product will be announced at the end of the year.

This development has been supported largely by internal Sumitomo funds. The combination of both CVD diamond research and HPHT diamond research has allowed them to set goals for the CVD technology whereby it can become economically competitive with high pressure technology. Sumitomo has projected the sales markets for diamond tools at approximately $\$ 12.5 \mathrm{M} / \mathrm{yr}$. Even now, the company believes the technology to be too immature and the markets too poorly defined to allow for sales estimates of optical or electronic products.

Sumitomo applies four criteria for commercialization of a product. One, Sumitomo must be creative in developing technologies. Two, there must be efficient and quick information exchange regarding technological problems and accomplishments. Three, cost reductions occur when products are constantly being produced. And four, a company must have patience. For any new technology, there is a long incubation period before the realization of products. Sumitomo supports new technologies through that period.

Sumitomo maintains creativity in technology by supporting $R \& D$ in the basic process technologies and by extracting the most from its researchers abilities and its collaborations with many universities. Sumitomo is collaborating with NIRIM and Penn State University on homoepitaxy, with Osaka University and the University of Michigan on optical properties of diamond, and with the Library 
and Information University on electron spin resonance characterization of diamond. Sumitomo seemed receptive to future collaborations with U.S. institutions and industry.

Sumitomo supports efforts in CVD diamond for a multiplicity of applications, for example: wear resistant coatings, coatings as on cemented carbides, coatings on ceramics, coatings on wire dies for the pulling of high $T_{c}$ superconducting wires. It supports knowledge bases for polycrystalline and single crystalline diamond deposition, for applications and markets. A knowledge base on applications and markets is developed by introducing a product to the consumer, by using feedback from the consumer to improve the product and then by resubmitting the product to the market.

Having the knowledge base obtained through 10 years of development in CVD diamond and HPHT diamond puts Sumitomo in a unique position to assess the status of CVD diamond technology relative HPHT diamond technology. In assessing the economics of diamond production one must consider the efficiency of the process, the production rate of a process, and the quality of the product produced.

Many CVD processes make inefficient use of the carbon in the reaction species because the percentage of carbon converted to diamond is small. Hot filament CVD converts only about $1 \%$ of the carbon available in the feed gas to diamond whereas the HPHT process converts about $70 \%$ of the carbon to diamond.

The production rates of different processes vary widely. The plasma jet process can produce diamond at rates comparable to or exceeding those in HPHT cells. However the quality of the CVD material is generally poorer than the quality of the HPHT material.

The large gas consumption of the high rate CVD processes makes costs high unless gas recycling techniques can be developed. Sumitomo has currently established critical goals for diamond CVD at growth rates greater than $90 \mu \mathrm{m} / \mathrm{hr}$. These are deposition areas larger than $500 \mathrm{~cm}^{2}$ and deposition temperatures below $450{ }^{\circ} \mathrm{C}$.

Sumitomo relies heavily on microwave plasma and hot-filament techniques for diamond deposition. The microwave plasma technique is preferred for electronic applications where high crystalline purity is important. Hot filament deposited films contained 20-30 parts per million tungsten contamination.

Sumitomo is experimenting with DC bias of the substrate during filament depositions, a process that appears to be the same as EACVD. Besides the filament and microwave techniques, Sumitomo is developing a plasma technique using $\mathrm{O}_{2} / \mathrm{CH}_{4}$ discharges with $60 \% \mathrm{O}_{2}$ and $40 \% \mathrm{CH}_{4}$. With this ratio of $\mathrm{CH}_{4}$ to $\mathrm{O}_{2}$, the spectrum from the discharge contains significant atomic hydrogen emission. Raman spectroscopy of the deposited diamond shows a dominant 1332 $\mathrm{cm}^{-1}$ line with a small amount of disordered carbon. Deviations from the feed gas ratios reduce the hydrogen emission and the quality of diamond as determined by the Raman spectrum.

Sumitomo has succeeded in achieving heteroepitaxial growth of diamond on $c B N$ (100) and (111) surfaces. The heteroepitaxy was determined via RHEED 
observations of the deposited diamond layer. The RHEED patterns could best be described as elongated spot patterns suggesting some roughness to the surface. No other data, such as micrographs of surface morphology or analysis of the surface chemical were given. Homoepitaxial growths as a function of $\mathrm{CH}_{4}$ fraction in the feed gas on different substrate orientations were discussed. The best morphology occurred on $\{100\}$ diamond surfaces. RHEED and Raman analysis showed the optimum growth conditions to be at a $6 \% \mathrm{CH}_{4}$ fraction in the feed gas. RHEED patterns at $6 \% \mathrm{CH}_{4}$ were uniformly streaked, and Raman analysis did not show any amorphous carbon present. Amorphous carbon was found in the films deposited with other $\mathrm{CH}_{4}$ fractions. A number of dopants were evaluated: $B, S, P, C 1$, As, and Se. $P$ doping resulted in n-type electric conduction but the electrical conductivity of the films was very low. The activation energy of the boron doped samples was observed as a function of the dopant concentration in the gas phase. The results are given in the GENERIC RESEARCH section of this report.

Mobility as a function of temperature was reported for one of the boron doped films. The hole concentration was $10^{13} / \mathrm{cm}^{3}$ at room temperature increasing to $10^{18} / \mathrm{cm}^{3}$ at $600{ }^{\circ} \mathrm{C}$. The hole mobility was $960 \mathrm{~cm}^{2} / \mathrm{V} / \mathrm{s}$ at room temperature declining to $70 \mathrm{~cm}^{2} / \mathrm{V} / \mathrm{s}$ at $600{ }^{\circ} \mathrm{C}$.

Diamond MESFETs were also fabricated from boron doped films. The gate length and width were $80 \mu \mathrm{m}$ and $150 \mu \mathrm{m}$, respectively. Ti was used for ohmic contact to the source and drain while $W$ was used for the Schottky contact. Transistor behavior was observed on a metalized $1 \mu \mathrm{m}$ thick p-type layer, but the source to drain current was extremely small. An increase in the source to drain current current occured when a $0.23 \mu \mathrm{m}$ intrinsic diamond layer was deposited over a $0.90 \mu \mathrm{m}$ p-type layer prior to metalization. The operation of these transistors at elevated temperatures was not reported.

Future work at Sumitomo is targeting perfection of epitaxy, fabrication of practical devices, and the fabrication of heterojunction devices. The committee was impressed with the CVD diamond effort at sumitomo.

\section{TOKYO INSTITUTE OF TECHNOLOGY (TIT)}

Date of visit: June 1, 1990

Visiting delegation: J. T. Glass, C. M. Stickley, K. A. Snail, and L. H. Schwartz

Two groups are working on diamond at TIT. The first is Professor Osamu Fukanaga's group; his group's research focuses on reducing pressures required for HPHT synthesis of diamond into the 3-4 GPa range using novel catalystsolvents (e.g., carbonates). This work is being done in collaboration with NIRIM. His group's other line of research focuses on alternative ways of enhancing surface mediated reactions in a CVD environment. His primary approach is to vary the power in a microwave reactor and look for changes in the stress of the deposited material, as measured by Raman peak shifts.

The second group, which is headed by Professor Masanori Yoshikawa, is focussed on tool and abrasive grit applications. This group has achieved a number of firsts with little government support and/or equipment. The main accomplishments are: The highest reported growth rate for CVD diamond, 
$920 \mu \mathrm{m} / \mathrm{hr}$ - $10 \mathrm{KW}$ in a DC plasma jet; and, the development of a novel technique for polishing CVD diamond with hot iron. They are also cutting and planing CVD diamond with a pulsed Nd:Yag laser. They are able to smooth films to $2-3 \mu \mathrm{m}$ average roughness with a laser and can cut $100 \mu \mathrm{m}$ deep grooves with modest laser powers $(7-8 \mathrm{~W})$. We recieved two publications from Professor Yoshikawa on the laser processing (in Japanese).

Professor Yoshikawa claims that his DC plasma jet can grow diamond at a cost of about 100 Yen/carat, or less than the current price for HPHT grit. After hearing the presentation during our visit to Sumitomo Electric, there is some skepticism about this claim. Professor Yoshikawa has broken up his diamond deposits using steel rollers and has bonded the grit to wheels for cutting. Using a Nd:Yag pulsed laser, he has cut and smoothed diamond films synthesized with the DC plasma jet; the films were then brazed to cutting tool inserts.

Professor Yoshikawa's polishing technique is very simple and is claimed to be able to polish the hard $\langle 111\rangle$ face of natural diamond. The technique involves polishing the diamond in a chamber on a hot $\left(700\right.$ to $900{ }^{\circ} \mathrm{C}$ ) iron lap in the presence of hydrogen and near a hot filament. Professor Yoshikawa now says he does not need a filament in his chamber; he can polish CVD diamond at a rate of $6 \mu \mathrm{m} / \mathrm{hr}$ at $900{ }^{\circ} \mathrm{C}$. Some prepolishing at lower temperatures may be required because experience at NRL indicates that the high applied forces needed for polishing diamond, in combination with the high temperatures, can cause scratching of the iron disk if the CVD diamond is too rough. 
TOSHIBA TUNGALOY INC.

Date of visit: May 30, 1990

Visiting delegation: A. Feldman, J. W. Mitchell, M. A. Tamor, and W. A.

Yarbrough

Toshiba Tungaloy is a moderately sized organization (approximately 245 million dollars in 1989 sales) specializing in the design and production of coated cutting tools of numerous types and designs and has its principal production and research facilities in Kawasaki, Japan near Tokyo. In recent years they began to market CVD coating equipment for conventional tool coatings ( $\mathrm{TiN} / \mathrm{TiCN} / \mathrm{Al}_{2} \mathrm{O}_{3}$ ) in addition to their principal cutting tool business. It was originally founded in 1934 and was reorganized in 1950 as spin off of Toshiba Corp. by Messrs. Momma and Ando. The latter is currently President and CEO. They have been pursuing CVD diamond coatings for tool applications since approximately 1984 under the leadership of Dr. Sokichi Takatsu, their chief engineer for materials. They have collaborated with numerous other research and development organizations, supporting research at several locations in Japan and the United States and have presented their work at numerous technical meetings and conferences. They are presently members of the Diamond and Related Materials Consortium at the Pennsylvania State University and have invested in both production and marketing facilities in the United States with a recently completed facility in Evanston, IL. They have affiliated subsidiaries in the United States under the names of Toshiba Tungaloy America Inc. and Toshiba Tungaloy Manufacturing Inc.

Production scale CVD deposition equipment (for conventional tool coatings) is marketed in North America and Europe by means of a joint venture with Lindberg, and this was discussed during the meeting. Toshiba Tungaloy is aggressively pursuing scale up strategies for microwave and hot filament deposition methods, and when asked, indicated that although no decision had been reached, they might well market a production scale reactor for diamond if a proprietary production reactor technology was developed. The team was not permitted to inspect their current large scale equipment, but was permitted to inspect microwave pilot equipment ( -6 inch capability) which appeared similar in design to equipment built by Showa Denko. The focus of most of the work discussed was on methods and strategies for achieving good adhesion to high cobalt containing $(8-12 \%)$ cemented carbide tool base materials. Strategies discussed included the removal by etching of cobalt from the surface of the tool materials followed by diamond deposition by both microwave and hot filament techniques. In addition they have experimented with sintered tungsten carbide (cobalt free) using a method by which the carbide surface is first decarburized in $\mathrm{H}_{2}$. This surface is then recarburized in the initial stages of diamond deposition producing a very finely crystalline tungsten carbide at the surface. Diamond nucleation then proceeds on this surface with a mechanical interlocking of the carbide and diamond. This was demonstrated to the team through some very excellent cross section electron microscopy. They reported that adhesion strength is improved by this technique and that a mechanical "interlocking" of the diamond layer with the underlying pore structure of the etched carbide tool base, or as the result of decarburization followed by recarburization on diamond deposition, is primarily responsible for this improvement. The best results with an etching strategy were obtained when the grain size of the diamond coating was similar to the sizes of the pores left in the tool surface. Cutting tests have been performed and 
satisfactory performance achieved in cutting of high silicon aluminum alloys $(10 \% \mathrm{Si})$. Adhesion is measured using a number of methods including an indentation method with a diamond Rockwell hardness cone. Although diamond coated lathe inserts for the automotive industry were obviously an immediate product interest, of considerably greater interest were methods for highly adherent diamond coatings for use where interrupted cuts were needed, e.g., surface milling operations, and where adhesion strength remained a concern. In addition, the surface modification of diamond to render it suitable for high speed ferrous metal machining was also discussed with obvious interest on the part of Toshiba Tungaloy personnel.

Considerable interest was expressed in the development of c-BN coatings in addition to diamond and, although some work has been pursued at Toshiba Tungaloy, it was considered too immature to report or discuss. It was noted however that they have been evaluating "cubic" BN coatings from a number of sources and have been attempting diamond deposition on them. In most cases, adhesion of these coatings to carbide tool bases has been unacceptably poor and difficulties were reported in nucleating diamond on many of these coatings. 


\section{APPENDIX D \\ Adminstration of Science and Technology in Japan}

In recent times Japan's technological system has been studied [1], modeled, and sometimes copied, perhaps more than any other. The reasons for this are many and stem from their industrial achievements which have led to international marketplace dominance in areas such as consumer electronics or impending capture of markets like semiconductor chips and devices. Their road to success is for the most part a Japanese "road" especially built to match their culture, traditions, and particularly, their technical status and needs. In the main, their industrial policy, fueled originally by profits from captured markets (e.g., steel, shipbuilding), has been directed not at failing or stagnant industries, but at the new opportunities and the strengthening of already vital, expanding private industrial segments. Currently Japan has reached a juncture in its industrial development, as past goals have been achieved and technological leadership or equality obtained. Long-term planning has been a key feature of their industrial strategy with the future the primary concern, not saving or recapturing the industrial past. Questions relative to Japan's current technological status are addressed at the cabinet level leading to frequently updated general S\&T guidelines. Its S\&T (and by implication, MSE) system is conceptually steered towards rapid technological leapfrog advancement or catch-up through technology purchase and enhancement (e.g., manufacturing $R \& D$ ), not strictly maintenance of a leadership position, like that of the United States. Hence basic research had not been emphasized previously, but now a more broad-based research front is viewed as necessary for additional/new advancement. Changes in this direction are already underway for certain key industrial areas like advanced materials and information technology.

The Japanese S\&T and MSE establishment is a highly structured enterprise, instrumental in numerous past technological successes and highly capable of more in the future. It is comprised, however, of conventional organizational elements and implementation/strategy instruments not too dissimilar from those available and used throughout the world. What is atypical to Japan is its systems approach - - its long-term and consistent policy, stimulated and coordinated by government but coupled to an effective communication link between the public and private sectors, including a multi-level advisory/committee arrangement. The term 'cooperative' has been frequently used to describe Japanese R\&D. A better descriptor might be 'orchestrated division of activities and responsibilities' with government acting as the catalyst and industry taking a lead role as a funder and performer of R\&D. As the research turns more product-oriented, cooperation in proprietary areas is almost minimal and company-to-company competition is intense. Communication, consensus, and common action by leaders for the national good is always maintained through the committee/public forum system, but never through paid lobbies, as this is not an allowed practice in Japan.

\footnotetext{
* Based on material from "International Cooperation and Competition in Materials Science and Engineering," NISTIR 89-4041, June 1989, updated with information from NSF's Tokyo Office and the visits made by members of the Diamond Technology visiting team.
} 
Within government, the highest policy making body for S\&T is the Office of the Prime Minister [1-3]. Chart D1 identifies the major government organizations in Japan responsible for S\&T. Two advisory councils, the Science and Technology Council (Kagaku Gijutsu Kaigi) and the Science Council, provide guidance on S\&T and on pure science matters. The membership on these councils are made up of leading spokespersons for $S \& T$ in government and out;

chairmanship resides with the Prime Minister of Japan. These councils establish national goals and provide broad directions for S\&T (and MSE) and, in general, decide S\&T issues of national import. Overall the councils have great impact on Japan's federal S\&T yearly budget of about $¥ 1.8$ billion in FY89, (Table D1).

Table D1. Yearly Comparison of Japan's Federal S\&T Budgets [4]

\begin{tabular}{|ccc|}
\hline Japanese Fiscal Year & Budget(in billion yen) & \% Change \\
\hline 1985 & $1,532.9$ & 3.3 \\
1986 & $1,606.4$ & 4.8 \\
1987 & $1,662.3$ & 3.5 \\
1988 & $1,715.7$ & 3.2 \\
1989 & $1,815.6$ & 5.8 \\
1990 & $1,919.6$ & 5.7 \\
\hline
\end{tabular}

Two ministries (MITI and MOMBUSHO) and one agency (STA) essentially share government operational responsibilities for $S \& T$, including planning, funding, and oversight. In addition to these, two others provide a check and balance mechanism. The Federal Trade Commission governs on the legality of business practices and often judges/rules on MITI plans and activities. The Ministry of Finance approves all budgets and justifications for enhancements and baseline support:

Science and Technology Agency (STA) This agency is located within the Prime Minister's Office. It receives about $26 \%$ of government R\&D funds [4] for major national projects like the space and the reactor programs. The agency also has the charge to stimulate basic research within industry, and through its Japan Research Development Corporation (JRDC) to support new technology developments (Exploratory Research for Advanced Technology-ERATO) using startup companies as one implementation mechanism. Attached to STA are six research institutes, two of which, NIRIM (National Institute for Research in Inorganic Materials) and NRIM (National Research Institute for Metals) are the principal laboratories most related to MSE. Although under STA, they often perform R\&D in cooperation with MITI, the industrial-oriented ministry.

The STA has no special "line-item" which is designated for the promotion of artificial diamond research. Rather, the decisions to carry out work in this 

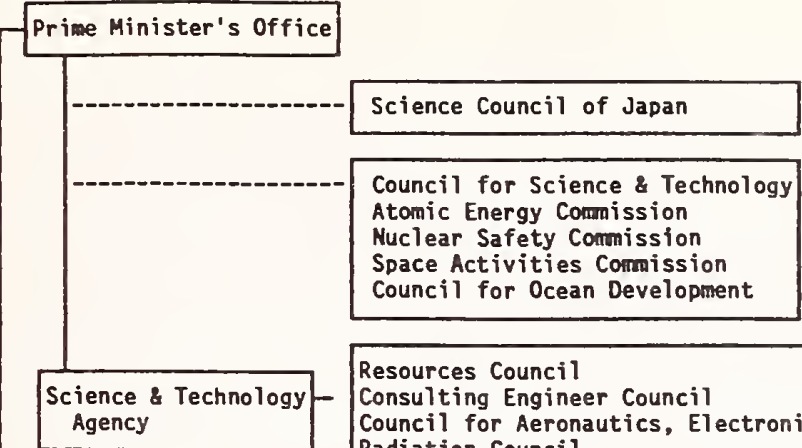

Resources Council

Consulting Engineer Council

Council for Aeronautics, Electronics \& Other Advanced Technologies Radiation Council

Attached Research Inst. National Aerospace Lab

National Res. Inst. for Metals

National Inst. of Radiological Sciences

National Res. Center for Disaster Prevention

National Inst. for Research in Inorganic Materials

National Inst. of Resources

Public Corporations

\begin{tabular}{|l|l|}
\hline Japan Atomic Energy Res. Inst. (JAERI) & Research Development Corporation of Japan (JRDC) \\
\hline $\begin{array}{c}\text { Power Reactor and Nuclear Fuel } \\
\text { Development Corporation (PNC) }\end{array}$ & National Space Development Agency of Japan (NASDA) \\
\hline $\begin{array}{c}\text { Japan Information Center of Science } \\
\& \text { Technology (JICST) }\end{array}$ & Japan Marine Science \& Technology Center (JAMSTEC) \\
\hline $\begin{array}{l}\text { Institute of Physical and Chemical } \\
\text { Research (IPCR) }\end{array}$ & \\
\hline
\end{tabular}

Ministry of Education
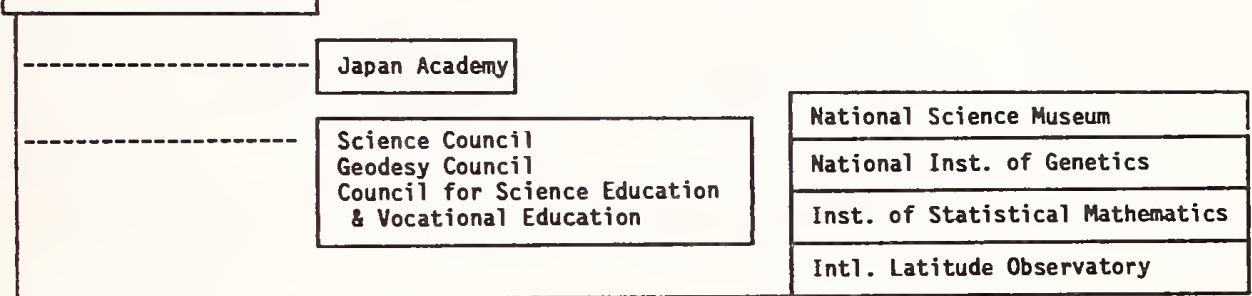

\begin{tabular}{|l|l|}
\hline & National Universities \\
\hline
\end{tabular}

Japan Society for the Promotion of Science (JSPS)

Ministry of International

Trade \& Industry

Industrial Technology Council

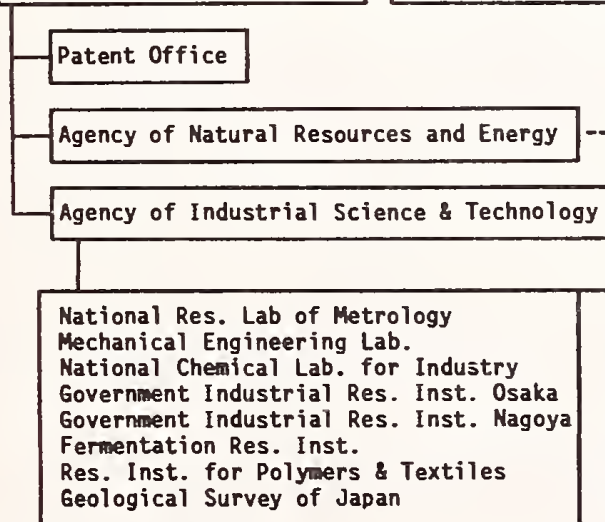

and other organizations

SOURCE: Combined information from [JTECH 1986; Ceramics - Japan 1984; JFCC Information Package 1987] 
area at NIRIM and to stimulate its commercialization through the JRDC are consequences of program evaluation made by the leadership of NIRIM and JRDC. These decisions are evaluated by the STA in the context of overall mission plans for the Agency in support of science and technology, and, in particular, in the context of a remarkable document referred to by our host at STA as the "Bible" on materials. The current version of this document, entitled "Government Research and Development Plan on Substance/Material Series of Science and Technology" was published on October 22, 1987, and is attributed directly to the Prime Minister of Japan. The "Bible" on materials is remarkable in its simplicity, consisting of only 21 pages of prose which define the goals for STA while giving maximum flexibility to the program and laboratory managers to achieve these goals. Operating under these general guidelines, annual budgets are constructed including long-term multi-year funding dealing with specific research goals.

The Research Development Corporation of Japan (JRDC), a subsidiary of STA, was founded in 1961 as an organizer of research and development projects encompassing governmental research institutions and universities. Its principal roles and associated budgets in FY 1989 are Development of New Technology (including licensing) at $¥ 4.6 \mathrm{~B}$, Exploratory Research for Advanced Technology (ERATO) at $¥ 6.0 B$, and a new program promoting International Research Exchanges at $¥ 0.9 \mathrm{~B}$. Among the 14 current ERATO projects are no less than seven dealing with materials: nano-mechanism (physical and mechanical properties of nano-size particles and the materials they yield); solid surface (methods of modifying surfaces by chemical or photochemical reactions); molecular dynamic assembly (science underlying self-assembling materials); molecular architecture (structural issues related to bio-materials); quantum wave (quantum wave effects in quantum microstructures); micro-photoconversion (use of laser light to bring about new processing in various areas including materials processing); and, atom craft (manipulation of single atoms or groups to form materials).

JRDC's technology development efforts are significant and worthy of study by any organization that proposes to emulate their mission of moving government funded R\&D into commercial application. It is noteworthy that the source of their portfolios of technologies (313 specific projects have been funded for technology development since initiation in 1961) is $51 \%$ from universities, $32 \%$ from national or public research institutes and $10 \%$ from public research foundations. Projects span the technological spectrum with $7 \%$ in metallurgy, $9 \%$ in measurement instruments, $21 \%$ in electrical engineering and electronics, etc. One measure of success of the process JRDC uses for selecting areas of investment is the fact that of its current budget about $42 \%$ was derived from repayment of loans for development funds and revenues from licensing.

Ministry of Education, Science and Culture (MOMBUSHO) This ministry accounts for about 47\% (in FY87) of government research funds [NSF-Tokyo Office 1987], the total of which is provided to the universities and national centers for scientific research. University research is supported directly by funds based on formulas (e.g., number of professors and other similar factors), peer reviewed research proposals, and by allocations according to salary costs, building facilities, and large-scale instrumentation. University-industry interactions are minimal (a problem recognized by MOMBUSHO) since paid consulting by professors is not allowed nor is joint university-industry 
research a common practice. (However, in the area of diamond technology there are important collaborations between university professors and industry.)

Ministry of International Trade and Industry (MITI) This ministry is the central government organization having industrial development as its primary charter. It receives only about $13 \%$ of government R\&D funds, relying on cooperative mechanisms with industry to leverage considerably more R\&D. MITI formulates industrial technology plans, determines and provides for subsidies and/or funding and selects/persuades/organizes participating industrial R\&D groups/associations to work with one or more of MITI's 16 national labs. The national labs fall under the jurisdiction of one of MITI's operational arms, AIST (Agency of Industrial Technology and Science). A sister agency, JITA (Japan Industrial Technology Association) functions as the licensing agency of AIST and provides regular information on foreign technology developments.

Typical of MITI's procedural mode is their program on advanced materials. The program, under the auspices of AIST, targets three general research areas, biotechnology, electronics devices, and new materials. In the general case, AIST forms a non-government advisory committee for each project and an industrial association is created to work cooperatively with all other members of the organization and MITI's national labs. Selection of participating companies is made by AIST based on financial standing, reputation, and R\&D ability. Its budget is controlled by MITI, but supplemented heavily by industry with equal or greater amounts. The national labs conduct the more basic/applied research while the industrial labs focus on development. All gained information is shared among member companies with a time lag assured before general distribution. MITI's goal is to produce a knowledge base and infrastructure for follow-on proprietary research by the now-experienced industrial groups.

Among the 16 research institutes under AIST, the oldest is the Electrotechnical Laboratory. ETL is also the largest national research organization in Japan and has contributed to the advancement of science and technology as well as the development of Japanese industry in the field of electrical engineering and electronics for almost a century.

\section{References:}

[1] JTECH (Japanese Technology Evaluation Program), JTEC Panel Report on Advanced Materials in Japan, Science Applications International Corp., LaJolla, CA, May (1986).

[2] J. Ronayne, "Science in Government," Edward Arnold Publishers, Ltc., England (1984).

[3] Ceramics-Japan, High-Technology Ceramics in Japan, NMAB-418, National Academy Press, Washington, DC (1984).

[4] NSF-Tokyo Office (National Science Foundation), "Japan's FY 1987 Science and Technology Budget," Report Memorandum 非144, Dec. 30 (1987). 
APPENDIX E

Delegation Members

Lyle H. Schwartz

Director, Materials Science and Engineering Laboratory

National Institute of Standards and Technology

Gaithersburg, MD 20899

John C. Angus

Department of Chemical Engineering

A. W. Smith Bldg.

Case Western Reserve University

Cleveland, $\mathrm{OH} 44106$

Jerome J. Cuomo

IBM Research

Division 22, T. J. Watson Research Center

P.0. Box 218

Kitchawan Road

Yorktown Heights, NY 10598

Albert Feldman

National Institute of Standards and Technology

A329 Materials Building

Gaithersburg MD 20899

Jeffrey T. Glass

Materials Science and Engineering

Box 7907

North Carolina State University

Raleigh, NC 27695-7907

Sandor Holly

Rocketdyne Division

Rockwell International

6633 Canoga Avenue

Canoga Park, CA 91303

James W. Mitchell

AT\&T Bell Laboratories

Materials Science and Engineering Research Division

1D239

600 Mountain Avenue

Murray Hill, NJ 07974

Ronald A. Rudder

Research Triangle Institute

Center for Semiconductor Research

P.0. Box 12194

Research Triangle Park, NC 27709-2194 
Keith A. Snail

Code 6520

Naval Research Laboratory

Washington, DC 20375-5000

C. Martin Stickley

BDM International, Inc.

Present Address:

Center for Research in Electro-Optics and Lasers

University of Central Florida

12424 Research Parkway, Suite 400

Orlando, FL 32826

Michae1 A. Tamor

Ford Motor Company

Scientific Research Laboratories

Box 2053, Room S3006

Dearborn, MI 48121

Walter A. Yarbrough

266 Materials Research Laboratory

Pennsylvania State University

University Park, PA 16802 
APPENDIX F

Biographies of Delegation Members

DR. LYLE H. SCHWARTZ, Chairman of the Visiting Delegation, is Director of the Materials Science and Engineering Laboratory at the National Institute of Standards and Technology. He is responsible for NIST's Materials Science and Engineering Laboratory, which has more than 350 scientists, engineers, technicians, and support personnel. The major research interests of MSEL are metals, polymers, ceramics, and composite materials. Dr. Schwartz is a graduate of Northwestern University, Evanston, Illinois, having received his bachelor of science in engineering (1959) and doctorate (1964) in materials science. Dr. Schwartz has published more than 80 technical papers in the area of phase transitions in iron alloys, applications of Mossbauer spectroscopy, $x$-ray and neutron diffraction, characterization of catalysts, and other aspects of materials science. He is a co-author of two textbooks on $x$-ray diffraction. He is a member of the Board of Directors of the National Materials Property Data Network, Inc., the Versailles Project on Advanced Materials and Standards, Fellow and Chairman of Technical Divisions Board of ASM International, and is a member of the American Crystallographic Association, TMS, American Physical Society, University Materials Council Advisory Board, and the Materials Research Society. He chaired the Panel on International Competition and Cooperation of the NRC study on Materials Science and Engineering, and was recently appointed chairman of the intergovernmental committee on materials, COMAT.

PROFESSOR JOHN C. ANGUS is a Professor of Engineering at Case Western Reserve University. He received his $\mathrm{Ph}$.D. in Chemical Engineering from the University of Michigan. He has over 106 publications in journals and conference proceedings and holds eleven patents. He has served on the National Research Council Committee on Superhard Materials and on the organizing committees of several major conferences about diamond and diamond films. The research interests of Professor Angus include metastable diamond growth, applied thermodynamics, electrochemical devices, crystal etching, etc. He was an early researcher in the deposition of diamond by chemical vapor deposition processes from the gas phase. He discovered the importance of atomic hydrogen for the deposition of diamond. Professor Angus has received numerous honors and is a member of several professional societies including a Full Grade Member of the American Institute of Chemical Engineers.

DR. JEROME $J$. CUOMO has been very active for many years in the field of Materials Science and has published some 105 papers, 5 book chapters and is co-editor of books on Ion Beam Processing and Plasma Processing. He has been involved in the study of thin film preparation and properties and is particularly involved in the study of sputtering, ion beam and plasma processing. He is the author or co-author of some 60 patents issued or pending and of about 215 patent publications. He has been very active in the American Vacuum Society as a member, Advisor to the Governors Scientific Community Council for Puerto Rico, Advisor for the Materials Science Departments of North Carolina State University, and Pennsylvania State University and as the chairman of various committees of the American Vacuum Society and the Materials Research Society. He has made important contributions to the development of $\mathrm{LaB}_{6}$ electron emitters and $\mathrm{Si}_{3} \mathrm{~N}_{4}$ as dielectric layers. He has pioneered work in selective chemical vapor 
deposition, dendritic solar thermal absorbers, sputtered amorphous silicon, amorphous magnetic bubble domain materials, ion beam modification and synthesis of materials, enhanced plasma processes, plasma sprayed high $T_{c}$ superconductors. He has been elected as a member of the National Research Council for Superhard Materials 1988-1989. He has been elected as a member of the Japanese and Untite States Workshop on Diamond Technology. He has also held various management positions at the IBM Research Center and is presently Manager-Materials Processing Laboratory. He is distinguished with the highest patent level in the IBM Corporation.

DR. ALBERT FELDMAN, the organizer of this study, is Leader of the Optical Materials Group at the National Institute of Standards and Technology. He received his $\mathrm{Ph}$.D. from the University of Chicago in the field of solid state physics. He has worked for the past 28 years in the areas of solid state physics and optical materials research. He has headed projects concerned with self-focusing mechanisms in optical materials, basic properties of bulk optical materials, and optical film research. Dr. Feldman has organized two conferences sponsored by NIST dealing with the basic properties of optical materials and he is cochairman of the Diamond Optics Conference Series sponsored by the SPIE. He served as Program Committee Chairman of the Fourth Annual SDIO/IST-ONR Diamond Technology Initiative Symposium and is on the Local Arrangements Committee for the Second International Conference on the New Diamond Science and Technology. He currently leads a project at NIST concerned principally with diamond film deposition and characterization. Dr. Feldman served on the National Research Council Committee on Superhard Materials. In 1980, he was awarded the U.S. Department of Commerce Bronze Medal

PROFESSOR JEFFREY T. GLASS is currently the Kobe Steel, Ltd. Assistant Professor of Materials Science and Engineering at North Carolina State University. He also serves as a consultant and Research and Development Director for the Electronic Materials Center, Kobe Steel Research Laboratories, U.S.A. In the past, he has worked as a materials engineer at the Ballistic Research Laboratory, Aberdeen Proving Ground. He was an international advisor for the First International Conference on the New Diamond Science and Technology (Tokyo, Japan) and Diamond Films '90 (Montreaux, Switzerland) and served on the program committees for the Fourth Annual SDIO/IST-ONR Diamond Technology Initiative Symposium and the Second International Conference on the New Diamond Science and Technology (Washington, D. C.). He was the Co-Chairman of the Fall 1989 Materials Research Society symposium on Diamond, Boron Nitride, Silicon Carbide and Related Wide Bandgaf Semiconductors. He is also a short course instructor for the Materials Research Society and is a member of Tau Beta Pi. Dr. Glass has published over 30 papers and given over 35 professional presentations in the United States, England, France and Japan, and is currently editing two books. His education has been in the area of Materials Science and he currently teaches Thermodynamics at NCSU. Research interests involve the growth and characterization of thin films, especially diamond.

DR. SANDOR HOLLY has been Staff Scientist within the Advanced Programs Department of the Rocketdyne Division of Rockwell International for over 14 years. He has extensive background in laser system analysis, conceptual design and design implementation of electro-optical and control systems. 
Previously he was Manager with a variety of responsibilities in Experimental Optics, Electro Optics and Alignment Systems. His formal education was in Electrical Engineering (M.Sc. from the Massachusetts Institute of Technology) and in Physics (Ph.D. from Harvard University). He has 30 years of experience in Electro Optics, Instrumentation, Lasers, Diagnostic Techniques, Metrology and solving difficult experimental problems. He has received 16 U.S. and several foreign patents. A variety of academic and industrial experiences include Member of the Faculty in the Physics Department at University of Maryland to Technical Director of a small company building Laser Instrumentation to Staff Scientist at Rockwell. His technical backgrounds are in Electromagnetic, Optics, Lasers (received the first U.S. patent issued on Free Electron Lasers), Instrumentation, Sensors, Control Systems, and New Materials. He has organized several conferences. He is one of the organizers and one of the cochairmen of the Diamond Optics Conferences (in its fourth year this July) and coorganizer of an International Conference in Hungary on "Computer Aided Laser Metrology" (September, 1990).

DR. JAMES W. MITCHELL heads the Analytical Chemistry Research Department of Bell Laboratories at Murray Hill, New Jersey. After receiving a B.S. degree in chemistry from the Agricultural and Technical State University of North Carolina at Greensboro (1965), he entered Iowa State University at Ames and earned the Ph.D degree in analytical chemistry in 1970. He joined AT\&T Bell Laboratories in March of that year as a Member of Technical Staff, accepted the position of Supervisor of the Inorganic Analysis Group in 1972, and was promoted to Head of the Department in 1975. In 1985 he was made an AT\&T Bell Laboratories Research Fellow for pioneering work in the creation and application of novel techniques for the analysis of chemical elements and components at unprecedentedly low levels of concentration. Dr. Mitchell's work includes using nuclear radiation and spectroscopy to develop high accuracy methods for ultratrace analysis, development of methods for the ultrapurification of analytical reagents and research chemicals, and exploiting microwave discharges and plasmas for analysis and synthesis of materials. He has lectured internationally on these subjects, co-authored a book on "Contamination Control in Trace Analysis," completed over 60 scientific papers for publication, and invented novel instruments and processes. He has served as a member of the Editorial Advisory Boards of three international analytical chemistry journals. Dr. Mitchell has received several awards for his work: the Pharmacia Industrial Analytical Chemistry Award in 1978, The Percy L. Julian Research Award in 1981 and the IR-100 Award in 1982. In 1989 he received a second IR-100 award and was inducted into the National Academy of Engineering.

DR. RONALD A. RUDDER is a research engineer in the Center for Semiconductor Research at Research Triangle Institute, Research Triangle Park, NC. He received a B.S. degree in mathematics and physics from Lynchburg College and a $\mathrm{PhD}$. degree in physics from North Carolina State University. He is responsible for the development of epitaxial chemical vapor deposition techniques both with and without plasma-activation. His research interests include epitaxial growths of diamond, silicon, germanium, gallium nitride, and alloys such as SiGe and dilute C, SiC alloys.

DR. KEITH A. SNAIL received a B. S. in physics in 1978 (summa cum laude) from the Honors Tutorial College at Ohio University. He went on to study nonimaging optics and solar energy under Roland Winston at the University of 
Chicago and received his Ph.D. in physics in 1983. He then began work as a research physicist at the Naval Research Laboratory's (NRL) Optical Sciences Division. Dr. Snail's research at NRL has focused on three areas: (1) the combustion and CVD synthesis of diamond, 2) the optical characterization of diamond and other optical materials, and 3) the development of high accuracy diffuse reflectometers. Dr. Snail has received 3 patents and is the author of over 20 publications.

DR. C. MARTIN STICKLEY received his BSEE from the University of Cincinnati, the MSEE from MIT, and the Ph.D from Northeastern University. His early research work was in the dynamics of optically-pumped crystalline lasers and in laser-induced damage to laser materials. He became the Director for Materials Sciences of the Advanced Research Projects Agency where he initiated a number of $R \& D$ programs to develop new optical and IR materials for use with lasers. He later became the Director of the Inertial Confinement Fusion Program at the Department of Energy where he initiated efforts to build the world's largest laser, NOVA, at the Lawrence Livermore National Laboratory. Subsequently, he joined BDM International, Inc., a professional and technical services firm which conducts research and development for clients. At BDM, he developed an Advanced Technology Group which conducts research in sensors, photonics, neural networks, applications of advanced computing architectures, intelligent controls for materials processing, and other subjects. Dr. Stickley is now Assistant Director and Professor of Electrical Engineering at the Center for Research in Electrooptics and Lasers at the University of Central Florida. He is a Fellow of the Institute of Electrical and Electronic Engineers and serves as an unofficial advisor to the Materials Sciences Division of the Defense Advanced Research Projects Agency.

DR. MICHAEL A. TAMOR earned his B.S. in Physics from the University of California, Los Angeles and his M.S. and PhD. in physics from the University of Illinois at Urbana-Champaign (1982). His thesis research involved a systematic study of the transport properties of excitons and electron-hole droplets in ultrapure silicon and germanium. Upon completion of his dissertation, Dr. Tamor joined the Research Staff of Ford Motor Company where he is now a principal research scientist in the Physics Department. While at Ford, he has worked in the areas of optical and electronic properties of semiconductor alloys, transport in highly disordered materials and electronics for high temperature operation. His current research is in the area of the formation, structure and applications of both diamond and diamondlike hard carbon materials.

PROFESSOR WALTER A. YARBROUGH has spent most of his career in industrial product and process development, first with Celanese Fibers Co. and subsequently with the Norton Co. of Worcester Massachusetts. He held several positions with both organizations, the most recent ones being Manager of Product Development and Senior Research Associate with the Norton Co. He returned to the academic community when offered the opportunity to work and study at the Materials Research Laboratory of the Pennsylvania State University where he completed a Ph.D in Solid State Science under Rustum Roy and where he is presently Assistant Professor of Solid State Science. He holds patents on industrial products in the fields of sol-gel chemistry and composite materials and is a consultant to research and business organizations. He has been an invited speaker and lecturer at many institutions, national and international meetings on sol-gel materials, the 
preparation of hard coatings, and low pressure diamond synthesis. Presently he supervises much of the current research in the deposition of diamond, boron nitride and related materials through the Diamond and Related Materials Consortium of The Pennsylvania State University. His research interests are in materials synthesis and his published and presented work includes the preparation of ceramics by chemical methods (e.g., "sol-gel"), the control of microstructure by seeding, the preparation of nanocomposites, the thermodynamics of materials synthesis, and presently focuses on the chemical vapor deposition of diamond and cubic boron nitride. 


\section{APPENDIX G \\ Itinerary}

DIAMOND TECHNOLOGY IN JAPAN - - Itinerary, Revision of May 23, 1990

(number of visitors in parenthesis)- Name represents site report coordinator

May 26 - 27 Travel to Japan

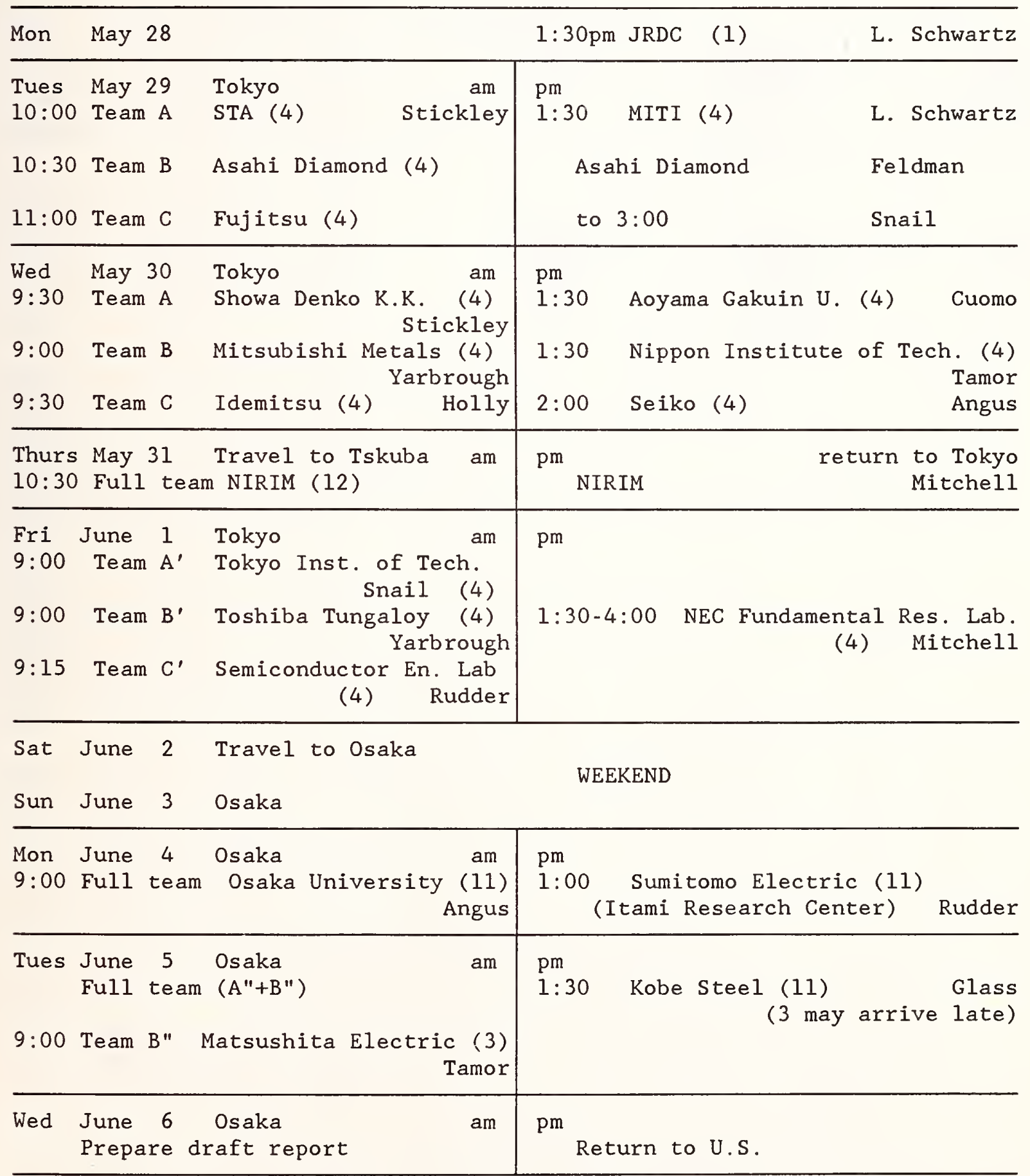


Visiting Teams

\begin{tabular}{|c|c|c|}
\hline Team A & Team A' & Team A" \\
\hline$\overline{\text { Schwartz }}$ & $\overline{\text { Schwartz }}$ & Glass \\
\hline Glass & Glass & Mitchell \\
\hline Cuomo & Stickley & Stickley \\
\hline Stickley & Snail & $\begin{array}{l}\text { Snail } \\
\text { Feldman } \\
\text { Yarbrough }\end{array}$ \\
\hline Team B & Team B' & Holly \\
\hline Feldman & Feldman & Rudder \\
\hline Yarbrough & Yarbrough & \\
\hline Tamor & Tamor & \\
\hline Rudder & Mitchell & \\
\hline Team C & Team $C^{\prime}$ & Team B" \\
\hline Snail & Angus & Angus \\
\hline Angus & Cuomo & Cuomo \\
\hline Mitchell & Holly & Tamor \\
\hline Holly & Rudder & \\
\hline
\end{tabular}


APPENDIX H

List of Companies, Universities and Government Agencies Visited

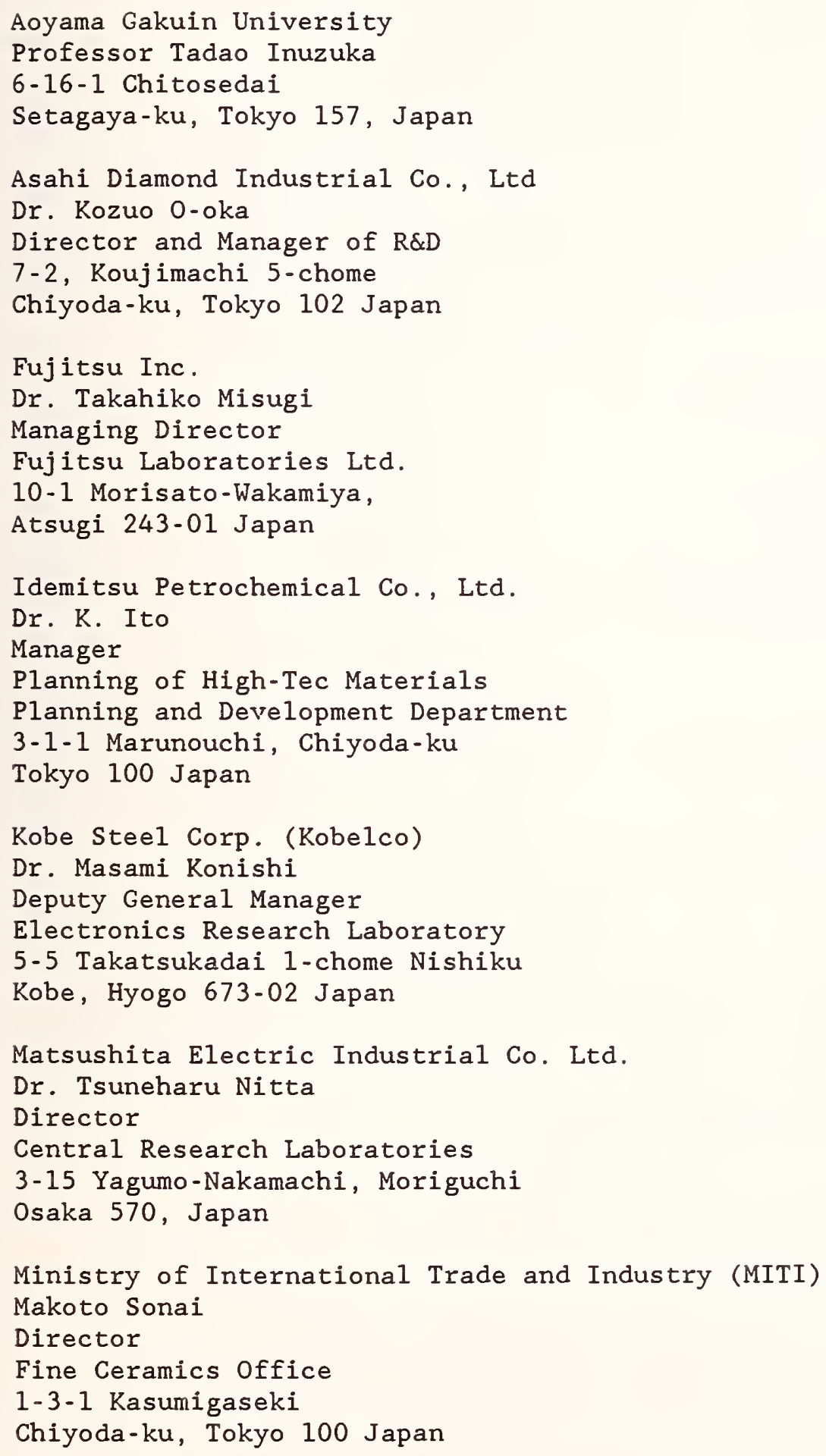


Mitsubishi Metal Corporation

Dr. Akihiko Nagasaka

Director of Research

1-297 Kitabukuro-cho

Omiya, Saitama 330 Japan

National Institute for Research in Inorganic Materials (NIRIM)

Dr. Yoichiro Sato

Diamond Group Leader

1-1 Namiki, Tsukuba

Ibaraki 305 Japan

NEC Corporation

Dr. Hisatsune Watanabe

General Manager

Fundamental Research Laboratories

34, Miyukigaoka

Tsukaba, Ibaraki 305 Japan

Nippon Institute of Technology

Professor Masao Murakawa

Mechanical Engineering Institute of Technology

Miyashiromachi

Saitama 345 Japan

Osaka University

Professor Akio Hiraki

Department of Electrical Engineering

Suita-shi, Osaka 565 Japan

Research and Development Corporation of Japan (JRDC)

Dr. Masaru Goto

5-2 Nagata-cho 2-chome

Chiyoda-ku, Tokyo 100 Japan

Science and Technology Agency (STA)

Takayuki Shirao

Director

Office of Materials Science and Technology

Bureau of Research and Development

2-2-1 Kasumigaseki

Chiyoda-ku, Tokyo Japan

Seiko Instruments

Ryoichiro Sakami

Director

Technology \& Project Administration Department

563, Shinden Takatsuka, Matsudo-shi

Chiba 271 Japan 
Semiconductor Energy Laboratory Co., Ltd.

Dr. Shumpei Yamazaki

President

398 Hase Atsugi-shi, Kanagawa-ken,

243 Japan

Showa Denko K.K. Annex

Dr. Junichi Sato

Chief Staff Manager

Ceramics Division

1-13-9 Shibadaimon, Minato-ku

Tokyo, 105 Japan

Sumitomo Electric Itami Research Center

Dr. Akio Hara, Director

1-1 Koyakita, 1 -chome

Itami-shi, Hyogo, 664 Japan

Tokyo Institute of Technology

Professor Osamu Fukunaga

Department of Inorganic Materials

2-12-1, 0-okayama

Meguro-ku, Tokyo 152 Japan

Tokyo Institute of Technology

Professor Masanori Yoshikawa

Department of Mechanical Engineering

2-12-1, 0-okayama

Meguro-ku, Tokyo 152 Japan

Toshiba Tungaloy Inc.

Dr. Tamotsu Fukatsu

Vice President and Director

General Manager of Technical Research Division

Toshiba Tungaloy Inc.

1-7, Tsukagoshi, Saiwai-ku

Kawasaki, 210 Japan 


\section{APPENDIX I \\ Alphabetical Listing of Abbreviations}

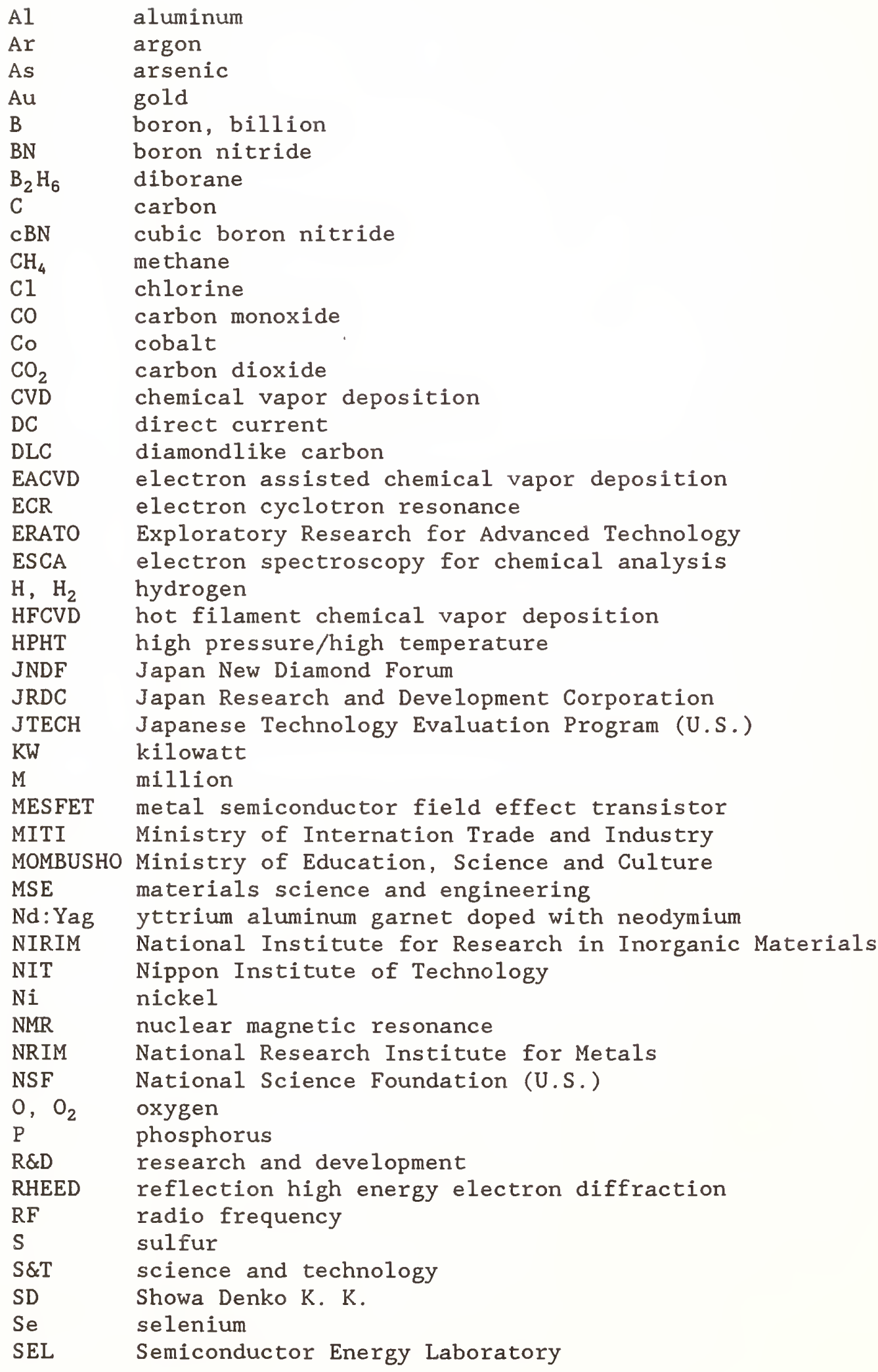




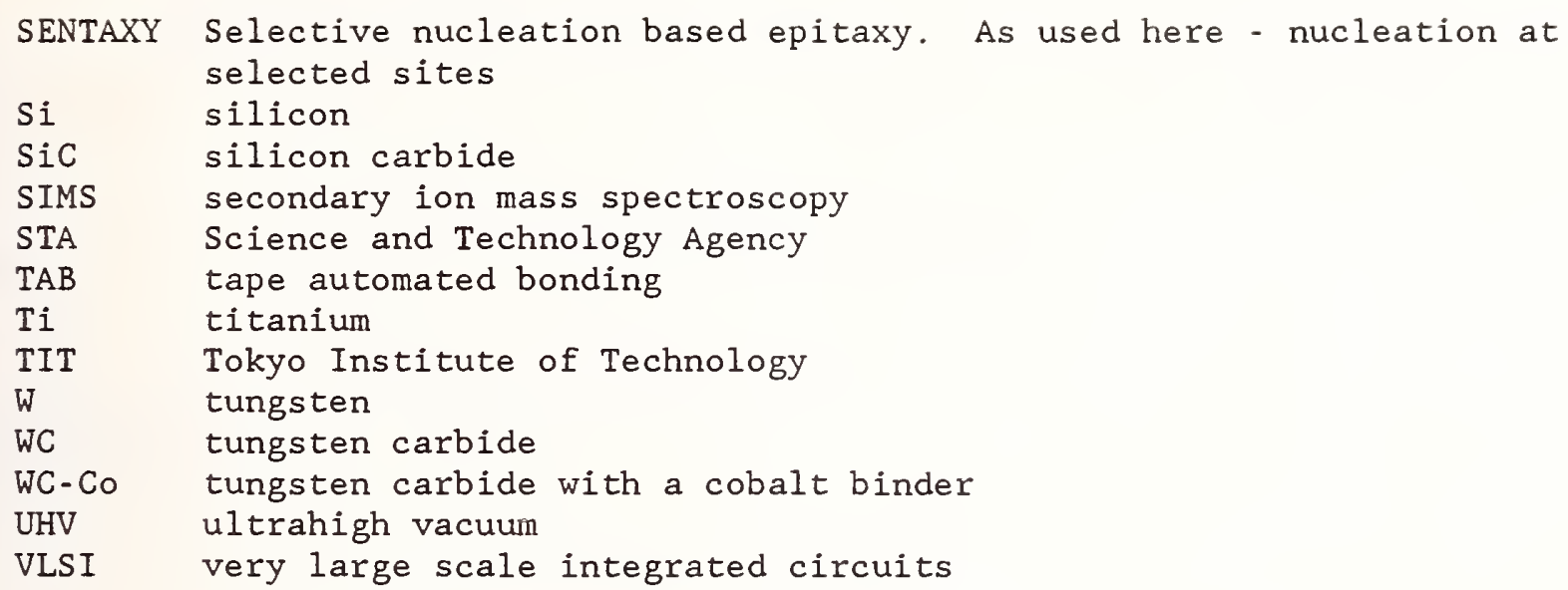



NIST-114A

(REV. 3-89)
U.S. DEPARTMENT OF COMMERCE

NATIONAL INSTITUTE OF STANDARDS AND TECHNOLOGY

\section{BIBLIOGRAPHIC DATA SHEET}

1. PUBLICATION OR REPORT NUMBER
NIST/SP-807

2. PERFORMING ORGANIZATION REPORT NUMBER

3. PUBLICATION DATE

January 1991

4. TITLEAND SUBTITLE

U.S. Assessment of the New Diamond Technology in Japan

5. AUTHOR(S)

Albert Feldman and Lyle H. Schwartz

6. PERFORMING ORGANIZATION (IF JOINT OR OTHER THAN NIST, SEE INSTRUCTIONS)

U.S. DEPARTMENT OF COMMERCE

NATIONAL INSTITUTE OF STANDARDS AND TECHNOLOGY

GAITHERSBURG, MD 20899

9. SPONSORING ORGANIZATION NAME AND COMPLETE ADDRESS (STREET, CITY, STATE, ZIP)

Same as item \#6

10. SUPPLEMENTARY NOTES

DOCUMENT DESCRIBES A COMPUTER PROGRAM; SF-185, FIPS SOFTWARE SUMMARY, IS ATTACHED.

1. ABSTRACT (A 200-WORD OR LESS FACTUAL SUMMARY OF MOST SIGNIFICANT INFORMATION. IF DOCUMENT INCLUDES A SIGNIFICANT BIBLIOGRAPHY OR LITERATURE SURVEY, MENTION IT HERE.)

This assessment of Japanese diamond technology was undertaken at the request of the joint committees for implementation of the 1988 United States-Japan Agreement on Cooperation in Research and Development in Science and Technology under the auspices of the Committee on Materials, Office of Science and Technology Policy. The purposes of the study were to assess the level of scientific activity, areas of intended commercialization, progress in commercialization, the role of the Japanese government in assisting industry to exploit the new diamond technology, and the relative positions of Japan and the U.S. in all aspects of synthesized diamond technology. Japanese efforts were chosen for assessment because Japan is the apparent world leader in the drive for commercialization of this technology. The principal focus of the study was diamond produced by chemical vapor deposition, with a peripheral investigation of cubic boron nitride and diamond-like carbon. Based on this assessment, a set of Conclusions and Recommendations is presented. This assessment is based on site visits in Japan between May 28 and June 5, 1990.

12. KEY WORDS (6 TO 12 ENTRIES; ALPHABETICAL ORDER; CAPITALIZE ONLY PROPER NAMES; AND SEPARATE KEY WORDS BY SEMICOLONS)

abrasives; adhesion; BN; bonding; boron nitride; chemical vapor deposition; commercialization; cubic boron nitride; cutting tools; CVD; diamond; diamond films; diamond technology; diamondlike carbon; doping; electronics, epitaxial growth; epitaxy; hard materials; heat conduction; heat sinks; machine tools; nucleation; optics; physical properties; polishing; thermal management

13. AVAILABILITY

$\mathrm{X}$ UNLIMITED

FOR OFFICIAL DISTRIBUTION. DO NOT RELEASE TO NATIONAL TECHNICAL INFORMATION SERVICE (NTIS).

ORDER FROM SUPERINTENDENT OF DOCUMENTS, U.S. GOVERNMENT PRINTING OFFICE, WASHINGTON, DC 20402.

ORDER FROM NATIONAL TECHNICAL INFORMATION SERVICE (NTIS), SPRINGFIELD, VA 22161.
14. NUMBER OF PRINTED PAGES

96

15. PRICE

\section{ELECTRONIC FORM}

*U.S.G.P.0:1991-281-557:40001 

Journal of Research of the National Institute of Standards and Technology-Reports NIST research and development in those disciplines of the physical and engineering sciences in which the Institute is active. These include physics, chemistry, engineering, mathematics, and computer sciences. Papers cover a broad range of subjects, with major emphasis on measurement methodology and the basic technology underlying standardization. Also included from time to time are survey articles on topics closely related to the Institute's technical and scientific programs. Issued six times a year.

\section{Nonperiodicals}

Monographs-Major contributions to the technical literature on various subjects related to the Institute's scientific and technical activities.

Handbooks-Recommended codes of engineering and industrial practice (including safety codes) developed in cooperation with interested industries, professional organizations, and regulatory bodies. Special Publications-Include proceedings of conferences sponsored by NIST, NIST annual reports, and other special publications appropriate to this grouping such as wall charts, pocket cards, and bibliographies.

Applied Mathematics Series-Mathematical tables, manuals, and studies of special interest to physicists, engineers, chemists, biologists, mathematicians, computer programmers, and others engaged in scientific and technical work.

National Standard Reference Data Series-Provides quantitative data on the physical and chemical properties of materials, compiled from the world's literature and critically evaluated. Developed under a worldwide program coordinated by NIST under the authority of the National Standard Data Act (Public Law 90-396). NOTE: The Journal of Physical and Chemical Reference Data (JPCRD) is published quarterly for NIST by the American Chemical Society (ACS) and the American Institute of Physics (AIP). Subscriptions, reprints, and supplements are available from ACS, 1155 Sixteenth St., NW., Washington, DC 20056.

Building Science Series-Disseminates technical information developed at the Institute on building materials, components, systems, and whole structures. The series presents research results, test methods, and performance criteria related to the structural and environmental functions and the durability and safety characteristics of building elements and systems.

Technical Notes-Studies or reports which are complete in themselves but restrictive in their treatment of a subject. Analogous to monographs but not so comprehensive in scope or definitive in treatment of the subject area. Often serve as a vehicle for final reports of work performed at NIST under the sponsorship of other government agencies.

Voluntary Product Standards-Developed under procedures published by the Department of Commerce in Part 10, Title 15, of the Code of Federal Regulations. The standards establish nationally recognized requirements for products, and provide all concerned interests with a basis for common understanding of the characteristics of the products. NIST administers this program as a supplement to the activities of the private sector standardizing organizations.

Consumer Information Series-Practical information, based on NIST research and experience, covering areas of interest to the consumer. Easily understandable language and illustrations provide useful background knowledge for shopping in today's technological marketplace.

Order the above NIST publications from: Superintendent of Documents, Government Printing Office, Washington, DC 20402.

Order the following NIST publications-FIPS and NISTIRs-from the National Technical Information Service, Springfield, VA 22161.

Federal Information Processing Standards Publications (FIPS PUB)-Publications in this series collectively constitute the Federal Information Processing Standards Register. The Register serves as the official source of information in the Federal Government regarding standards issued by NIST pursuant to the Federal Property and Administrative Services Act of 1949 as amended, Public Law 89-306 (79 Stat. 1127), and as implemented by Executive Order 11717 (38 FR 12315, dated May 11, 1973) and Part 6 of Title 15 CFR (Code of Federal Regulations).

NIST Interagency Reports (NISTIR)-A special series of interim or final reports on work performed by NIST for outside sponsors (both government and non-government). In general, initial distribution is handled by the sponsor; public distribution is by the National Technical Information Service, Springfield, VA 22161, in paper copy or microfiche form. 


\section{U.S. Department of Commerce}

National Institute of Standards and Technoiogy

(formerly National Bureau of Standards)

Galthersburg, MD 20899

Officiai Business

Penalty for Private Use $\$ 300$ 